\author{
Universidade de São Paulo \\ Escola de Engenharia de São Carlos \\ Departamento de Engenharia Elétrica
}

GEYVERSON TEIXEIRA DE PAULA

\title{
Influência da saturação no torque da máquina síncrona de ímã permanente no rotor
}

São Carlos

2013 



\title{
GEYVERSON TEIXEIRA DE PAULA
}

\section{Influência da saturação no torque da máquina síncrona de ímã permanente no rotor}

\author{
Dissertação de Mestrado apresentada a Es- \\ cola de Engenharia de São Carlos como parte \\ dos requisitos para obtenção do título de Mes- \\ tre em Ciências, Programa de Engenharia Elé- \\ trica. \\ Área de Concentração: Sistemas Dinâmicos. \\ Orientador: Prof. Dr. José Roberto Boffino de \\ Almeida Monteiro
}

São Carlos

2013 

de São Paulo, 2013.

1. Máquina síncrona. 2. Ímã permanente. 3. saturação. 4. Torque eletromagnético. I. Título. 


\section{FOLHA DE JULGAMENTO}

\section{Candidato: Engenheiro GEYVERSON TEIXEIRA DE PAULA}

Título da dissertação: "Influência da saturação no torque da máquina síncrona de ímã permanente no rotor".

Data da defesa: $25 / 07 / 2013$

\section{Comissão Julgadora:}

\section{Resultado:}

Prof. Dr. José Roberto Boffino de Almeida Monteiro (Orientador)

(Escola de Engenharia de São Carlos/EESC)

Prof. Dr. Manoel Luís de Aguiar

(Escola de Engenharia de São Carlos/EESC)

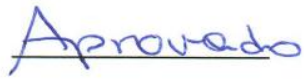

Prof. Dr. Darizon Alves de Andrade

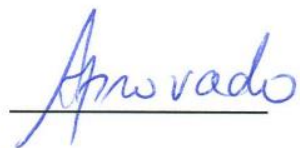

(Universidade Federal de Uberlândia/UFU)

Coordenador do Programa de Pós-Graduação em Engenharia Elétrica e Presidente da Comissão de Pós-Graduação:

Prof. Titular Denis Vinicius Coury 

Aos meus pais, verdadeiros heróis, que inúmeras vezes se sacrificaram para ver os sonhos de seus filhos serem alcançados. 



\section{Agradecimentos}

Ao Prof. Dr. José Roberto Boffino de Almeida Monteiro pela excelente orientação ao longo deste trabalho e esclarecimento de inúmeras dúvidas sobre máquinas elétricas e eletrônica de potência.

Ao Prof. Dr. Diógenes Pereira Gonzaga que me apresentou o incrível universo das máquinas elétricas.

Ao Prof. Dr. Manoel Luís de Aguiar pelo apoio e incentivo em estudar a aplicação de máquinas elétricas em veículos elétricos.

Aos meus amigos, Thales, Marcelo, Tati, William, Moussa, Liciane, Artur e Jhonatan pela companhia nos momentos de estudos e nas inúmeras empreitadas durante o mestrado. 

"Ninguém baterá tão forte quanto a vida. Porém, não se trata de quão forte pode bater, se trata de quão forte pode ser atingido e continuar seguindo em frente. É assim que a vitória é conquistada." 



\section{Resumo}

Paula, G. T. (2013). Influência da Saturação no Torque da Máquina Síncrona de Ímã Permanente no Rotor. Dissertação (Mestrado) - Escola de Engenharia de São Carlos, Universidade de São Paulo, São Carlos, 2013.

O presente trabalho trata do estudo e análise da influência da saturação magnética no torque de uma máquina síncrona com ímã permanente no rotor. A máquina síncrona em estudo trata-se de uma máquina cuja forma de onda de força contra eletromotriz é trapezoidal. Inicialmente é feito um estudo sobre os efeitos da saturação magnética nos três principais parâmetros da máquina, indutância de fase, relutância (vista pelo circuito que tem como fonte de fluxo magnético os ímãs permanentes) e a força contra eletromotriz. Em seguida, realizase um estudo sobre o torque eletromagnético para a máquina e a importância dos parâmetros estudados, demonstrando a forte dependência da qualidade do torque com estes parâmetros. Com base nos estudos sobre saturação e torque, objetiva-se, portanto, descrever o comportamento de cada um dos parâmetros quando da saturação da máquina e quanto/como cada um deles afeta o torque eletromagnético da máquina. A fim de se estudar cada componente do torque separadamente, avalia-se a máquina por meio do Método da Permeabilidade Fixa. Por fim, faz-se simulações em elementos finitos empregando o método apresentado e os resultados são analisados.

Palavras-chave: Máquina Síncrona, Ímã Permanente, Saturação, Torque Eletromagnético 



\section{Abstract}

Paula, G. T. (2013). The Influence of Saturation on Torque of Permanent Magnet Synchronous Machine. (Master Degree) - Escola de Engenharia de São Carlos, Universidade de São Paulo, São Carlos, 2013.

This work deals with the influence of magnetic saturation on torque of permanent magnet synchronous machine. At first, a study of magnetic saturation is carried out in order to understand its influence on three main machine's parameters, phase inductance, magnet reluctance and back electromotive force. A study describing the electric torque and its components is carried out. This study explain the importance of each machine's parameter on electric torque's smoothness and amplitude. In order to investigate and describe each torque's component, a review on Frozen Permeability Method is developed. At last, some simulation by means of finite element method with Frozen Permeability Method are carried out. The results are shown and analyzed.

Key-Word: Synchronous Machine, Permanent Magnet, Magnetic Saturation, Electromagnetic Torque, brushless. 



\section{Lista de Figuras}

Figura 2.1 - Curva de magnetização da lâmina M-27 .................................................... 8

Figura 2.2 - Disposição dos domínios magnéticos. ....................................................

Figura 2.3 - Comportamento das linhas de fluxo magnético........................................... 10

Figura 2.4 - Máquina de um polo por ranhura por fase ................................................... 12

Figura 2.5 - Circuito magnético. ......................................................................... 13

Figura 2.6 - 2p/2 circuitos magnéticos............................................................... 14

Figura 2.7 - Desalinhamento de polos................................................................. 14

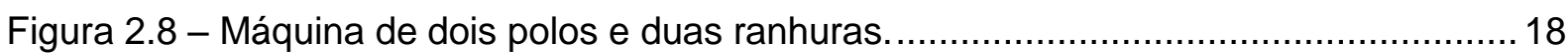

Figura 2.9 - Circuito magnético proposto para uma bobina. ............................................. 19

Figura 2.10 - Disposição dos condutores dentro da ranhura........................................... 22

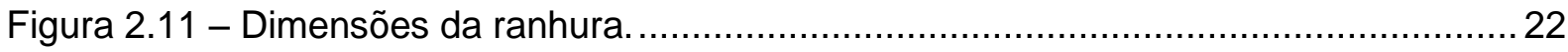

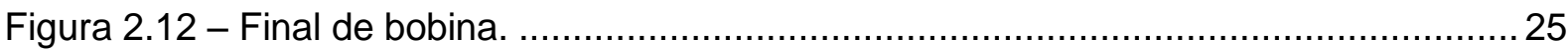

Figura 2.13 - Comparação entre formas de onda de força contra eletromotriz. ...................27

Figura 3.1 - Variação dos valores de indutância.......................................................... 31

Figura 3.2 - Variação dos valores de Torque de Borda. ................................................ 33

Figura 3.3 - Distorção da Força Contra Eletromotriz. .................................................. 34

Figura 4.1 - Princípio do Método da Permeabilidade Fixa. ............................................... 38

Figura 4.2 - Método da Permeabilidade Fixa................................................................ 38

Figura 4.3 - Método da Permeabilidade Fixa Melhorado................................................. 39

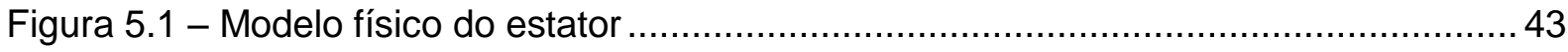

Figura 6.1 - Máquina síncrona com ímãs permanentes semi-enterrados. ........................... 48

Figura 6.2 - Máquina síncrona com ímãs permanentes na superfície do rotor. ................... 48

Figura 6.3 - Corrente de alimentação para a máquina trapezoidal .................................... 49

Figura 6.4 - Linhas de fluxo eletromagnético............................................................. 50

Figura 6.5 - Linhas de fluxo eletromagnético obtidas pela utilização do software do presente

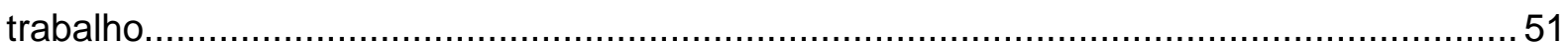

Figura 6.6 - Perfil da densidade de fluxo radial ao longo do rotor.................................... 52

Figura 6.7 - Perfil da densidade de fluxo radial ao longo do rotor................................... 52



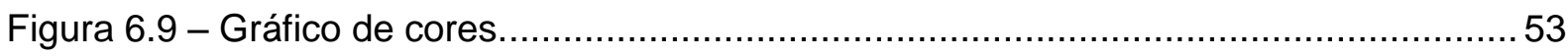

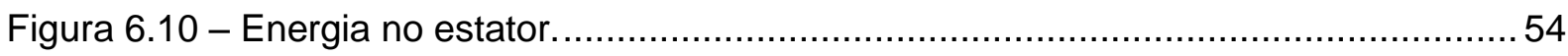




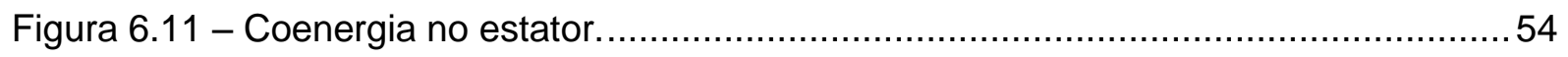

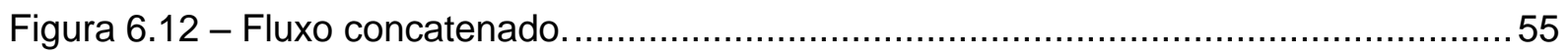

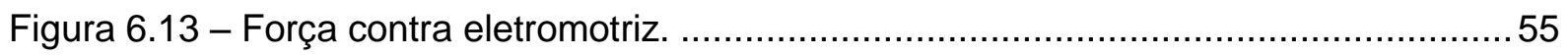

Figura 6.14 - Fluxo concatenado por fase (operação sem corrente) ..................................56

Figura 6.15 - Conteúdo harmônico do fluxo concatenado pela fase A (operação sem corrente).

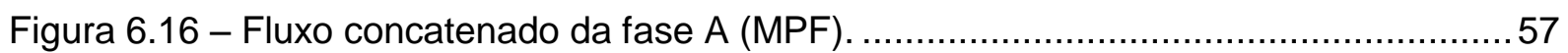

Figura 6.17 - Conteúdo harmônico do fluxo concatenado pela fase A (MPF). ......................58

Figura 6.18 - Força contra eletromotriz por fase (operação sem corrente) . ......................... 58

Figura 6.19 - Conteúdo harmônico da força contra eletromotriz da fase A (operação sem

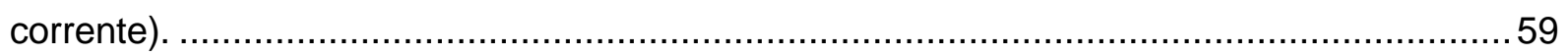

Figura 6.20 - Força contra eletromotriz da fase A (MPF) ............................................ 59

Figura 6.21 - Conteúdo harmônico da força contra eletromotriz da fase A (MPF). ..............60

Figura 6.22 - Perfil da indutância de linha. ............................................................. 61

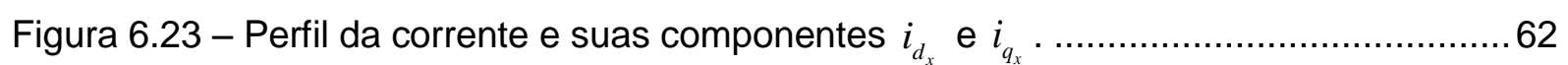

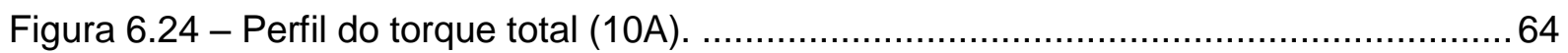

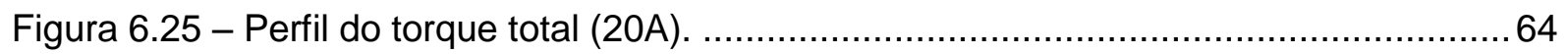

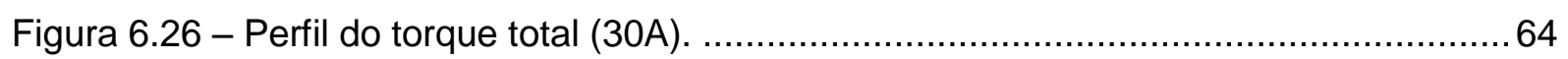

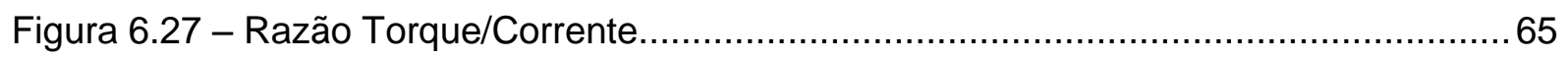



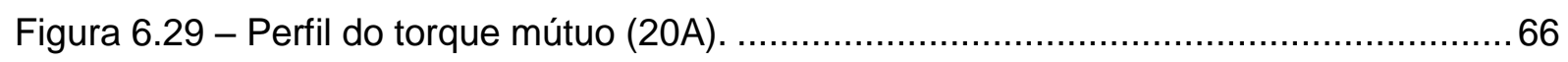

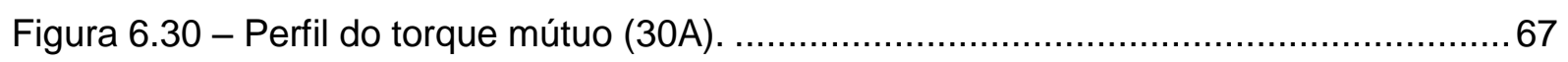

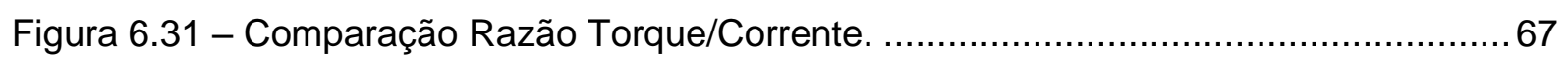

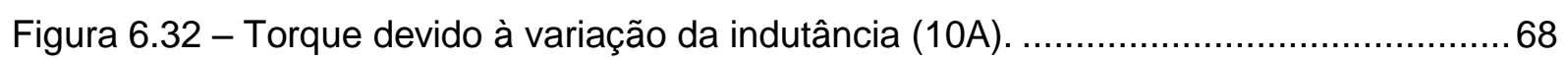

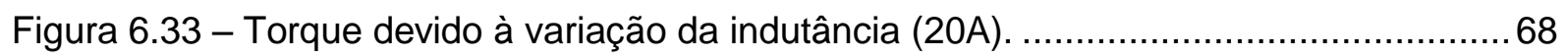

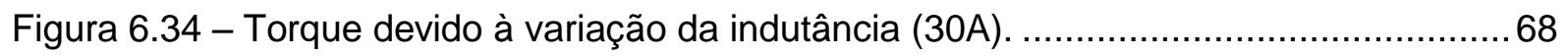

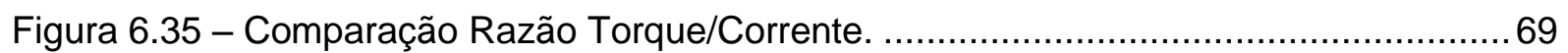

Figura 6.36 - Torque de borda (sem corrente) ..................................................... 70

Figura 6.37 - Torque de borda (Maxwell - MPF) . ................................................... 71

Figura 6.38 - Perfil da coenergia total do sistema (MPF Convencional). ............................ 72

Figura 6.39 - Perfil da coenergia total do sistema (MPF Melhorado). ................................ 72

Figura 6.40 - Torque de borda (Trabalho Virtual - MPF Convencional) ............................. 73

Figura 6.41 - Torque de borda (Trabalho Virtual - MPF Melhorado). ................................. 73

Figura 6.42 - Comparação Razão Torque/Corrente. ......................................................... 73

Figura 6.43 - Torque de borda pela diferença dos torques (MPF) . ................................... 74

Figura 6.44 - Comparação do perfil de torque (10A) . .................................................... 75 
Figura 6.45 - Comparação do perfil de torque (20A). .75

Figura 6.46 - Comparação do perfil de torque (30A). 



\section{Lista de Tabelas}

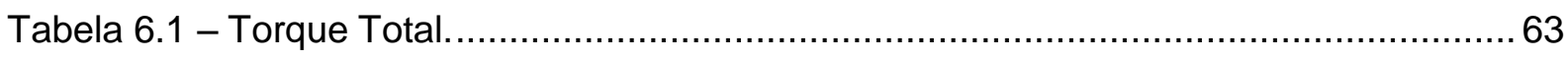

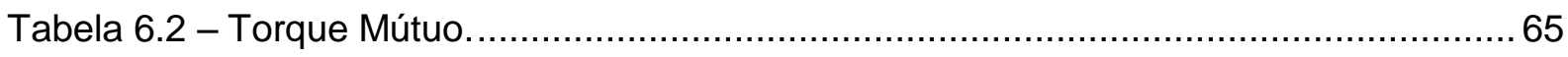

Tabela 6.3 - Torque devido à variação da indutância ................................................. 69

Tabela 6.4 - Torque de borda (Maxwell) .............................................................. 71

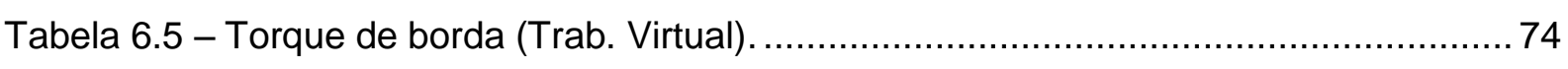

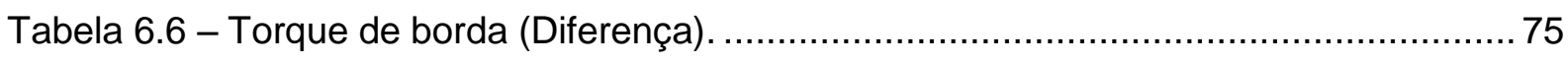

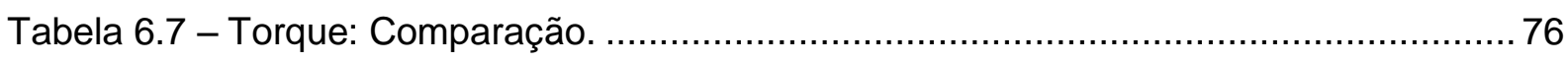





\section{Sumário}

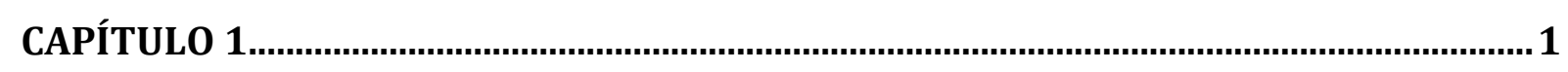



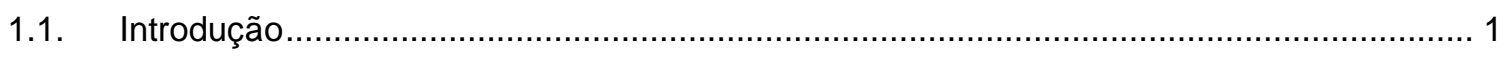

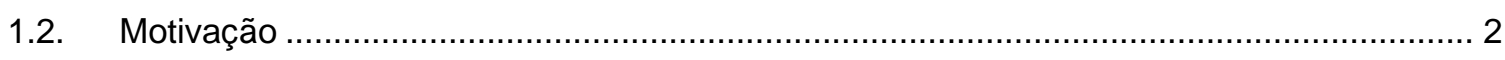

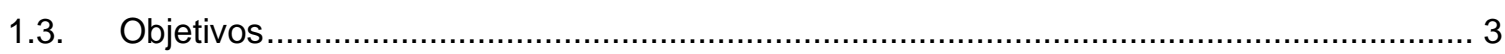



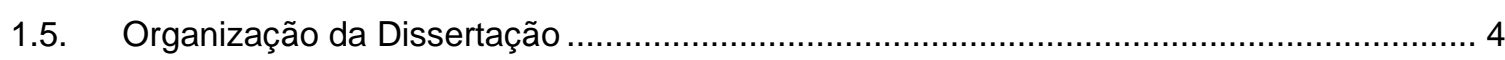

CAPÍTULO 2

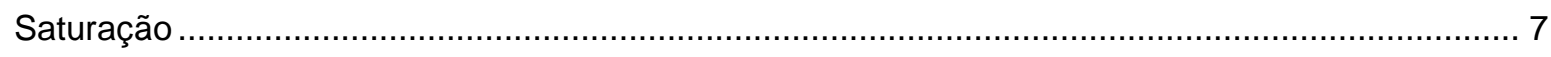



2.2. Variação na Relutância do Circuito de Rotor ............................................................. 11



2.3.1 Indutância de entreferro (Air-gap inductance) ........................................................ 18

2.3.2 Indutância de dispersão na ranhura (Slot leakage inductance) ...................................... 21

2.3.3 Indutância de final de bobina (End turn inductance) ...................................................... 24

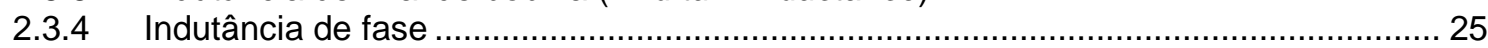

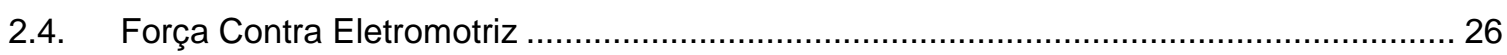

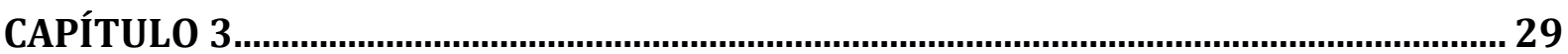

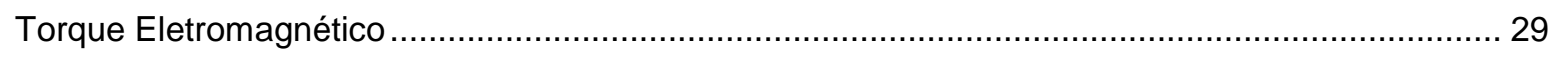

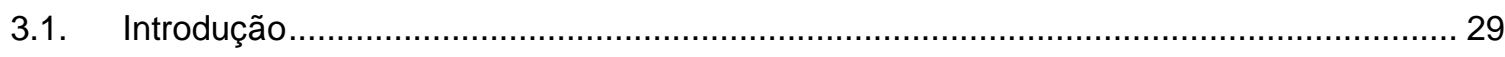

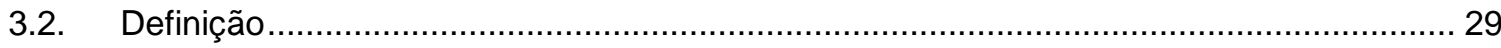

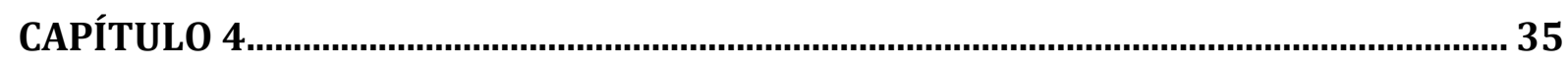

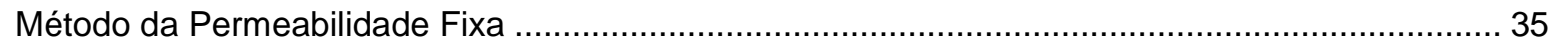

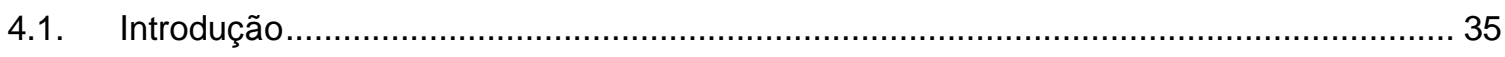

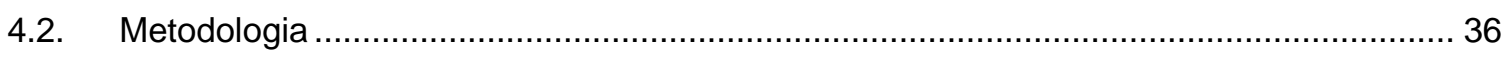

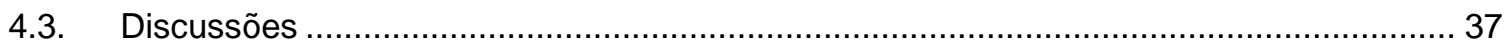




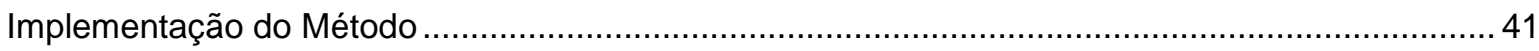





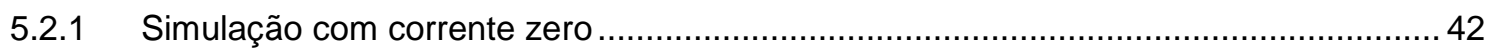

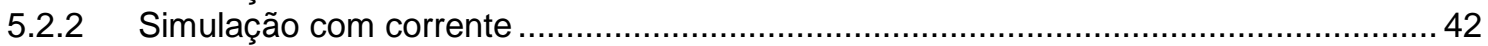

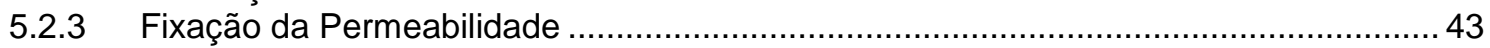

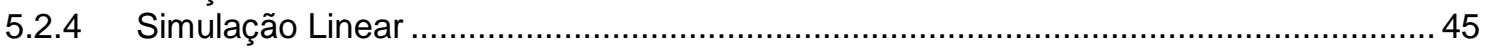

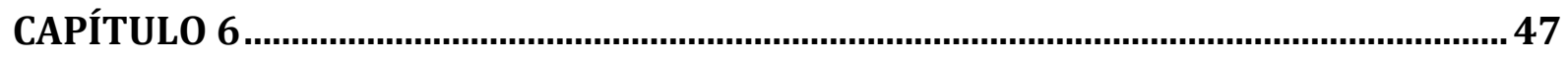

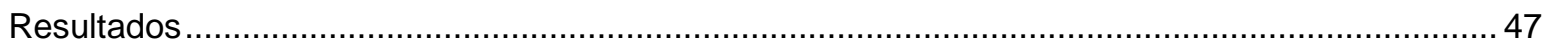

6.1. Máquina Síncrona com Ímã Permanente Semi-Enterrado............................................. 49

6.2. Máquina Síncrona com Ímãs Permanentes na Superfície do Rotor ..................................56

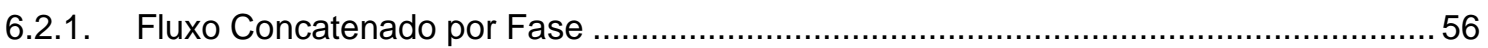



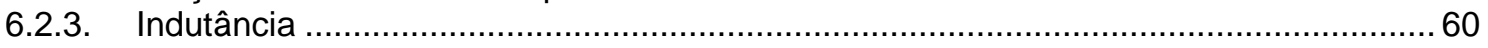

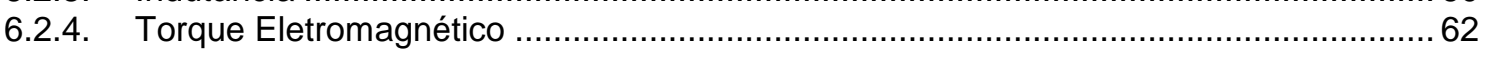



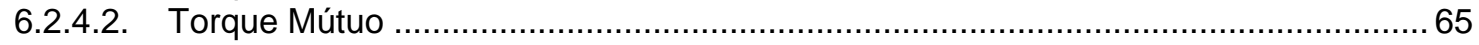

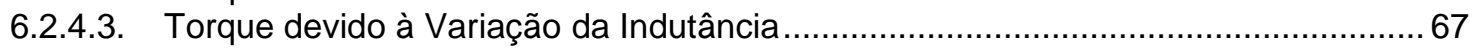

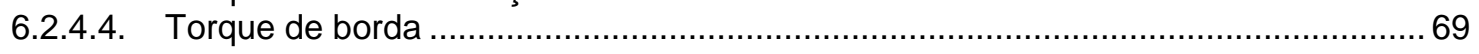



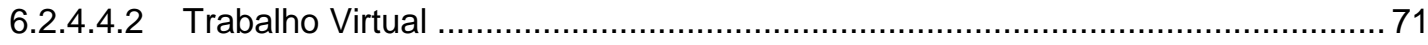

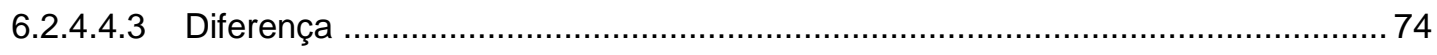

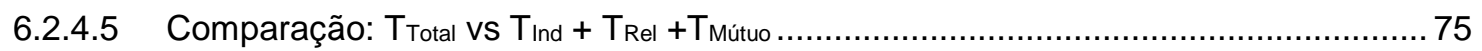

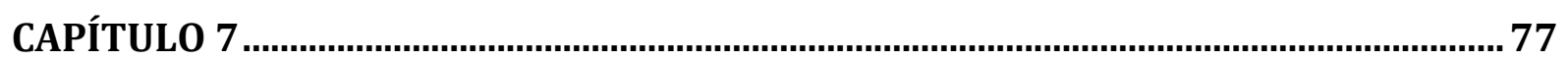

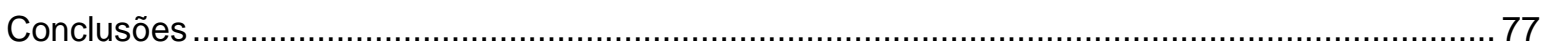

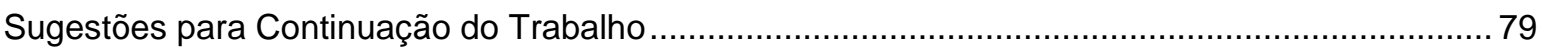

REFERÊNCIAS BIBLIOGRÁFICAS ......................................................................... 81 


\section{Capítulo 1}

\section{Introdução}

\subsection{Introdução}

$\mathrm{Na}$ atualidade, os mercados mundiais em crise e a crescente pressão por medidas mais sustentáveis de crescimento, por parte de uma sociedade cada vez mais ativa e exigente, têm forçado as empresas a buscarem medidas cada vez mais eficientes de consumo de energia.

No que diz respeito ao consumo de energia no mundo, é estimado que cerca de $65 \%$ de toda a energia elétrica disponível seja consumida por motores elétricos (Gieras; Wing, 2002). Dessa forma, principalmente nas indústrias, que constituem-se as maiores consumidoras de energia e cujas quantidade e potência de motores é maior do que qualquer outro setor, as políticas de melhoria de eficiência energética envolvem diretamente a substituição e aquisição de motores altamente eficientes.

$\mathrm{Na}$ busca por novos motores para aplicações industriais de grande porte, os motores brushless com ímã permanente no rotor vêm se destacando no mercado como a alternativa mais promissora. Isso se dá graças não apenas a sua alta eficiência, mas também a sua alta confiabilidade e a sua alta densidade de energia (Chau; Chan, 2008). Esta característica permite motores com níveis elevados de torque/corrente e torque/volume.

Em linhas gerais, os motores brushless de ímã permanente podem ser divididos em dois tipos: o brushless $A C$ (BLAC) e o brushless DC (BLDC) (Miyamasu; Akatsu, 2011). A 
divisão é feita segundo a forma de onda da força contra eletromotriz, sendo os BLAC máquinas síncronas com ímã permanente no rotor (acrescida de um inversor AC) cuja forma de onda da força contra eletromotriz é senoidal e os BLDC máquinas síncronas com ímã permanente no rotor (acrescida de um inversor AC) cuja forma de onda da força contra eletromotriz é trapezoidal.

Um estudo realizado por (Miyamasu; Akatsu, 2011) mostra ainda que, os motores BLDC apresentam níveis de eficiência maiores que os BLAC. Esse estudo é conduzido seguindo técnicas comuns de acionamento para esses dois tipos de motores, sendo avaliadas as perdas por PWM (Pulse With Modulation), histerese, efeito joule, perdas no núcleo e as eficiências do inversor e da máquina. Vale notar que as máquinas testadas apresentavam as mesmas dimensões e com ímãs com mesmo produto de energia.

\subsection{Motivação}

A principal motivação para o desenvolvimento desse trabalho, diz respeito ao estudo das máquinas síncronas com ímã permanente no rotor $^{1}$, cuja forma de onda da força contra eletromotriz é idealizada com formato trapezoidal, em regimes de altas correntes.

Conforme apresentado na introdução, alguns estudos vêm sendo realizados, principalmente ao longo da última década, sobre as distorções na forma de onda da força contra eletromotriz (Azar; Zhu; Ombach, 2012), variações na magnitude e frequência do torque de borda (Sung; Park; Jang, 2010), variação dos valores de indutância (Schmidt; Susic, 2012) e alterações no torque eletromagnético (Azar; Zhu; Ombach, 2012) em máquinas síncronas de ímã permanente no rotor com forma de onda de força contra eletromotriz senoidal. Em alguns desses estudos, tais como (Azar; Zhu; Ombach, 2012), (Schmidt; Susic, 2012), (Tangudu et al., 2009), a análise e descrição do torque eletromagnético, fluxo concatenado por cada fase, indutância e corrente são realizados sobre os eixos $d q$.

Levando-se em conta que não é relatado na literatura específica nenhum estudo sobre a máquina síncrona de ímã permanente no rotor com forma de onda de força contra eletromotriz trapezoidal, relacionado a regimes de altas correntes e possíveis consequências na forma de onda da força contra eletromotriz, torque de relutância, indutância e perturbações no torque eletromagnético, esse trabalho se dispõe a ser inovador nesse quesito, apresentando a descrição dos efeitos no desempenho da máquina provenientes do regime em altas

\footnotetext{
1 Esse tipo de máquina é um dos constituintes dos motores BLDC, conforme já mencionado e, esse texto utiliza esse termo quando quer se referir somente à máquina elétrica e não ao conjunto conversor + máquina.
} 
correntes.

\subsection{Objetivos}

Mediante o que foi apresentado, apresentam-se abaixo os objetivos dessa dissertação de mestrado:

- Descrição das alterações na força contra eletromotriz devido às distorções, essas proporcionadas pela operação da máquina em regime de alta corrente;

- Descrição das alterações no torque de relutância vista pelo circuito de rotor (cogging torque ou torque de borda), tais como magnitude e frequência, assim como em (Sung; Park; Jang, 2010);

- Descrição das alterações nos valores de indutância de cada fase. Alterações, essas, que provocam o aparecimento de um torque indesejável e consequentemente, oscilações no torque eletromagnético.

\subsection{Publicações}

Os artigos desenvolvidos pelo candidato a Mestre em Ciências, relacionados com esse trabalho, aceitos ou já publicados, são listados abaixo:

- PAUlA, G. T. ; AlMeidA, T. E. P. ; MONTEiRO, J. R. B. A. ; SANTANA, M. P. ; Pereira, W. A comparative study of different slot configurations for PM brushless machines used for vehicle traction. In: IECON13 39th Annual Conference of the IEEE Industrial Electronics Society, 2013, Viena.

Outras publicações, aceitas ou já publicadas, produzidas pelo grupo de pesquisa o qual o candidato participa e que houve participação direta do mesmo, são listadas abaixo:

- PAUla, G. T. ; AlmeidA, T. E. P. ; MONTEIRO, J. R. B. A. ; SANTANA, M. P. ; ROMERO, G. B. ; FARACCO, J. C. . Development of an Autonomous Aquatic Vehicle Employed on Special Activities. In: International Conference on Electrical Systems for Aircraft, Railway and Ship Propulsion, 2012, Bologna. Proceedings of International Conference on Electrical Systems for Aircraft, Railway and Ship Propulsion, 2012.

- PAUlA, G. T. ; MONTEIRO, J. R. B. A. ; AlMEIDA, T. E. P. ; SANTANA, M. P. ; 
FARACCO, J. C. . Comparative Study of PMSM with Circular PM shape and Circular/Rectangular Coil. In: Congresso Brasileiro de Automática, 2012, Campina Grande. Anais do XIX Congresso Brasileiro de Automática, 2012.

- santana, M. P. ; monteiro, J. R. B. A. ; PAUla, G. T. ; Almeida, T. E. P. ; FARACCO, J. C. . ESTRATÉGIAS PARA IDENTIFICAÇÃO DE FALTAS EXTERNAS E OPERAÇÃO DO GERADOR DE INDUÇÃO DUPLAMENTE ALIMENTADO. In: Congresso Brasileiro de Automática, 2012, Campina Grande. Anais do XIX Congresso Brasileiro de Automática, 2012.

- MONTEIRO, J. R. B. A. ; SUETAKE, M. ; PAULA, G. T. ; ALMEIDA, T. E. P. ; SANTANA, M. P. ; ROMERO, G. B. ; FARACCO, J. C. ; MONACO, F. J. ; PINTO, R. S. . Wind Velocity Neural Estimator for Small Autonomous Surface Vehicle. In: II Brazilian Conference on Critical Embedded Systems, 2012, Campinas. Proceedings of II Brazilian Conference on Critical Embedded Systems, 2012.

- SANtAnA, M. P. ; MONTEIRO, J. R. B. A. ; PAUla, G. T. ; AlMEIDA, T. E. P. ; ROMERO, G. B. ; FARACCO, J. C. . Fault Identification in Doubly Fed Induction Generator Using FFT and Neural Networks. In: International Conference on Intelligent Data Engineering and Automated Learning, 2012, Natal. Proceedings of International Conference on Intelligent Data Engineering and Automated Learning, 2012.

Depósito de patente:

- MONTEIRO, J. R. B. A. ; Paula, G. T. ; Santana, M. P. . GERADOR DE INDUÇÃO DUPLAMENTE ENROLADO SEM ESCOVAS COM EXCITAÇÃO INDEPENDENTE. 2012, Brasil. Patente: Privilégio de Inovação. Número do registro: BR102012002011 4, data de depósito: 30/01/2012, título: "GERADOR DE INDUÇÃO DUPLAMENTE ENROLADO SEM ESCOVAS COM EXCITAÇÃO INDEPENDENTE". Instituição financiadora: USP.

\subsection{Organização da Dissertação}

O presente documento está organizado da seguinte maneira:

O Capítulo 2 apresenta uma revisão teórica sobre as propriedades magnéticas dos materiais ferromagnéticos que compõe o estator da máquina em estudo. Detalham-se as consequências nos valores de indutância, relutância e a distorção da forma de onda da força contra eletromotriz quando da operação da máquina em condições nominais e em saturação. 
No Capítulo 3 é apresentado o equacionamento do torque eletromagnético e a descrição detalhada de cada termo do equacionamento. Desta maneira, torna-se possível observar e analisar, mesmo que de maneira superficial inicialmente, os efeitos provenientes da saturação do estator para a produção de torque na máquina.

No Capítulo 4 é estudado o método mais recente para análise de máquinas em plena carga - no que diz respeito à interação entre fluxo magnético de estator/rotor. O método em questão é conhecido na literatura como Frozen Permeability Method (Método da Permeabilidade Fixa) e permite a separação das fontes de excitação de campo magnético dentro da máquina.

No Capítulo 5 são apresentadas a maneira como o Método da Permeabilidade Fixa foi implementado, o passo-a-passo da implementação, o software desenvolvido e as considerações necessárias para a implementação do método.

No Capítulo 6 são apresentados os resultados das simulações realizadas para uma máquina síncrona de ímãs permanentes semi-enterrados no rotor, semelhante à máquina simulada em (Chu; Zhu, 2013, 2013), a fim de se validar o software desenvolvido no presente trabalho. Também são apresentados os resultados das simulações realizadas para uma máquina síncrona com ímãs na superfície do rotor, contendo 24 ranhuras no estator e 4 polos no rotor. A máquina foi avaliada sob cinco condições de corrente, 10, 20, 30A, sendo 11A a condição calculada para a operação da máquina à 4500rpm segundo (Teixeira, 2006).

No Capítulo 7 são apresentadas as conclusões do trabalho e as sugestões para a continuidade do trabalho. 



\section{Capítulo 2}

\section{Saturação}

\subsection{Definição}

Tanto no projeto de uma máquina elétrica quanto na análise do comportamento do campo magnético dentro da mesma, é preciso observar o estator, de um modo simplificado, como um guia para o fluxo magnético dentro da máquina, em que a baixa absorção da força magneto motriz por parte do mesmo é de grande importância para a concentração do fluxo magnético no entreferro (Hanselman, 1994), local em que contribuirá para a produção de torque.

Ao se observar a máquina elétrica em estudo, e levando-se em consideração a afirmação acima, nota-se que existem duas regiões fronteiriças ao entreferro, de um lado se encontram os ímãs do rotor e do outro lado os dentes do estator. Dessa forma, no projeto de uma máquina é dada especial atenção ao projeto dos dentes uma vez que, estes são projetados para guiarem a maior quantidade de fluxo magnético possível.

No entanto, por se tratar de um material ferromagnético, este apresenta um valor máximo de densidade de fluxo magnético $\left(B_{M A ́ X}\right)$, e portanto intensidade magnética máxima $\left(H_{M A ́ X}\right)$, a partir do qual sua permeabilidade magnética relativa, principal fator indicativo de quão facilitador como guia de fluxo magnético é o material, cai continuamente até atingir valores próximos à unidade, como ilustra a Figura 2.1.

A Equação (2.1) demonstra a relação entre densidade de fluxo magnético $(B)$ e a intensidade magnética $(H)$. 


$$
B=\mu_{R} \mu_{0} H
$$

Onde,

- $B \quad-$ Densidade de fluxo magnético.

- $\quad$ - Intensidade magnética.

- $\mu_{R} \quad$ - Permeabilidade magnética relativa.

- $\mu_{0} \quad$ - Permeabilidade magnética do vácuo, $4 \pi 10^{-7}($ T.m/A).

Figura 2.1 - Curva de magnetização da lâmina M-27.

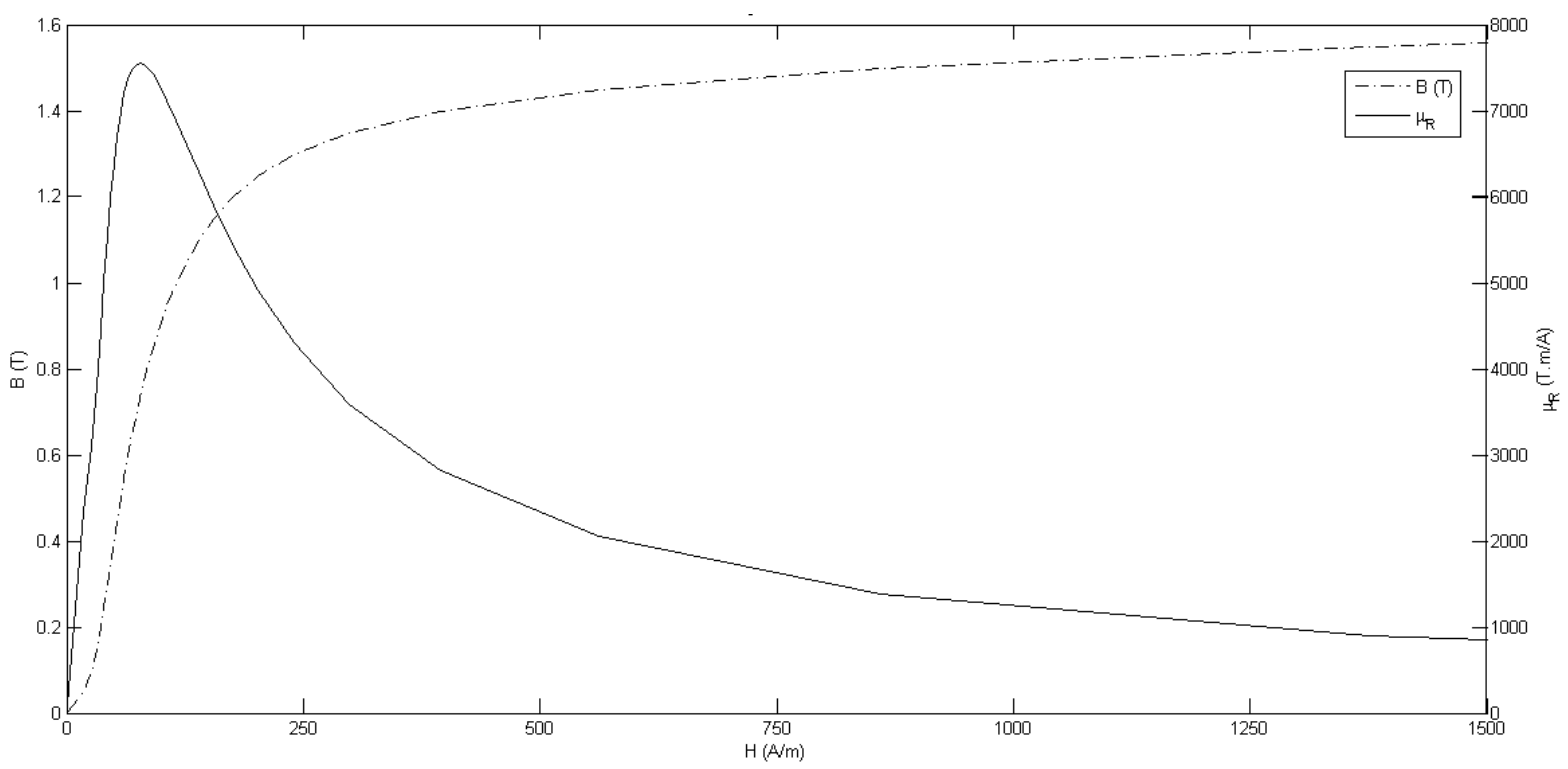

Fonte: Meeker (2012).

Como é apresentado na Seção 2.2, a permeabilidade magnética relativa exerce papel fundamental no circuito magnético uma vez que, o valor de relutância é inversamente proporcional à permeabilidade, tornando o estator um meio mais "atrativo" para o fluxo magnético dependendo do valor de $\mu_{R}$.

De uma maneira geral, os dentes e o estator são projetados para operarem com densidade de fluxo magnético entre 1,5T e 1,7T conforme o material utilizado no pacote de lâminas do estator. No entanto, em operações com regime de altas correntes, a densidade de fluxo magnético nos dentes pode facilmente ultrapassar 1,8T e entrar na região de saturação, afetando assim, o desempenho da máquina. 
A saturação é caracterizada por uma larga faixa de magnetização do material do estator em que, o acréscimo da intensidade magnética $(H)$ acarreta um baixo acréscimo na densidade de campo magnético $(B)$. Como pode ser observado na Figura 2.1, a saturação corresponde à região de baixos valores de permeabilidade relativa. Na Figura 2.1, essa região corresponde ao lado direito da inflexão da curva de permeabilidade magnética.

Do ponto de vista microscópico, quando da saturação do estator, os domínios magnéticos se encontram totalmente alinhados com o campo magnetizante, como pode ser visto na Figura 2.2.

Figura 2.2 - Disposição dos domínios magnéticos.
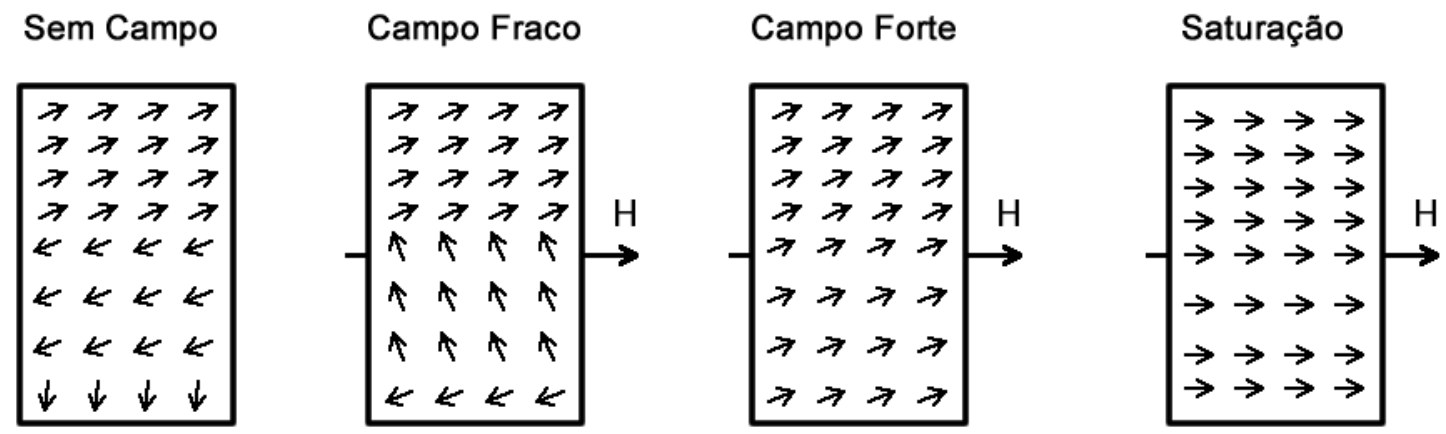

Uma vez saturado, o estator apresenta baixa permeabilidade magnética, tornando-se um guia magnético menos atrativo, resultando em maior queda da força magneto motriz e maior dispersão de fluxo magnético. Dessa forma, o desempenho e a eficiência da máquina sofrem uma redução considerável com relação a seus valores nominais.

Como já mencionado, o núcleo deve apresentar baixa queda de força magneto motriz a fim de concentrar a maior parte da mesma no entreferro, possibilitando, assim, a produção do torque desejado. No entanto, quando saturado, portanto com maior queda de força magneto motriz no estator, surgem alterações no torque. Essas alterações são resultantes da saturação, como mencionado por (Hanselman, 1994), (Azar; Zhu; Ombach, 2012), já que o fluxo magnético dentro da máquina não se comporta da mesma maneira como fora projetado.

No que diz respeito ao comportamento do fluxo magnético dentro da máquina, quando esta se encontra saturada, é possível notar grande dispersão das linhas de fluxo magnético, o que reduz a quantidade de fluxo concatenado com as bobinas de fase, afetando a produção de torque e a qualidade da força contra eletromotriz. A Figura 2.3 mostra a diferença entre as linhas de fluxo magnético para um estator em diferentes condições de operação, i.e., baixa, média e elevada intensidade de fluxo magnético. 
Figura 2.3 - Comportamento das linhas de fluxo magnético.

a)

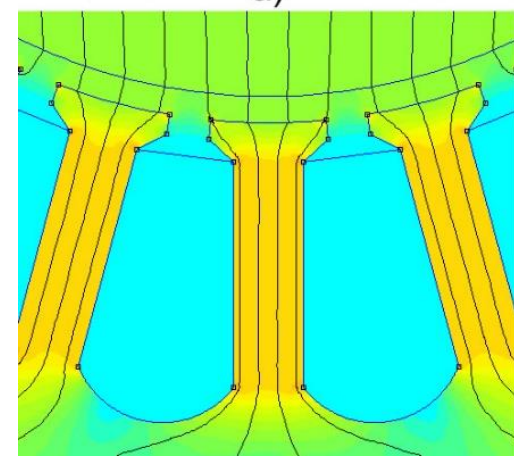

b)

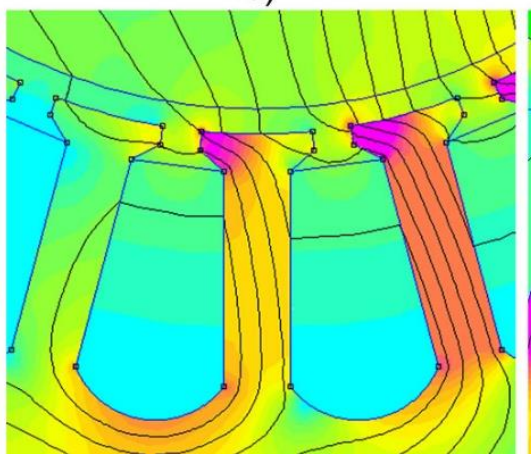

c)

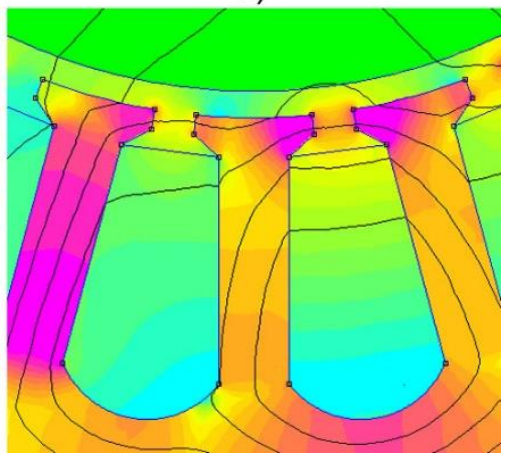

a) Baixo valor de $H$; b) Médio valor de $H$; c) Elevado valor de $H$.

A saturação causa o aumento das perdas resistivas, já que a relação Torque/Corrente diminui significativamente. $\mathrm{O}$ aumento dessas perdas afeta diretamente a eficiência da máquina e o aumento da temperatura nos enrolamentos e nos ímãs. O aumento de temperatura afeta a vida útil da isolação dos condutores utilizados no enrolamento. Sendo que, o aumento de $10^{\circ} \mathrm{C}$ acima da temperatura máxima designada pela classe de isolação utilizada nos condutores do enrolamento, acarreta a redução da vida útil da isolação pela metade segundo (Fuchs; Roesler; Kovacs, 1986).

No caso dos ímãs permanentes, o aumento da temperatura afeta o valor da densidade de fluxo magnético remanescente, reduzindo o mesmo como pode ser visto em (2.2). Um projetista de máquinas com ímã geralmente recorre à curvas de magnetização fornecidas pelo fabricante do ímã em que são apresentadas informações para diferentes temperaturas, além da temperatura máxima que é fornecida pela classe térmica do ímã (Miller; Hendersot Jr, 1995).

$$
B_{r(T)}=B_{r(20)}\left[1+\frac{\alpha_{B r}(T-20)}{100}\right]
$$

Onde,

- $B_{r(20)} \quad$ - Densidade de fluxo magnético remanescente à temperatura de $20^{\circ} \mathrm{C}$;

- $\quad \alpha_{B r} \quad$ - Coeficiente de temperatura reversível da densidade de fluxo magnético remanescente, $B_{r}$;

- $T$ - Temperatura do ímã em ${ }^{\circ} \mathrm{C}$. 
Nas seções seguintes, trata-se da influência da saturação magnética em cada um dos seguintes parâmetros:

- Relutância vista pelo circuito de rotor (ímã como fonte de fluxo magnético);

- Indutância;

- Força contra eletromotriz.

Parâmetros estes que, como mencionados, afetam o torque eletromagnético da máquina, cada qual ao seu modo.

\subsection{Variação na Relutância do Circuito de Rotor}

Antes de se iniciar o estudo dos efeitos da saturação na relutância da máquina, realizase uma breve revisão do conceito de relutância, apresentando a sua formulação de maneira a deixar claro quais fatores a saturação altera. Apresenta-se também, a relutância resultante vista pelo circuito magnético, que tem como fonte de fluxo os ímãs permanentes do rotor, quando a máquina se encontra em operação nominal e quando em saturação.

De forma análoga a circuitos elétricos, a relutância exerce em um circuito magnético papel similar ao papel exercido pela resistência elétrica representando uma queda no valor da força magneto motriz, como pode ser visto em (2.3).

$$
F M M=\phi \Re
$$

Onde,

- $\quad F M M$ - Força Magneto Motriz (Ae);

- $\phi \quad$ - Fluxo Magnético $(\mathrm{Wb})$;

- $\quad$ R - Relutância (Ae/Wb);

Como será visto mais a frente, considerando um fluxo magnético constante $(\phi)$ no circuito magnético do motor, quanto maior o valor da parcela da relutância relacionada ao estator, maior será a queda, ou seja, a absorção da força magneto motriz dentro do mesmo e menor será o valor da força magneto motriz no entreferro, consequentemente menor o torque produzido.

De maneira análoga à formulação da resistência elétrica, a formulação da relutância 
depende de características físicas do meio tais como a área de condução do fluxo, o comprimento do caminho magnético, i.e., o percurso realizado pelo fluxo magnético, e a permeabilidade magnética do meio, seja este ferromagnético ou não.

A Equação (2.4) apresenta a formulação simplificada para a relutância.

$$
\mathfrak{R}=\frac{l}{\mu_{R} \mu_{0} A}
$$

Onde,

- $\quad l \quad$ - Comprimento do caminho magnético;

- A - Área de condução do fluxo magnético.

A modelagem que se segue, tem como base o modelo apresentado na Figura 2.4, em que se recorre a uma máquina de um polo por ranhura por fase, assim como em (Hanselman, 1994). A opção por esse modelo simplificado se faz necessária uma vez que a intenção do presente tópico é demonstrar a importância da saturação na variação da relutância do circuito magnético, que tem como fonte de fluxo magnético os ímãs do rotor; e posteriormente, quando da definição e formulação do torque eletromagnético da máquina seja possível elucidar os prováveis problemas resultantes da variação dessa relutância. Modelos mais complexo e detalhados são facilmente encontrados na literatura, tendo como ponto comum que a variação dessa relutância na máquina segue uma periodicidade que depende do número de ranhuras $\left(\mathrm{N}_{\mathrm{S}}\right)$ e do número de polos $(2 \mathrm{p})$.

Figura 2.4 - Máquina de um polo por ranhura por fase.

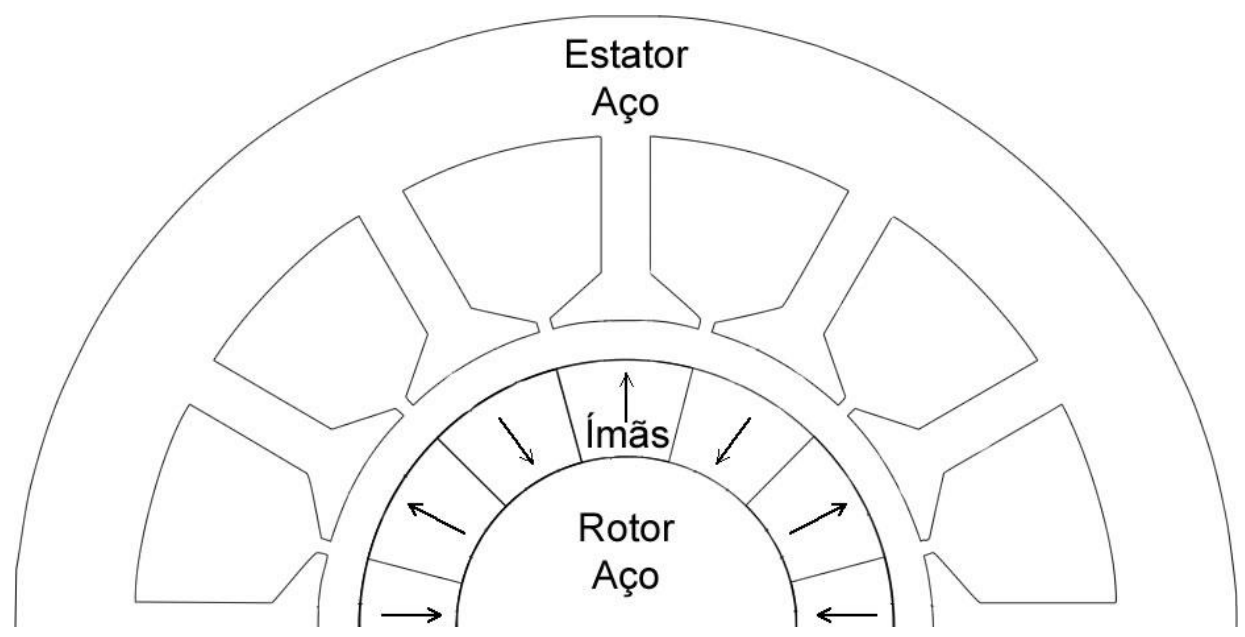

A partir do modelo apresentado na Figura 2.4, pode-se por simetria, simplificar a descrição do circuito magnético ao se observar que metade do fluxo, relativo a um polo, que 
atravessa o entreferro, tem como destino o polo adjacente, possibilitando dessa maneira, 0 enlace das linhas de fluxo magnético. A Figura 2.5 apresenta o circuito proposto acima.

Figura 2.5 - Circuito magnético.

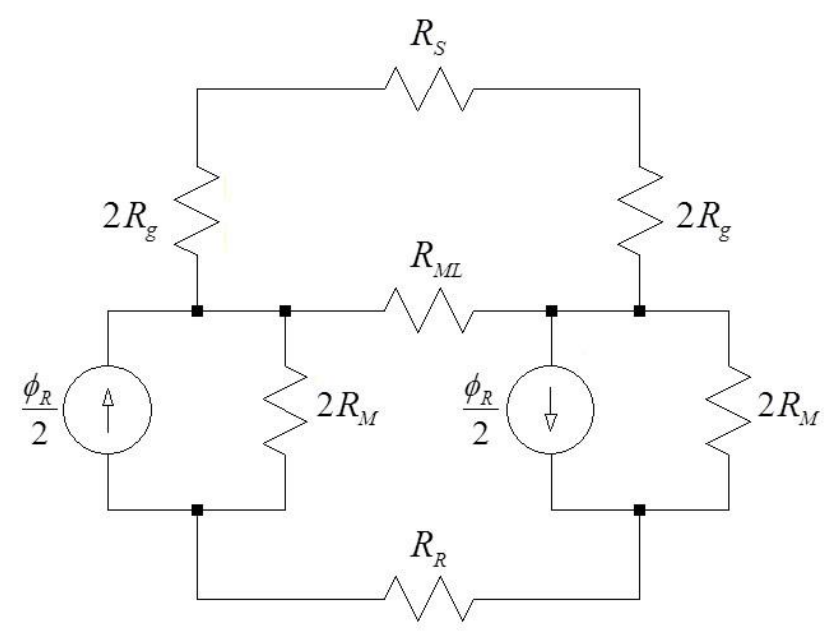

Onde,

- $\frac{\phi_{R}}{2}$ - Metade do fluxo remanescente de um polo (ímã permanente);

- $\mathfrak{R}_{g} \quad$ - Relutância do entreferro;

- $\mathfrak{R}_{S}$ - Relutância do estator;

- $\quad \mathfrak{R}_{R}$ - Relutância do rotor;

- $\quad \mathfrak{R}_{M}$ - Relutância do ímã permanente;

- $\mathfrak{R}_{M L}$ - Relutância entre os polos adjacentes.

Deve-se notar que esse circuito não é único para toda a máquina. Há, no total, $2 p$ circuitos semelhantes a este e independentes na máquina. Para o modelo proposto, os outros $2 p-1$ circuitos são idênticos ao apresentado na Figura 2.5 já que esse modelo propõe uma máquina de um polo por ranhura por fase. Portanto, todos os polos se encontram ora alinhados ora desalinhados nas mesmas proporções com relação aos dentes do estator que estão guiando o fluxo magnético. A Figura 2.6 ilustra o conceito apresentado acima, mostrando os $2 \mathrm{p} / 2$ circuitos na mesma máquina.

Para máquinas cuja razão número de ranhura por número de polos não seja inteira, nem todos os polos se encontram alinhados/desalinhados da mesma maneira, há portanto 
circuitos magnéticos cujos caminhos magnéticos sejam maiores em alguns pontos, principalmente quando se observa os polos que se encontram desalinhados, apresentando caminho magnético $(l)$ ligeiramente maior para o cálculo da relutância do entreferro. A Figura 2.7 ilustra o desalinhamento dos polos em uma máquina cuja razão número de ranhuras por número de polos não é inteira.

Figura $2.6-2 p / 2$ circuitos magnéticos.



Figura 2.7 - Desalinhamento de polos.

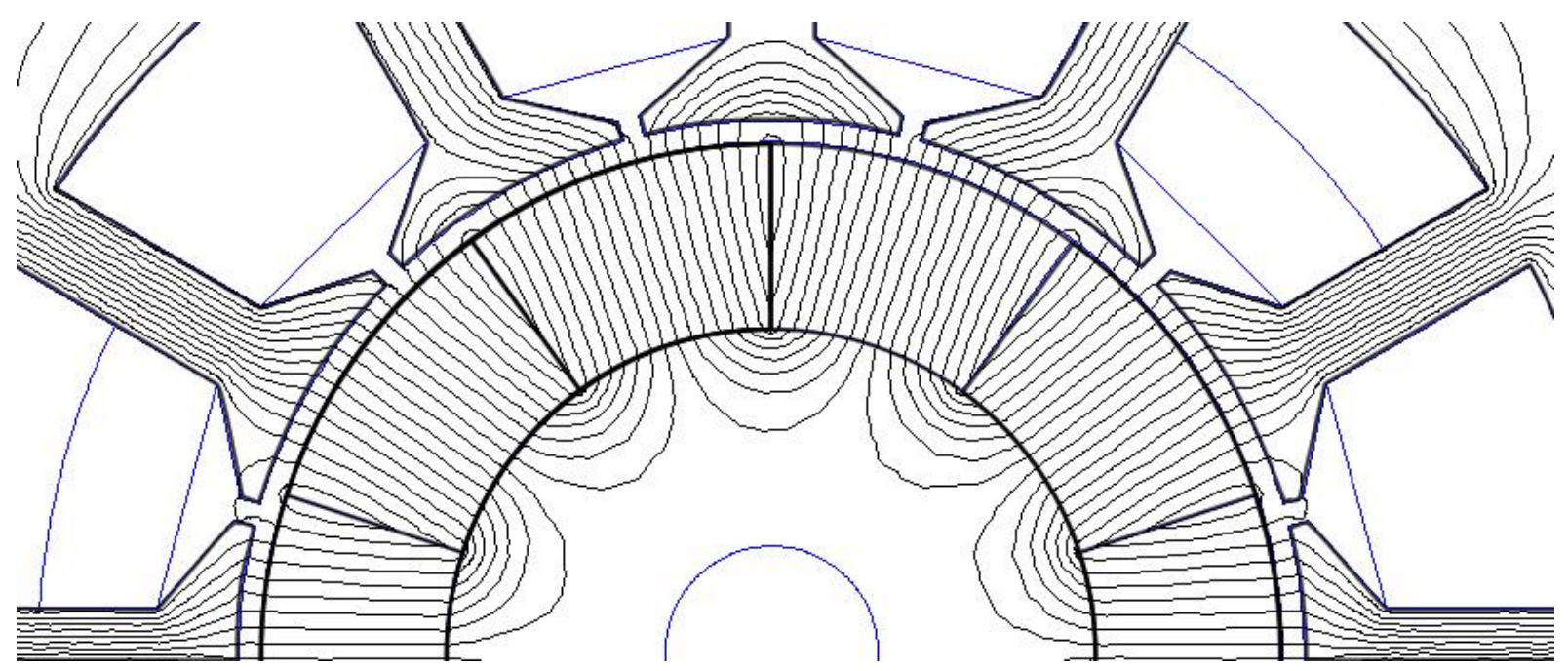

Retomando ao circuito proposto na Figura 2.5, em máquinas de alto desempenho, a relutância magnética devido ao espaço entre polos magnéticos adjacentes, $\mathfrak{R}_{M L}$, apresenta valor elevado quando comparado aos valores das outras relutâncias, até mesmo $\mathfrak{R}_{g}$. Dessa forma, pode-se considerar o ramo o qual $\mathfrak{R}_{M L}$ faz parte, como um circuito aberto. 
Para um máquina operando longe de seus limites operacionais, e portanto, não saturada, o circuito pode ser simplificado ao se observar que $\mathfrak{R}_{S}$ e $\mathfrak{R}_{R}$ apresentam valores baixos quando comparados aos valores das relutâncias de entreferro e dos próprios ímãs. Essa simplificação resulta na relutância equivalente apresentada pela expressão (2.5).

$$
\mathfrak{R}_{E q}=4\left(\Re_{g}+\mathfrak{R}_{M}\right)=4\left(\frac{g}{\mu_{0} A_{g}}+\frac{l_{M}}{\mu_{R M} \mu_{0} A_{M}}\right)
$$

Onde,

- $A_{g} \quad$ - Área do entreferro vista pelas linhas de fluxo provenientes de um polo;

- $A_{M}$ - Área de um polo;

- $g$ - Comprimento do entreferro;

- $\quad l_{M} \quad$ - Espessura do ímã;

- $\quad \mu_{R M}$ - Permeabilidade magnética relativa do ímã;

Se for considerado que a permeabilidade magnética relativa do ímã é próxima à unidade e que a área do entreferro tem valor próximo ao da área do polo magnético, a equação resulta em um expressão mais simplificada, como visto em (2.6).

$$
\mathfrak{R}_{E q}=4\left(\frac{g+l_{M}}{\mu_{0} A_{M}}\right)
$$

No entanto quando em saturação, as simplificações realizadas acima deixam de ser válidas, exceto a de que a relutância magnética devido ao espaço existente entre polos adjacente, $\mathfrak{R}_{M L}$, apresente valor elevado o suficiente para que possa ser desprezada no circuito resultante (circuito aberto). O mais correto nesse caso, é considerar o circuito magnético proposto na Figura 2.4, porém, com maior riqueza de detalhes, passando a considerar mais de um circuito para descrever o fluxo que sai de um polo com destino ao polo adjacente. Para a análise mais detalhada, faz-se necessário o emprego de softwares para resolução do problema por meio de modelos de circuitos magnéticos equivalentes ou através de técnicas empregando o método dos elementos finitos. 
Diferentemente do modelo sem saturação, os valores de relutância do estator e do rotor passam a ser significativos no circuito magnético. Esse fato ocorre devido à queda no valor da permeabilidade magnética relativa do pacote de lâminas do estator e núcleo do rotor, tornando o valor da relutância dos mesmos um valor considerável na análise do circuito magnético.

A queda no valor da permeabilidade magnética relativa é o principal responsável pelo acréscimo do valor da relutância, mas não é o único. Como pode ser visto na Figura 2.3c, a saturação altera o caminho das linhas de fluxo $(l)$, tornando-o mais longo e mais complexo do que quando a máquina não se encontrava em saturação, sendo difícil de defini-lo de maneira analítica. As alterações não se limitam apenas à permeabilidade e ao caminho magnético, a área efetiva de condução de fluxo magnético passa a ser menor já que várias partes dos dentes, principalmente nas sapatas, deixam de ser meios atrativos para a condução de fluxo magnético.

A implicação de todas as alterações acima é principalmente o aumento da absorção da força magneto motriz no estator, reduzindo, dessa maneira, a parcela da força magneto motriz no entreferro. Afetando, portanto, o torque eletromagnético produzido pela máquina.

Nota-se que, a redução no valor da permeabilidade magnética relativa provoca uma reação em cascata nas outras variáveis, sendo essa a principal propriedade a ser observada na aquisição do material ferromagnético das lâminas do estator.

\subsection{Variação na Indutância}

Antes de se iniciar o estudo dos efeitos da saturação na indutância da máquina, realiza-se uma breve revisão do conceito de indutância, apresentando a sua formulação de maneira a deixar claro quais parâmetros a saturação altera, apresentando também, a indutância de fase, que tem como fonte de fluxo as bobinas do estator, quando a máquina se encontra em operação nominal e quando em saturação.

Segundo (Miller; Hendersot Jr, 1995), a indutância exerce papel importante na alimentação da máquina, onde o valor da indutância é responsável pela taxa de crescimento ou decaimento da corrente nos enrolamentos de estator, ou seja, o quão rápido se pode alcançar a corrente de referência. Juntamente com o valor de resistência dos enrolamentos do estator, a indutância descreve a constante de tempo elétrica da máquina em estudo, Equação (2.7). 


$$
\frac{d i}{d t}=\frac{V_{S}-R i-e}{L}
$$

Vale notar que, a indutância é responsável pelo armazenamento da energia no campo magnético como expresso em (2.8).

$$
W_{C}=\frac{1}{2} L i^{2}
$$

A formulação do valor da indutância para qualquer circuito é apresentada na Equação (2.9).

$$
L=\frac{\phi}{i}=\frac{N^{2}}{\mathfrak{R}_{E q}}
$$

Onde,

- $\phi \quad$ - Fluxo concatenado com a bobina;

- $\quad i \quad$ - Corrente que circula pela bobina;

- $\quad N \quad$ - Número de espiras da bobina;

- $\mathfrak{R}_{E q}$ - Relutância equivalente do circuito magnético.

O termo $\mathfrak{R}_{E q}$ diz respeito a relutância equivalente vista pelo circuito magnético que tem como fonte de fluxo a bobina em estudo. Este circuito magnético é diferente do circuito apresentado na Seção 2.2 em que o ímã era a fonte de fluxo.

No estudo da indutância existem dois tipos diferentes de indutância, a auto indutância e a indutância mútua. A auto indutância está relacionada com a parcela do fluxo concatenado com a bobina que é gerado pela corrente da própria bobina. A indutância mútua está relacionada com a parcela do fluxo concatenado com a bobina que é gerado por outra bobina.

A literatura trata o cálculo da indutância de fase para máquinas de ímã permanente em três parcelas distintas (Miller; Hendersot Jr, 1995),(Hanselman, 1994):

- Indutância de entreferro (Air-gap inductance); 
- Indutância de dispersão na ranhura (Slot leakage inductance);

- Indutância de final de bobina (End turn inductance).

\subsubsection{Indutância de entreferro (Air-gap inductance)}

Assim como na Seção 2.2, o modelo aqui adotado diz respeito a uma máquina com um polo por ranhura por fase (Figura 2.4) do mesmo modo que em (Hanselman, 1994). Adotase, como ferramenta de análise, o circuito magnético equivalente de uma única bobina, a partir do qual, tira-se conclusões a respeito da interferência da saturação nos parâmetros envolvidos no cálculo dessa parcela da indutância. De modo similar ao apresentado em (Hanselman, 1994), porém com base nas leis de Faraday, os autores de (Miller; Hendersot Jr, 1995) chegam ao mesmo resultado e com um pouco mais de esforço analítico propõe uma solução mais generalista, que inclui tanto a auto indutância quanto a indutância mútua para várias bobinas de uma mesma fase.

Essa parcela da indutância é de grande importância por lidar com o fluxo magnético que atravessa o entreferro, e como já mencionado, esse fluxo é responsável pela produção do torque na máquina.

A primeira análise é feita com base em um máquina de dois polos e duas ranhuras (Figura 2.8). A partir da análise dessa máquina, parte-se para um modelo generalizado, i.e., $2 p$ polos e $N_{\text {RANHURAS }}$ ranhuras. A Figura 2.9 apresenta o circuito equivalente de uma bobina.

Figura 2.8 - Máquina de dois polos e duas ranhuras.

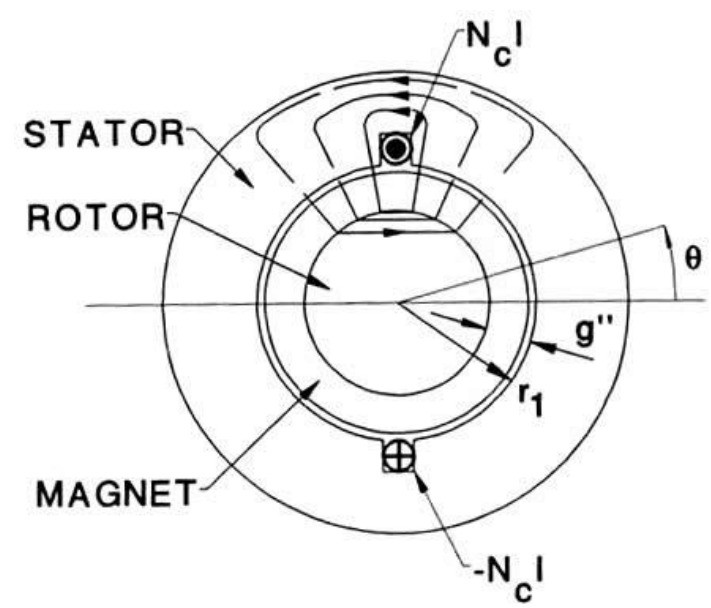

Fonte: Miller; Hendersot Jr (1995) 
Figura 2.9 - Circuito magnético proposto para uma bobina.

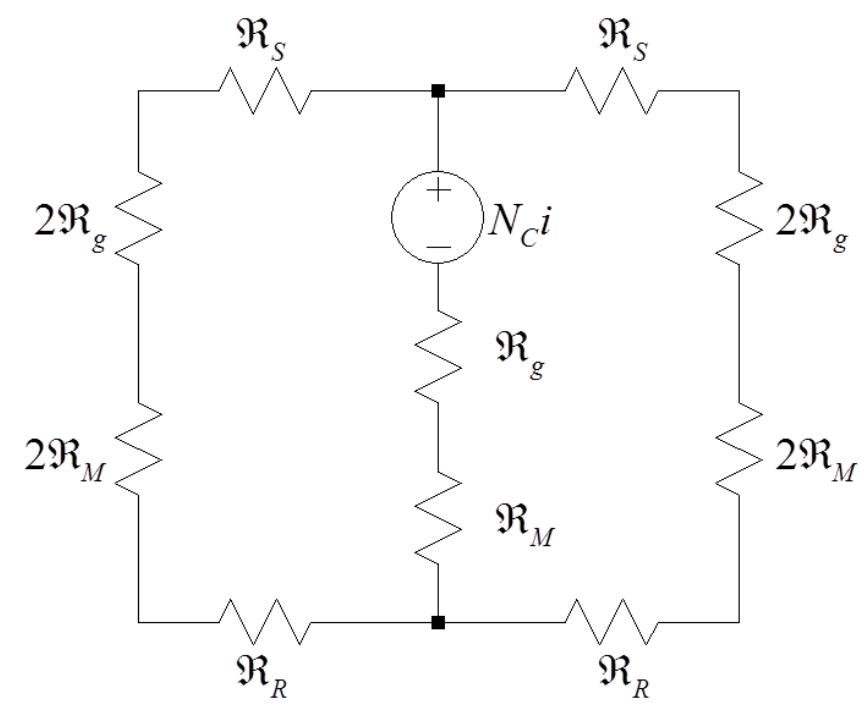

Onde:

- $\quad N_{C}$ - Número de condutores na ranhura;

- $\quad i \quad$ - Corrente em cada condutor;

Para um máquina operando abaixo de seus limites operacionais, portanto não saturada, o circuito pode ser mais simplificado ao se observar que $\mathfrak{R}_{S}$ e $\mathfrak{R}_{R}$ apresentam valores baixos quando comparados aos valores das relutâncias de entreferro e dos próprios ímãs. Essa simplificação resulta na relutância equivalente descrita pela expressão (2.10).

$$
\mathfrak{R}_{E q}=\frac{2\left(l_{M}+\mu_{R} g\right) p}{\mu_{R} \mu_{0} \pi L_{S T K} r_{1}}
$$

Vale notar que $A_{M}$ e $A_{g}$ são iguais e descritas como em (2.11).

$$
A_{M}=A_{g}=\frac{L_{S T K} \pi r_{1}}{p}
$$

Onde:

- $\quad L_{S T K} \quad$ - Altura do pacote de lâminas do estator;

- $\quad r_{1} \quad$ - raio interno do estator; 
- $\quad$ - pares de polos.

A partir de (2.9) e (2.10), obtém-se a expressão para a indutância de entreferro proposta em (2.12) (Hanselman, 1994).

$$
L_{g}=\frac{\mu_{R} \mu_{0} \pi r_{1} L_{S T K} N_{C}^{2}}{2 p\left(\mu_{R} g+l_{M}\right)}
$$

Segundo (Miller; Hendersot Jr, 1995), para se generalizar o problema para uma máquina de $2 p$ polos, basta substituir $N_{C}$ por $N_{p h} / p$. Onde, $N_{p h}$ é o número de espiras em série por fase.

Obviamente, este modelo é uma simplificação perto do problema real que é o cálculo da indutância por fase. No entanto, este modelo é a base para o desenvolvimento de estimativas mais complexas para o valor da indutância. A complexidade nesse tipo de estimativa se dá pelo fato de que o comportamento do campo magnético dentro da máquina só pode ser descrito em maiores detalhes com o auxílio de métodos numéricos e médio esforço computacional, onde é possível desfrutar da análise sem haver a preocupação com a disposição das bobinas no estator.

Outra dificuldade reside na estimativa do valor da indutância mútua entre duas bobinas da mesma fase e entre duas bobinas de fases diferentes. De um modo geral, a estimativa da indutância mútua se baseia nas formulações apresentadas acima e leva em consideração a disposição das duas bobinas no estator, determinando assim, a maneira como estas estão acopladas magneticamente, i.e., o quanto de fluxo magnético gerado por uma bobina é concatenado com outra. Muitas vezes, a literatura relata a indutância mútua sendo proporcional à auto indutância.

Do mesmo modo como é mencionado na Seção 2.3 e diferentemente do modelo sem saturação, os valores de relutância do estator e do rotor passam a ser significativos no circuito magnético que tem a bobina como fonte de fluxo. Esse fato ocorre devido à queda no valor da permeabilidade magnética relativa do pacote de lâminas do estator e corpo do rotor, tornando o valor da relutância dos mesmo um valor considerável na análise do circuito magnético.

Uma vez que o caminho seguido pelas linhas de fluxo magnético, seja no estator ou no rotor, e a permeabilidade relativa desse caminho não são parâmetros fáceis de serem 
determinados de maneira analítica, o equacionamento da estimativa do valor da auto indutância sofre o mesmo problema, necessitando-se assim, de auxílio computacional para a determinação de seu valor quando da saturação do estator.

Notoriamente, ao afetar a auto indutância, a saturação afeta também a indutância mútua. Como já visto, esse fato ocorre devido ao acoplamento magnético entre as bobinas envolvidas.

\subsubsection{Indutância de dispersão na ranhura (Slot leakage inductance)}

Enquanto a Subseção 2.3.1 lida com a parcela da indutância relacionada com as linhas de fluxo magnético geradas pela bobina e que atravessam o entreferro, a presente seção lida com as linhas de fluxo que cruzam a área da ranhura, atravessando os condutores da bobina. A primeira consideração a ser tomada aqui é que as linhas de fluxo que cruzam a área da ranhura são paralelas ao entreferro, como pode ser visto na Figura 2.3c.

A indutância de dispersão na ranhura é fortemente dependente dos parâmetros dimensionais dos dentes do estator, além da disposição dos condutores dentro da ranhura (Miller; Hendersot Jr, 1995), (Hanselman, 1994). Os autores de (Miller; Hendersot Jr, 1995) comparam os valores de indutância de dispersão de ranhura para alguns casos, considerados os mais importantes de posicionamento dos condutores dentro da ranhura. A Figura 2.10 ilustra os casos apresentados por esses autores.

Segundo os autores, o caso b) apresenta o valor máximo de indutância possível, obtida com um único condutor localizado no fundo da ranhura. $\mathrm{O}$ caso c) apresenta o menor valor de auto indutância, praticamente zero. $\mathrm{O}$ caso a) apresenta valor equivalente a um terço do valor máximo de indutância. $\mathrm{O}$ caso d) apresenta valor equivalente a dois terços do valor máximo de indutância. Já o caso e) apresenta valor equivalente a um sexto do valor máximo de indutância.

Dentes com sapata apresentam valores maiores de indutância do que dentes retos (sem sapatas) uma vez que há maior quantidade de fluxo atravessando a área da ranhura por meio das sapatas devido à baixa relutância existente entre as sapatas. Os dentes com sapatas são os mais empregados no projeto do tipo de máquina em estudo, principalmente pelo fato que os dentes retos acarretam maiores valores de torque de borda (cogging torque) (Miller; Hendersot Jr, 1995). 
Figura 2.10 - Disposição dos condutores dentro da ranhura.

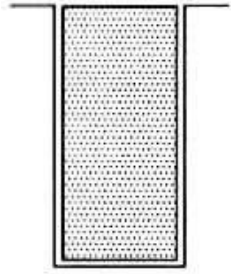

(a)

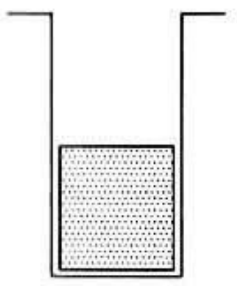

(d)

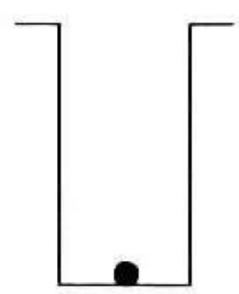

(b)



(e)

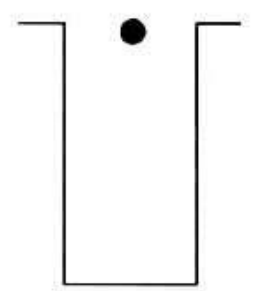

(c)

a) $L=1 / 3 L_{\text {MÁX }}$

b) $L=L_{\text {MÁX }}$

c) $L=0$

d) $L=2 / 3 L_{\text {MAXX }}$

e) $L=1 / 6 L_{\text {MÁX }}$

Fonte: Miller; Hendersot Jr (1995).

Para a análise da indutância de dispersão na ranhura, deve-se levar em consideração a Figura 2.11, que serve como base para a estimativa da indutância para uma ranhura completamente preenchida pelos condutores da bobina, assim como na Figura 2.10a..

Figura 2.11 - Dimensões da ranhura.

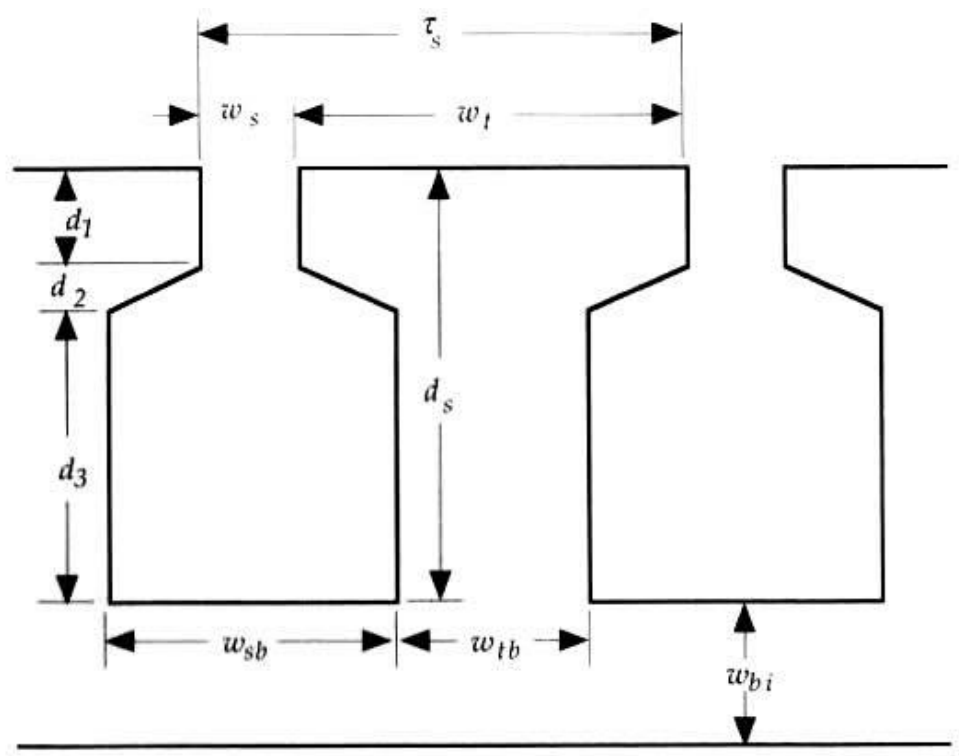

Fonte: Hanselman (1994)

Segundo o autor de (Hanselman, 1994), o cálculo dessa indutância pode ser dividida em três componentes. A primeira é relativa ao corpo principal da ranhura, que compreende a 
área maior de condução do fluxo através da ranhura pelo caminho $w_{s b}$. A segunda componente está relacionada à segunda área de condução de fluxo (logo abaixo da abertura de ranhura), que compreende o caminho médio $\left(w_{s}+w_{s b}\right) / 2$. A terceira e última componente, diz respeito a área de condução de fluxo através da abertura de ranhura, cujo caminho é $w_{s}$.

A Equação (2.13) apresenta a formulação para a indutância de dispersão de ranhura.

$$
L_{S}=N_{C}^{2}\left[\frac{1}{3} \frac{\mu_{0} d_{3} L_{S T K}}{w_{s b}}+\frac{\mu_{0} d_{2} L_{S T K}}{\left(w_{s}+w_{s b}\right) / 2}+\frac{\mu_{0} d_{1} L_{S T K}}{w_{s}}\right]
$$

Vale notar que, para os outros caso de distribuição dos condutores dentro da ranhura, basta alterar de forma apropriada o valor de 1/3 presente na primeira componente da expressão (2.13) por um dos valores mencionados na descrição da disposição dos condutores na Figura 2.10. Em caso de algum preenchimento diferente dos apresentados, ou até mesmo algum preenchimento especial, basta fazer uma busca na literatura ou empregar algum software de elementos finitos ou de análise de campo magnético para determinar o valor dessa componente.

As segunda e terceira componentes tratam, essencialmente, dos dentes com sapatas. Caso os dentes empregados no projeto da máquina sejam retos, a Equação (2.13) será constituída apenas da primeira componente. Ao se observar estas duas componentes, reforça-se o conceito apresentado no início dessa subseção, em que os dentes com sapatas proporcionam valor de indutância maior do que os dentes sem sapatas, mesmo com o aumento do valor de $d_{3}$. Outro fato importante que deve ser observado, é o quão dominante a terceira componente pode vir à ser no cálculo da indutância. Quanto maior a razão entre $w_{s b}$ e $w_{s}$, i.e., quanto menor for o valor de ws (por exemplo, suficientemente pequeno para se passar um único condutor), maior será o valor da indutância de dispersão de ranhura (Hanselman, 1994), sendo os valores das outras componentes praticamente desprezíveis.

As saliências dos dentes, i.e., as próprias sapatas dos dentes, são o principal alvo da saturação uma vez que nessas saliências se concentram o fluxo magnético proveniente dos imãs e o fluxo magnético gerado pela corrente que circula nas bobinas. Portanto, a densidade de fluxo magnético nessa região é maior do que em outras partes do dente. Na pior das hipóteses para a saturação, essas saliências comportam-se como o ar, com permeabilidade magnética relativa próxima à unidade (Hanselman, 1994). Assim sendo, o valor da indutância de 
dispersão de ranhura, que em operação nominal da máquina é dominante na parcela da indutância de fase devido ao baixo valor de $w_{s}$, passa a apresentar valor menor.

Valores baixos de indutância trazem consigo duas implicações: a facilidade para o controle da máquina, visto que a constante de tempo elétrica da máquina é baixa e a velocidade com que se atinge o valor de corrente desejado é maior; e nas condições de falta da máquina, a baixa constante de tempo elétrica permite que a corrente no circuito aumente rapidamente, dificultando a ação de proteção.

Enquanto o valor da indutância mútua para a indutância de entreferro representa uma quantidade significativa quando comparada a auto indutância de entreferro, o mesmo não ocorre com a indutância mútua de dispersão de ranhura, sendo o cálculo da mesma, muitas vezes desprezado (Hanselman, 1994),(Miller; Hendersot Jr, 1995).

\subsubsection{Indutância de final de bobina (End turn inductance)}

Discute-se no presente tópico, a última parcela de indutância que compõe a indutância de fase da máquina. Esta parcela diz respeito ao fluxo concatenado com a parte da bobina exterior ao estator, i.e., fora das ranhuras, que não está face-a-face com o fluxo do entreferro e nem mesmo com o fluxo que atravessa a ranhura.

Segundo os autores de (Hanselman, 1994) e (Miller; Hendersot Jr, 1995), a dificuldade de se calcular de forma precisa o valor dessa parcela de indutância está diretamente relacionada com a dificuldade de se descrever, de maneira apropriada, o fluxo magnético nessa região da máquina. No entanto, ambos autores relatam que mesmo diante dessa dificuldade, uma formulação relativamente simples, que será apresentada, possibilita uma boa estimativa para o valor dessa parcela da indutância.

Para a compreensão da formulação dessa parcela da indutância, deve-se levar em consideração a Figura 2.12, em que são apresentados alguns parâmetros dimensionais da máquina.

A formulação para a indutância de final de bobina é expressa na Equação (2.14).

$$
L_{\text {end }}=\frac{\mu_{0} N_{C}^{2} r_{w} \alpha}{2} \ln \left(\frac{4 r_{w} \alpha}{0,447 \sqrt{A_{\text {Ranhura }}}}-2\right)
$$


Onde:

- $r_{w} \quad$ - raio do enrolamento, medido entre o centro da máquina e o centro da ranhura;

- $\alpha \quad$ - ângulo do enrolamento;

- $A_{\text {Ranhura }}$ - área da ranhura, que pode ser definida pelo produto de $w_{s b}$ por $d_{3}$;

Figura 2.12 - Final de bobina.

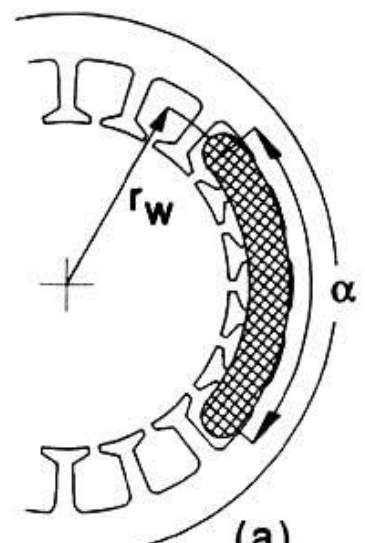

(a)

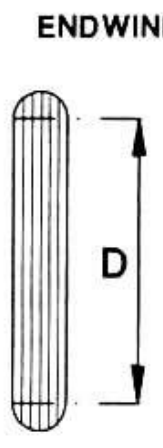

(b)

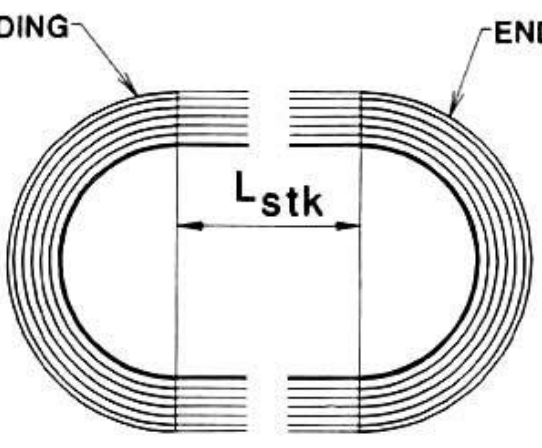

(c)

Fonte: Miller; Hendersot Jr (1995).

Diante da formulação apresentada na Equação (2.14) e da disposição dessa parte da bobina, i.e., exterior ao estator, nota-se que a estimativa apresentada pode ser utilizada tanto para a máquina operando em condições nominais quanto para a máquina operando em saturação uma vez que, o meio é não magnético (ar) e sua permeabilidade magnética é praticamente a permeabilidade do vácuo.

Enquanto a indutância mútua, com relação à indutância de dispersão de ranhura, é desprezível quando comparada ao valor de sua respectiva auto indutância, a estimativa da indutância mútua de final de bobina é desprezada pelo mesmo motivo e por apresentar grande dificuldade de modelagem analítica, tendo em vista a complexidade de descrição do fluxo magnético na região externa ao estator e da disposição dos finais de bobinas no estator. Sendo a estimativa da auto indutância de final de bobina descrita na Equação (2.14) suficiente para descrever a indutância de final de bobina (auto + mútua).

\subsubsection{Indutância de fase}

Realizadas as formulações das três parcelas da indutância de fase da máquina, cabe à estimativa da indutância de fase da máquina juntar as três parcelas, com suas respectivas 
indutâncias mútuas, a fim de se obter o valor que totalize a indutância de fase. O cálculo que se procede é simples. Como as estimativas realizadas em cada parcela eram para uma única bobina, basta somar essas parcelas e multiplicar o resultado pelo número de bobinas por fase $N_{\frac{b o b}{f a s e}}$, como demonstra a Equação (2.15).

$$
L_{\text {fase }}=N_{\frac{b o b}{\text { fase }}}\left(L_{g}+L_{S}+L_{\text {end }}\right)
$$

\subsection{Força Contra Eletromotriz}

No presente tópico, apresenta-se a formulação da força contra eletromotriz da máquina síncrona de ímã permanente com forma de onda trapezoidal, salientando os pontos de maior importância para o desenvolvimento do presente trabalho. Vale ressaltar que não serão abordados parâmetros, tais como o fator de enrolamento, fator de distribuição de enrolamento, entre outros, visto que esses parâmetros são voltados, principalmente, para questões de projeto e otimização de projeto. Como o objetivo, a priori, é a observação e descrição dos efeitos causados pela saturação do estator na máquina, discorrer-se-á, exclusivamente, dos parâmetros que influenciem de maneira direta a obtenção da força contra eletromotriz na mesma forma com que esta foi concebida em projeto, i.e., focar nos parâmetros que constituem a força contra eletromotriz e como eles são afetados quando da saturação da máquina.

A forma de onda da força contra eletromotriz para a máquina em estudo é idealizada como trapezoidal, com patamar superior de $120^{\circ}$ elétricos de comprimento, no entanto, na prática esse trapézio dificilmente apresenta exatos $120^{\circ}$ elétricos de comprimento, e apresenta, também, bordas mais suaves que o formato ideal. A Figura 2.13 apresenta uma comparação entre o forma de onda da força contra eletromotriz ideal e a forma de onda de uma máquina projetada.

Apesar de não serem idênticas, considera-se como requisito de operação da máquina que a forma de onda é trapezoidal ideal e cuja constante de velocidade descreve o pico da força contra eletromotriz segundo a velocidade de rotação da máquina. Formulando-se assim, uma equação simples para descrever o valor da força contra eletromotriz (2.16).

$$
e=k_{E} \omega_{M e c}
$$


Onde:

- $k_{E} \quad$ - Constante de velocidade da máquina;

- $\omega_{M e c}-$ Velocidade mecânica angular da máquina.

Uma formulação mais detalhada, a qual permita melhor descrição dos parâmetros envolvidos, pode ser obtida a partir da lei de Faraday, em que a variação de fluxo magnético em uma bobina induz uma tensão nos terminais da mesma, conforme a Equação (2.17).

Figura 2.13 - Comparação entre formas de onda de força contra eletromotriz.

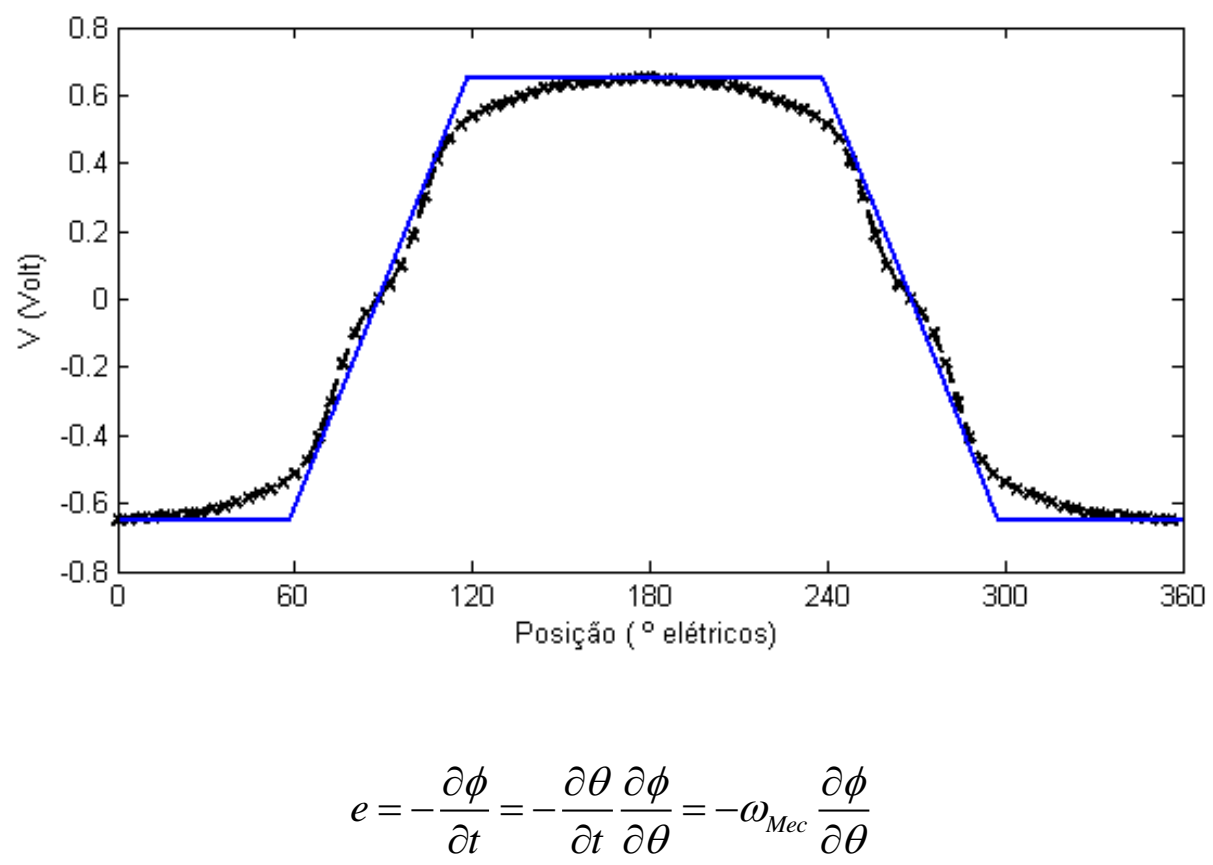

O fluxo concatenado com as bobinas, simbolizado por $\phi$ na Equação (2.17), pode ser descrito segundo a Equação (2.18).

$$
\phi=N_{C} r_{1} L_{S T K} \int_{\theta_{1}}^{\theta_{2}} B(\theta) d \theta
$$

Subistituindo (2.18) em (2.17), obtém-se a Equação (2.19).

$$
e=-\omega_{M e c} N_{C} r_{1} L_{S T K} \frac{\partial}{\partial \theta} \int_{\theta_{1}}^{\theta_{2}} B(\theta) d \theta
$$


A maior dificuldade presente no equacionamento desenvolvido está na descrição da densidade de fluxo magnético dentro das bobinas, $B(\theta)$, para o cálculo da variação do fluxo magnético concatenado com as mesmas. Quando a máquina não está saturada, o fluxo magnético concatenado é praticamente o mesmo fluxo que atravessa o entreferro, com baixa dispersão. No entanto, quando da saturação, os dentes - responsáveis por guiarem o fluxo dos ímãs por entre as bobinas - deixam de ser um meio "atrativo", reduzindo, dessa forma, a quantidade de fluxo concatenado com as bobinas e afetam diretamente a composição da forma de onda da força contra eletromotriz, distorcendo a mesma. Como evidenciado nas Seções 2.2 e 2.3, a região com maior sensibilidade na formação da força contra eletromotriz diz respeito às sapatas dos dentes.

A distorção da força contra eletromotriz, para a máquina síncrona de ímã permanente no rotor e cuja forma de onda é trapezoidal, é tratada como uma hipótese a ser averiguada no presente trabalho. Essa hipótese está embasada em confirmações da existência de distorções na forma de onda da força contra eletromotriz em máquinas síncronas de ímã permanente no rotor cuja forma de onda é senoidal, como mostram os trabalhos (Azar; Zhu; Ombach, 2012), (Tangudu et al., 2009).

Como é mostrado no Capítulo 3, o estudo da distorção na forma de onda da força contra eletromotriz é de grande importância já que ela é a principal responsável pela produção de torque na máquina em estudo. Portanto, qualquer distorção na mesma acarreta distorção no torque eletromagnético produzido. 


\section{Capítulo 3}

\section{Torque Eletromagnético}

\subsection{Introdução}

Neste capítulo é apresentada a formulação do torque eletromagnético a partir da coenergia e, mediante a formulação apresentada, discute-se cada termo da mesma, de maneira a justificar o estudo apresentado no Capítulo 2. Como será visto, a variação de cada parâmetro apresentado no Capítulo 2 acarretará problemas na produção de um torque suave, sem oscilações.

\subsection{Definição}

O torque eletromagnético é a grandeza de maior importância em qualquer motor. É a partir dessa grandeza que se torna possível determinar a aplicabilidade de um determinado motor em uma determinada aplicação (Miller; Hendersot Jr, 1995).

A quantidade de torque produzido por uma máquina depende fortemente da quantidade de energia armazenada no campo magnético da mesma, sendo este um ponto em que as máquinas síncronas de ímã permanente se destacam. Já a qualidade do torque produzido, i.e., o quão suave e sem oscilações é a forma de onda do torque, depende, dentre outros parâmetros intrínsecos à máquina, da qualidade do acionamento elétrico empregado. Notoriamente, uma máquina bem projetada exige menos "esforço" da parte de acionamento e controle para que se desenvolva um torque suave (Miller; Hendersot Jr, 1995). 
A formulação do torque pode ser derivada tanto da energia $(W)$ quanto da coenergia $\left(W_{C}\right)$ do campo magnético, como pode ser visto nas Equações (3.1) e (3.2) respectivamente.

$$
\begin{gathered}
T=-\frac{\partial W}{\partial \theta} \\
T=\frac{\partial W_{C}}{\partial \theta}
\end{gathered}
$$

A Equação (3.1), relativa a energia do campo magnético, demonstra que valores positivos de torque contribuem para o decréscimo da energia do sistema, enquanto a Equação (3.2), relativa a coenergia do campo magnético, demonstra que valores positivos de torque contribuem para o acréscimo da coenergia do sistema (Hanselman, 1994).

Segundo (Hanselman, 1994), a descrição do torque eletromagnético por meio da coenergia é mais conveniente por tratar do equacionamento da mesma em termos de corrente, ao contrário da descrição por meio da energia, cujo equacionamento é feito em termos do fluxo concatenado. A Equação (3.3) descreve a coenergia de um sistema com alimentação de campo magnético feita por ímãs e por corrente.

$$
W_{C}=\frac{1}{2} L i^{2}-\frac{1}{2} \Re \phi_{M}^{2}+N i \phi_{M}
$$

A partir das Equações (3.2) e (3.3), obtém-se a formulação do torque eletromagnético para a máquina síncrona em estudo.

$$
T=\frac{1}{2} i^{2} \frac{d L}{d \theta}-\frac{1}{2} \phi_{M}^{2} \frac{d \Re}{d \theta}+N i \frac{d \phi_{M}}{d \theta}
$$

O primeiro termo da Equação (3.4) diz respeito ao torque produzido pela variação da indutância. Essa parcela do torque é considerada indesejável nas máquinas síncronas de ímãs permanente montados na superfície do rotor. Essa variação é desprezível para situações em que a máquina opera em condições nominais, no entanto, pode se tornar significativa quando a máquina opera em saturação caso ocorra variações significativas nos valores de indutância. 
Alguns trabalhos, tais como (Schmidt; Susic, 2012) e (Azar; Zhu; Ombach, 2012), apresentam resultados para a variação da indutância em máquinas síncronas de ímã permanente com forma de onda senoidal, aplicando análise dos valores nos eixos dq. A Figura 3.1, extraída de (Arellano-Padilla et al., 2010), mostra a variação nos valores da auto indutância dos eixos $d q\left(L^{\prime} q\right.$ e $\left.L^{\prime} d\right)$ e da indutância mútua dos eixos $d q\left(L^{\prime} q d\right.$ e $\left.L^{\prime} d q\right)$ quando da operação da máquina em condição de saturação do estator. Variações como as apresentadas na Figura 3.1, caso estejam presentes na máquina síncrona em estudo, provocam oscilações no torque da máquina, como demonstrado na Equação (3.4).

Figura 3.1 - Variação dos valores de indutância.

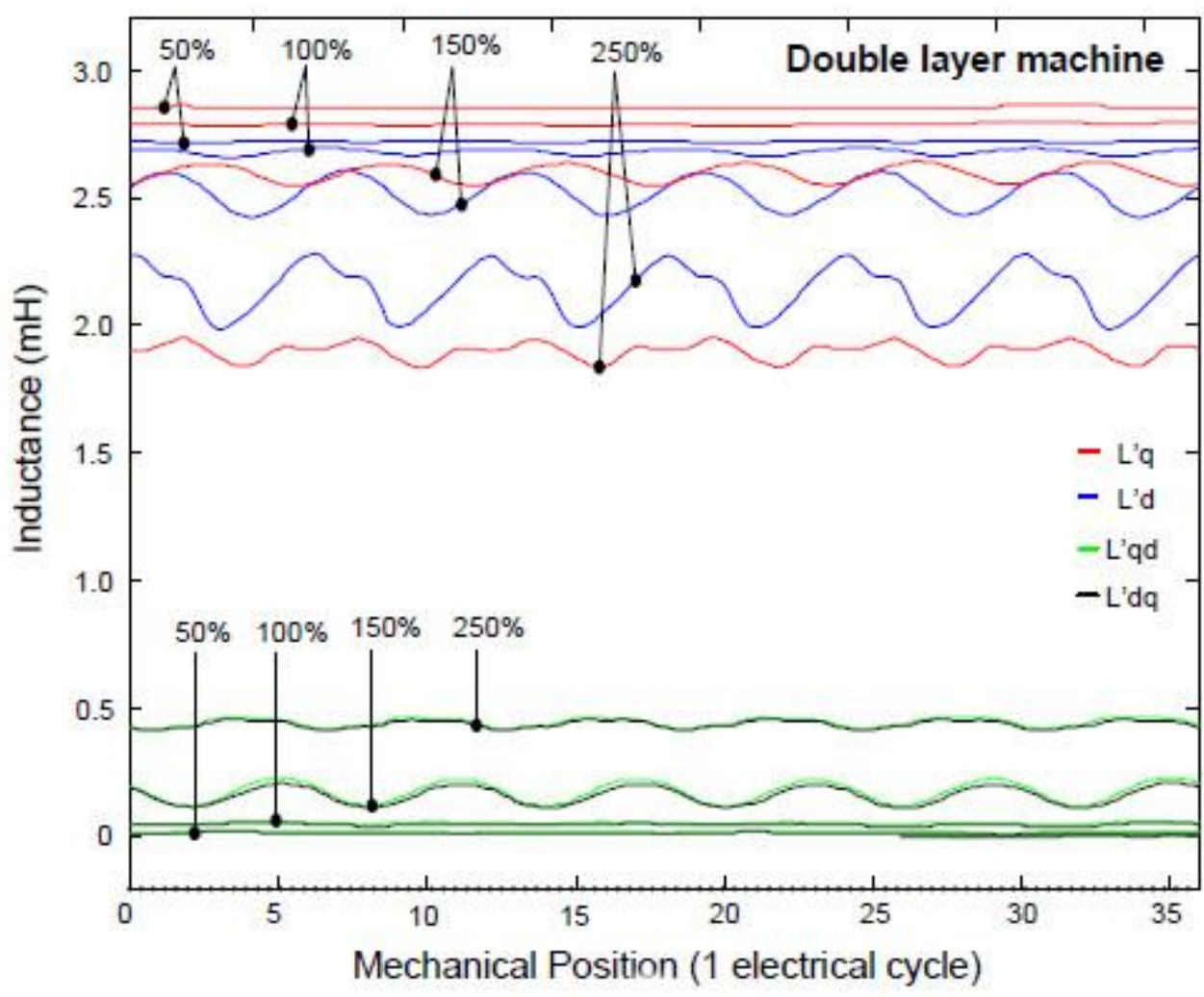

Fonte: Arellano-Padilla et al (2010).

O segundo termo da Equação (3.4) diz respeito ao torque produzido pela variação da relutância vista pelo circuito magnético que tem como fonte de fluxo os ímãs permanentes. Essa parcela do torque, apesar de indesejada, é intrínseca às máquinas de ímã permanente com ranhuras no estator, sendo conhecida na literatura como torque de borda (em inglês, cogging torque). Desde o desenvolvimento das primeiras máquinas de ímã permanente com ranhuras no estator, estudos vêm sendo realizados e novas técnicas vêm sendo ora desenvolvidas ora aprimoradas para a mitigação dessa parcela a fim de tornar o torque o mais suave possível. Muitas dessas técnicas envolvem questões de projeto descrevendo a escolha mais plausível para determinados parâmetros em vias de se reduzir o torque de borda; outra propõe 
a inclinação do pacote de lâminas do estator, sendo essa a mais empregada por apresentar maior eficácia; outra, apresenta método semelhante à técnica anterior, no entanto, a inclinação não é aplicada no pacote de lâminas, mas sim no processo de magnetização dos ímãs permanentes, sendo este um processo mais caro que a técnica anterior (Miller; Hendersot Jr, 1995).

O torque de borda tem comportamento oscilatório com frequência bem descrita na literatura para condições de operação da máquina em vazio. Sendo essa frequência descrita em relação a ordem do primeiro harmônico de um período elétrico da máquina, como pode ser visto pela Equação (3.5),(Chabchoub; Salah, 2012).

$$
f_{\operatorname{cog}}(i)=\frac{M M C[2 p, N s]}{2 \pi} i
$$

Onde:

- $\quad M M C$ - Mínimo Múltiplo Comum;

- $i \quad$ - Ordem da harmônica.

- $f_{\text {cog }}(i)$ - Frequência do torque de borda para a i-ézima harmônica.

Alguns trabalhos, tais como (Bianchi; Bolognani, 2002), (Islam et al., 2005) e (Sung; Park; Jang, 2010), trazem um estudo mais detalhado a respeito dos harmônicos, amplitude do torque de borda, além da escolha adequada de valores de alguns parâmetros de projeto em máquinas síncronas de ímã permanente com ranhuras. O trabalho (Sung; Park; Jang, 2010) analisa a variação da frequência do torque de borda caso os ímãs não estejam uniformemente magnetizados ou os dentes do estator apresentem alguma geometria circunferencial em suas sapatas.

Um trabalho relevante no estudo dos efeitos da saturação em máquinas síncronas de ímã permanente com forma de onda senoidal é (Azar; Zhu; Ombach, 2012), em que é apresentado a variação da frequência e da amplitude no torque de borda quando a máquina passa a operar em condição de saturação, não apresentando os valores previstos de amplitude e frequência quando da sua avaliação em vazio. A Figura 3.2, extraída de (Azar; Zhu; Ombach, 2012), exemplifica essa variação.

O terceiro termo da Equação (3.4) diz respeito ao torque produzido pela variação do fluxo magnético, tendo os ímãs do rotor como fonte, concatenado com as bobinas do estator. 
Essa parcela do torque é a principal produtora de torque eletromagnético nesse tipo de máquina, demonstrando o acoplamento entre as duas principais fontes de fluxo magnético, os ímãs permanentes e as bobinas excitadas pela corrente de acionamento.

Para a máquina em estudo, a forma idealizada da força contra eletromotriz é trapezoidal; no entanto, na prática não se obtém uma forma de onda tal como a idealizada - vide Figura 2.13. Outra oscilação pertinente ao terceiro termo da Equação (3.4) está relacionada ao conceito de que as correntes de alimentação das bobinas de fase são constantes e sem oscilações, o que, de fato, não ocorre. É sabido na literatura, em trabalhos como (Hanselman, 1994) e (Miller; Hendersot Jr, 1995), que os inversores empregados no acionamento de tais máquinas, quando operados em modo de seis pulsos, não são capazes de produzir uma forma de onda de corrente quadrada ideal devido à indutância de fase da máquina e por possuírem fonte de tensão.

Figura 3.2 - Variação dos valores de Torque de Borda.

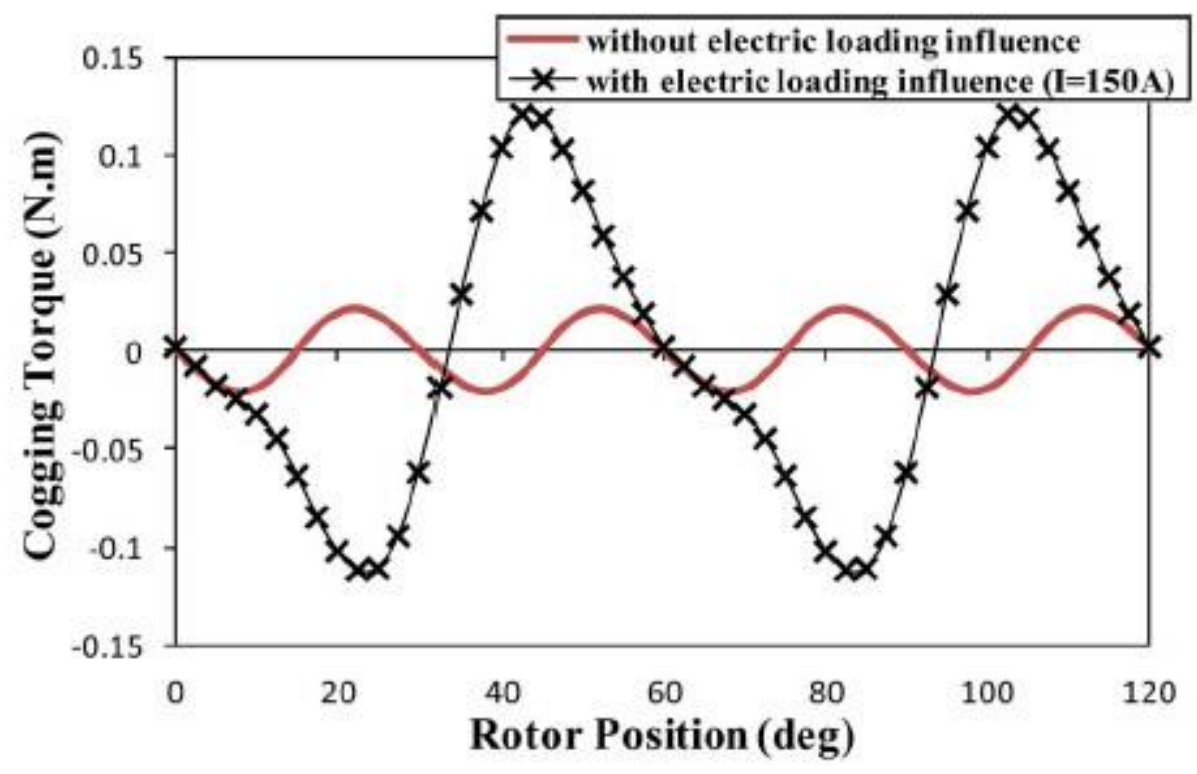

Fonte: Azar; Zhu; Ombach (2012).

Um trabalho recente, (Monteiro, 2002), propõe a modelagem vetorial para a máquina síncrona de ímã permanente com forma de onda trapezoidal, permitindo, assim, o acionamento da máquina com baixos níveis de variação na corrente e consequentemente, redução nas ondulações da forma de onda do torque. A modelagem proposta, de certa forma, faz o "casamento" entre a forma de onda da força contra eletromotriz com a forma de onda da corrente de acionamento, acarretando, assim, menores níveis de ondulações no torque. Contudo, a forma de onda da força contra eletromotriz utilizada na modelagem foi tomada com a máquina em vazio, portanto para operação em regime de altas correntes surgem algumas alterações nessa forma de onda. 
Trabalhos mais recentes, como (Azar; Zhu; Ombach, 2012) e (Tangudu et al., 2009), demonstram a distorção da forma de onda da força contra eletromotriz em máquinas síncronas de ímã permanente com forma de onda senoidal. Assim como nos casos de variação da indutância e da variação da relutância, a distorção na forma de onda da força contra eletromotriz acarreta oscilações no torque eletromagnético produzido pela máquina.

A Figura 3.3, extraída de (Azar; Zhu; Ombach, 2012), exemplifica a distorção da forma de onda da força contra eletromotriz em uma máquina síncrona de ímã permanente com forma de onda senoidal.

Figura 3.3 - Distorção da Força Contra Eletromotriz.

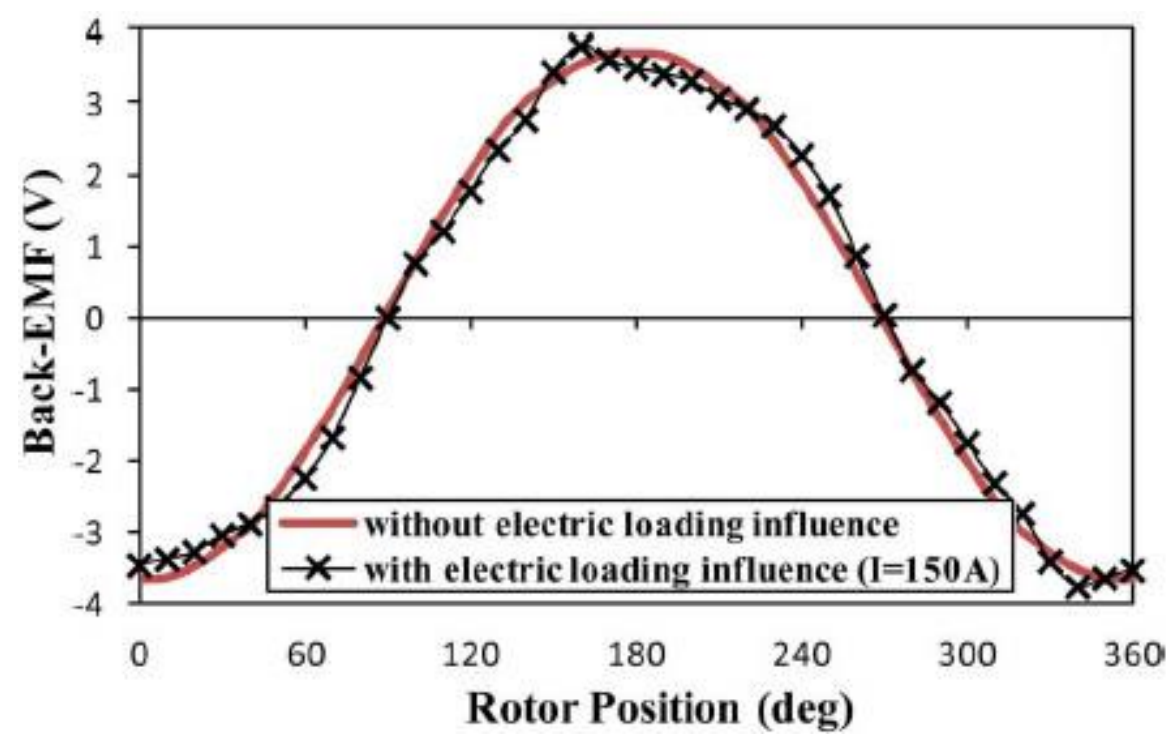

Fonte: Azar; Zhu; Ombach (2012). 


\section{Capítulo 4}

\section{Método da Permeabilidade Fixa}

\subsection{Introdução}

Neste capítulo é apresentado o método empregado para separação das componentes do torque eletromagnético de um máquina quando a mesma se encontra alimentada.

O método, conhecido como, Método da Permeabilidade Fixa (Frozen Permeability Method), foi apresentado no final da década de 1990 em (Bianchi; Bolognani, 1998) como tentativa de separar as componentes do torque eletromagnético, permitindo a análise de cada componente. A maior dificuldade do método está relacionada ao esforço computacional requerido, uma vez que o método necessita de mais duas simulações após a avaliação da máquina alimentada com corrente. Outra grande dificuldade, que a princípio gerou certa resistência à aceitação do método, diz respeito à comprovação dos dados obtidos, pois não se consegue extrair cada componente isoladamente quando a máquina está em operação. Dessa forma, como último recurso para validar o método, compara-se o torque obtido pela soma das componentes com o torque gerado com a máquina alimentada com corrente.

Apesar dessas críticas, o método tem sido bem aceito e largamente empregado na última década, tendo os trabalhos mais relevantes datados de 2005 (Islam et al., 2005), 2009 (Tangudu et al., 2009), 2012 (Azar; Zhu; Ombach, 2012, 2012), (Schmidt; Susic, 2012) e 2013 (Chu; Zhu, 2013, 2013). No entanto, todos esses trabalhos tratam de máquinas síncronas com ímãs permanentes no rotor com forma de onda de força contra eletromotriz senoidal. Devese salientar que sugestões de melhorias e avaliações do método tem sido investigadas a fim 
de torná-lo mais confiável e robusto. Uma melhoria para o método é apresentada em (Chu; Zhu, 2013), visando à correção da quantidade de energia armazenada no estator calculada no método da permeabilidade fixa convencional.

\subsection{Metodologia}

O Método da Permeabilidade Fixa consiste em quatro etapas de simulação em elementos finitos. O método permite, em uma de suas etapas, a linearização do problema, possibilitando a separação das componentes do torque eletromagnético na etapa seguinte.

- Na primeira etapa, a máquina é simulada sem corrente (havendo, apenas os ímãs permanentes como fonte de fluxo magnético) a fim de se obter os valores de amplitude, frequência e forma de onda do torque de borda e a forma de onda da força contra eletromotriz. A obtenção de tais parâmetros permite uma avaliação inicial da máquina e uma base comparativa para os valores com corrente.

- Na segunda etapa, realiza-se a simulação da máquina com corrente, havendo tanto os ímãs permanentes quanto as bobinas alimentadas com corrente como fonte de fluxo magnético. A partir dessa simulação são extraídos os valores de amplitude e forma de onda do torque eletromagnético da máquina, a frequência e a amplitude das oscilações. Outros dados como amplitude, frequência e forma de onda de fluxo concatenado por fase também são extraídos. Obtidos todos os dados, a malha de elementos finitos com os dados de permeabilidade magnética de cada elemento é salva, fixando-se a permeabilidade em cada elemento. Essa maIha é utilizada nas próximas etapas.

- Na terceira etapa, a partir da malha salva com os dados de permeabilidade magnética de cada elemento, realiza-se a simulação da máquina empregando como única fonte de fluxo magnético os ímãs permanentes. Essa simulação permite a obtenção de valores de amplitude, frequência e forma de onda do torque de borda e a forma de onda da força contra eletromotriz para a máquina quando esta se encontra alimentada com corrente.

- Na quarta etapa, a partir da malha salva com os dados de permeabilidade magnética de cada elemento, realiza-se a simulação da máquina empregando como única fonte de fluxo magnético as bobinas alimentadas com corrente. Essa simulação permite a obtenção de valores de amplitude, frequência e forma de onda da indutância, do fluxo concatenado e do torque de relutância (devido à variação da 
indutância) para a máquina quando esta se encontra alimentada com corrente.

Como pode ser notado, a linearização ocorre ao fim da segunda etapa ao se fixar a permeabilidade de cada elemento dentro da malha de elementos finitos. Retomando-se a curva de magnetização apresentada na Figura 2.1, ao se fixar a permeabilidade magnética do material ferromagnético na simulação, o problema deixa de ser não linear e passar a ser linear. $O$ artifício de se fixar a permeabilidade magnética possibilita, como proposto pelo método, o desacoplamento das componentes do torque eletromagnético, tendo em vista que o teorema da sobreposição de fontes passa a ser válido para a análise do circuito magnético.

Dessa forma, as contribuições na densidade de fluxo magnético por parte dos ímãs permanentes e por parte das bobinas podem ser somadas, i.e., a densidade de fluxo magnético do ponto de operação da máquina $\left(B_{\text {all }}\right)$ é igual a soma da densidade de fluxo magnético proveniente dos ímãs $\left(B_{P M}\right)$ com a densidade de fluxo magnético proveniente das bobinas $\left(B_{i}\right)$. Sem a linearização, apenas a intensidade de fluxo magnético do ponto de operação da máquina $\left(H_{\text {all }}\right)$ é igual à soma das contribuições de intensidade de fluxo magnético dessas duas partes, imãs permanentes $\left(H_{P M}\right)$ e bobinas $\left(H_{i}\right)$. A Figura 4.1, extraída de (Chu; Zhu, 2013), exemplifica a linearização proposta pelo método.

As terceira e quarta etapas podem ser realizadas em qualquer ordem, dependendo apenas do que se deseja analisar, sejam os efeitos da corrente ou do ímã permanente no comportamento da máquina.

O fluxograma apresentado na Figura 4.2 resume as quatro etapas do método da permeabilidade fixa.

\subsection{Discussões}

Apesar do método ser bem aceito no meio científico e estar sendo largamente empregado, restam algumas dúvidas e críticas sobre a implementação e o processo de linearização presente no método.

A maior crítica está relacionada com a linearização proposta no método. Ao se tomar o ponto de operação A da Figura 4.1 e a partir deste obter-se $\mu_{\text {all }}$, o comportamento do material ferromagnético passa a seguir a reta cujo coeficiente de inclinação é $\mu_{\text {all }}$. Dessa forma, as contribuições de energia tanto dos ímãs permanentes quanto das bobinas para a energia total do sistema passam a ser diretamente proporcionais à intensidade magnética de cada um, seguindo a mesma proporção. 
Figura 4.1 - Princípio do Método da Permeabilidade Fixa.

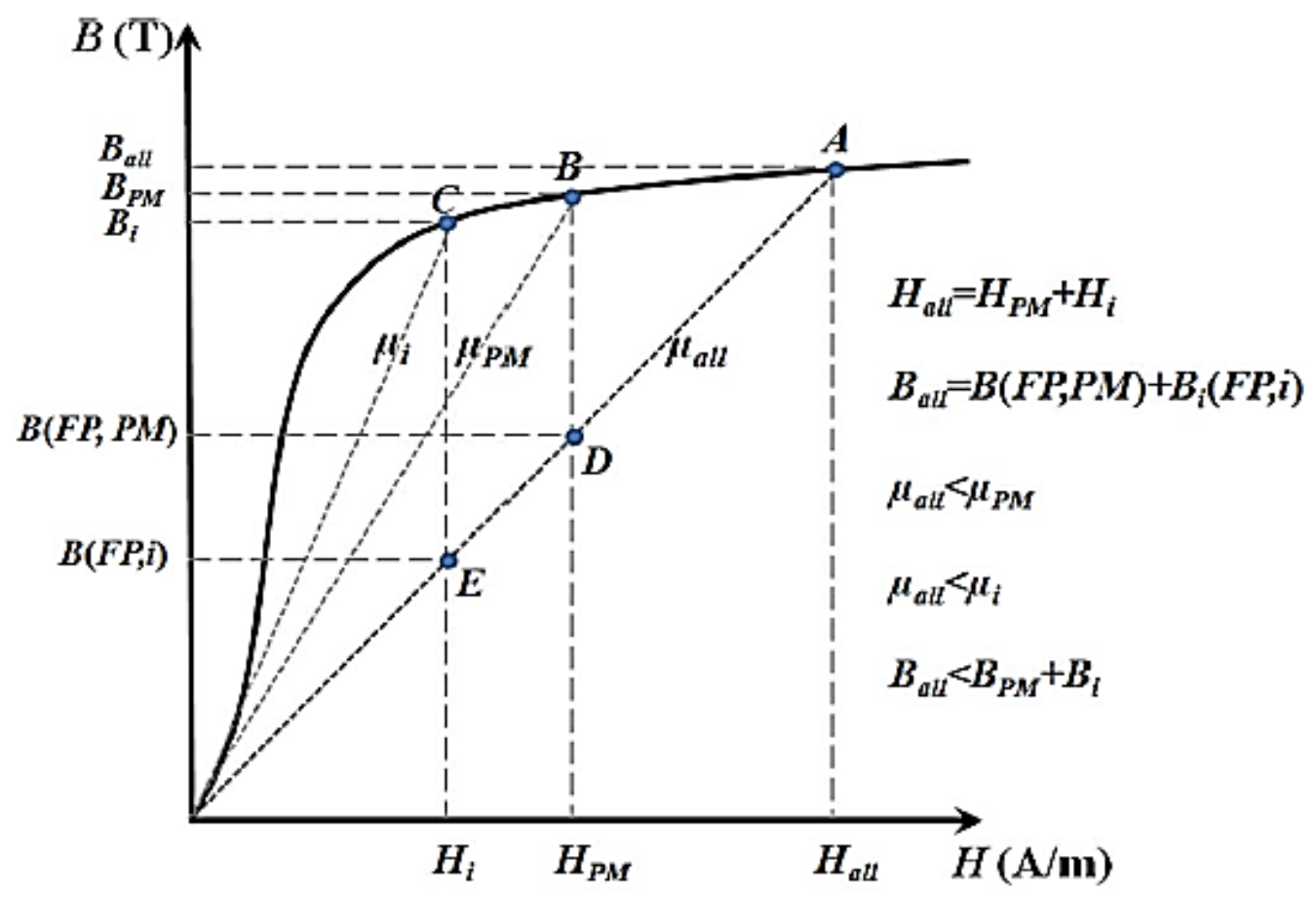

Fonte: Chu; Zhu (2013)

Figura 4.2 - Método da Permeabilidade Fixa.

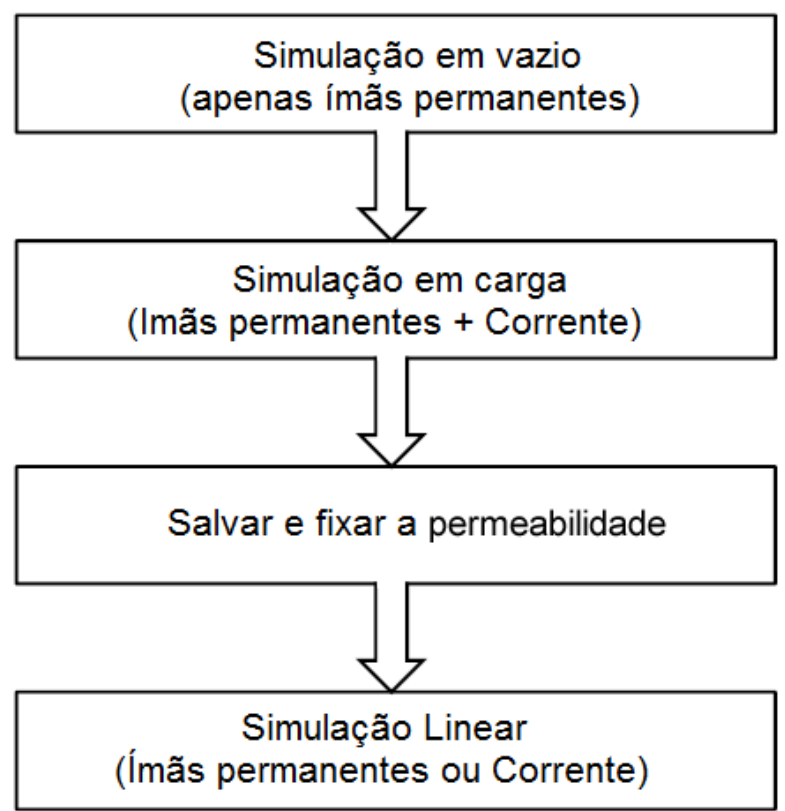

Claramente, a proporcionalidade descrita é inerente a qualquer processo de linearização. No entanto, a forma com que a linearização é conduzida acarreta erros significativos no cálculo das contribuições de energia de cada fonte, seja a fonte os ímãs permanentes ou as bobinas, ora sobre estimando ora sub estimando a parcela de contribuição de energia. Como 
o principal interesse no emprego do método é a separação das componentes do torque eletromagnético, e consequentemente a separação de cada parcela de energia, e não o cálculo do torque eletromagnético total (ou a energia total), tais erros acabam por mascarar o verdadeiro comportamento de cada componente do torque eletromagnético.

Tendo por base a crítica apresentada, os autores de (Chu; Zhu, 2013) propõe uma melhoria para o método da permeabilidade fixa. A melhoria ocorre nas terceira e quarta etapas do método, onde ao invés de calcular a energia com base no triângulo ODG da Figura 4.3, para o caso da parcela de energia proveniente do ímã, utiliza-se o triângulo OFG (método melhorado, proposto pelos autores de (Chu; Zhu, 2013)) da Figura 4.3. Para isso, busca-se o ponto $\mathrm{F}$ na curva de magnetização material ferromagnético. À primeira vista, para a parcela dos ímãs permanentes, a quantidade de energia calculada por essa melhoria acarreta um erro menor do que o método convencional por se aproximar da área pintada acima da curva de magnetização.

Figura 4.3 - Método da Permeabilidade Fixa Melhorado.

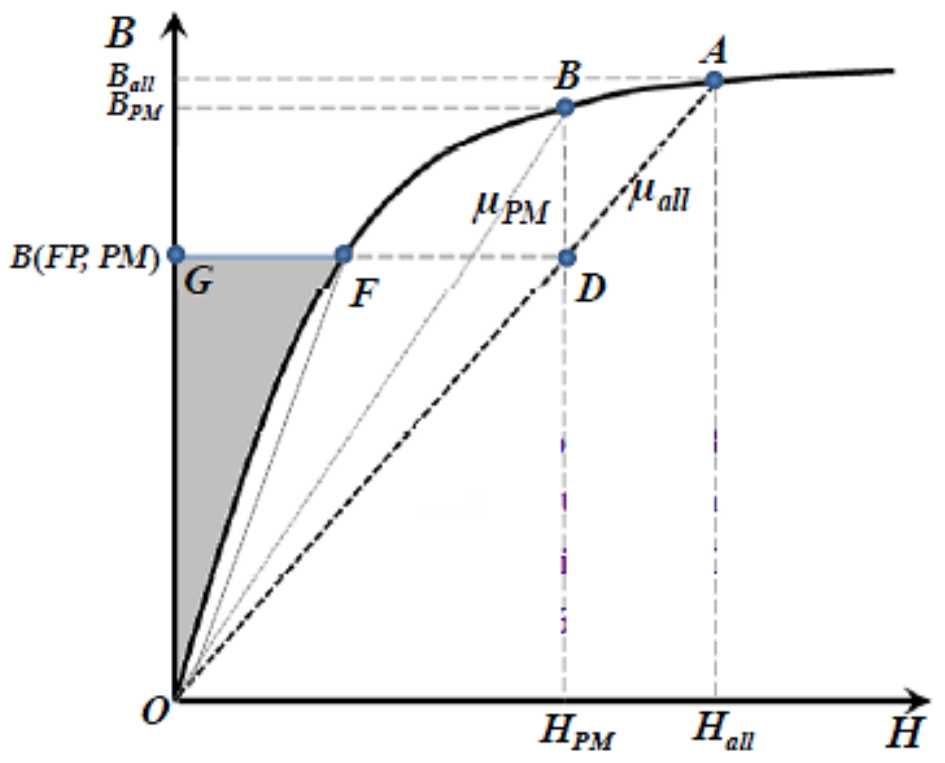

Fonte: Chu; Zhu (2013) 



\section{Capítulo 5}

\section{Implementação do Método}

\subsection{Introdução}

Neste capítulo são apresentados a implementação do Método da Permeabilidade Fixa, o software desenvolvido e as considerações necessárias para a implementação do método.

O software empregado nas simulações da máquina em elementos finitos é o FEMM (Meeker, 2012). Esse software é livre para fins acadêmicos e uso pessoal, tendo o seu código aberto, aceitando contribuições, sugestões e relatório de erros por parte dos usuários a fim de aprimorá-lo cada vez mais. Assim como renomados softwares comerciais, o FEMM permite que o usuário refine a malha de elementos finitos (triângulos) com o objetivo de melhorar os resultados da simulação, tornando-o robusto e forte concorrente de softwares comerciais para simulação em duas dimensões.

Tendo em vista que nem todos os softwares de simulação em elementos finitos têm o Método da Permeabilidade Fixa implementado e, visando o emprego do método melhorado proposto por (Chu; Zhu, 2013), o FEMM se destaca dentre inúmeros softwares por apresentar duas grandes vantagens que o tornam flexível e adaptável ao problema. Essas duas vantagens estão ligadas à possibilidade de emprego de scripts baseados em LUA (lerusalimschy; Celes; Figueiredo, 2012) para manipulação de todos os passos de simulação, assim como a aquisição dos resultados de cada passo; e à possibilidade de interação com outro software por meio de conexão ActiveX (MSDN, 2012). 


\subsection{Passo-a-Passo da Implementação}

Esta seção toma por base a metodologia apresentada na Seção 4.2 e a elucidação da mesma apresentada na Figura 4.2. As subseções a seguir dispõe a entrada de dados necessárias para a realização de cada uma das etapas, assim como a saída de dados. Algumas dessas subseções são apresentadas de maneira sucinta a fim de se evitar redundância com o que já foi apresentado na Seção 4.2. Outras subseções cobrem mais detalhes do processamento dos dados da etapa anunciada no título da mesma. Nessas, o detalhamento tem como objetivo deixar claro os procedimentos e considerações realizados para a conclusão da etapa.

\subsubsection{Simulação com corrente zero}

Nessa etapa, a partir do arquivo de entrada contendo o modelo físico da máquina (estator, rotor, ímãs, bobinas, materiais) - arquivo “.fem" -, executa-se um script LUA no próprio FEMM que realiza a simulação de uma revolução elétrica da máquina, discretisada em noventa passos. Como resultado têm-se a forma de onda do fluxo concatenado por cada fase (e a partir desses, a forma de onda da força contra eletromotriz), a forma de onda do torque de borda e os valores de coenergia para o entreferro, para as bobinas, para o rotor, para o estator e a coenergia total.

\subsubsection{Simulação com corrente}

Nessa etapa, a partir do arquivo de entrada contendo o modelo físico da máquina arquivo ".fem" - e, já conhecidos os pontos de chaveamento de cada fase, executa-se um script LUA no próprio FEMM que realiza a simulação de uma revolução elétrica da máquina, discretisada em noventa passos, com o valor de corrente desejado para cada fase.

Como resultado têm-se a forma de onda do fluxo concatenado por cada fase, a forma de onda do torque eletromagnético e os valores de coenergia para o entreferro, para as bobinas, para o rotor, para o estator e a coenergia total.

Nessa etapa, para cada passo de simulação são armazenados um novo arquivo de entrada ".fem" e um arquivo de resposta ".ans". Esse novo arquivo de entrada contém o modelo físico da máquina para uma posição angular $\theta$. Para essa mesma posição, existe um arquivo de resposta que contém a malha de elementos finitos e o valor do campo potencial magnético, $A$, para cada vértice dos elementos. 


\subsubsection{Fixação da Permeabilidade}

Foi necessário o desenvolvimento de um software para, a partir dos arquivos de resposta gerados na etapa anterior, interagir com o FEMM por meio de uma conexão ActiveX e obter os valores de permeabilidade magnética relativa de cada elemento.

A partir dos valores de permeabilidade de cada elemento e, conhecendo-se a localização de cada elemento na malha de elementos finitos, o software desenvolvido agrupa elementos vizinhos com valores de permeabilidade relativa próximos (seguindo uma margem de tolerância "a", determinada pelo usuário) em uma mesma região. Obtidas as regiões de mesma permeabilidade relativa, o software recria o modelo físico do estator - que antes era um elemento com material homogêneo (Figura 5.1a), mantendo-se todas as outras características elétricas do material empregado nas lâminas do estator e tornando o modelo físico do estator um elemento com diferentes características ferromagnéticas (Figura 5.1b). Recriado o modelo físico da máquina, gera-se dois novos arquivos de entrada: "modelo_PM.fem" e "modelo_CURRENT.fem".

Figura 5.1 - Modelo físico do estator

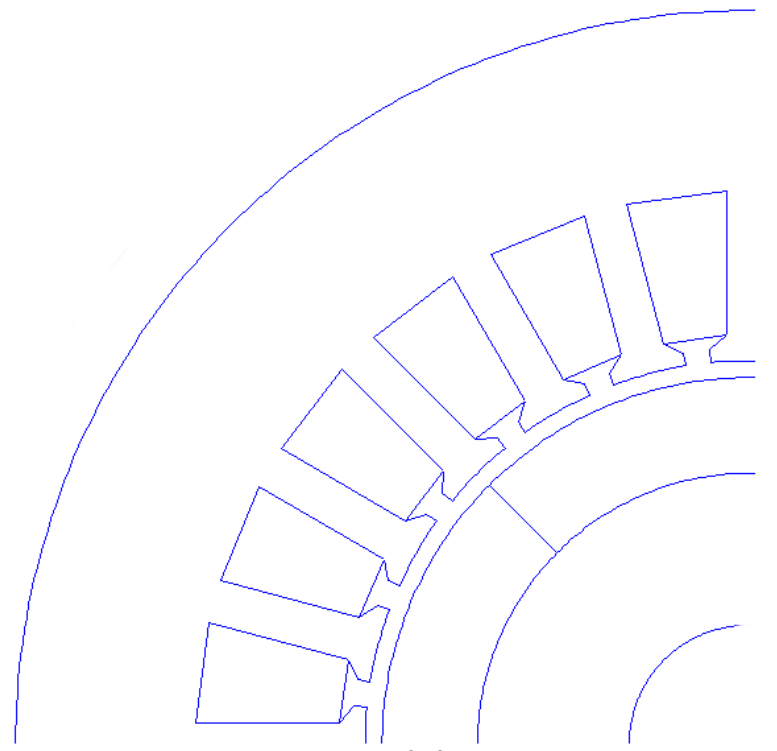

(a)

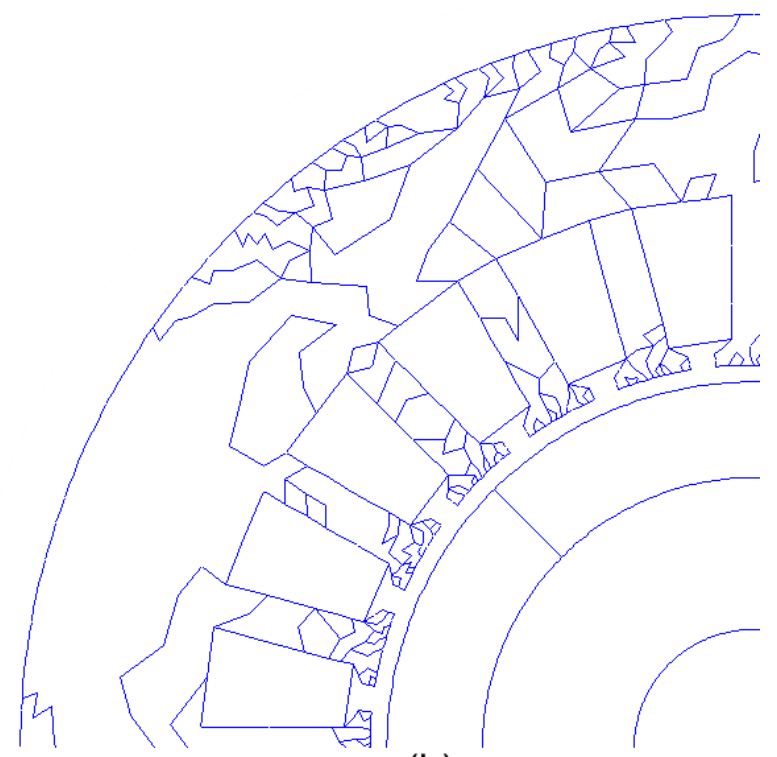

(b)

a) material homogêneo; b) material não homogêneo.

A justificativa para se agrupar vizinhos com valores próximos de permeabilidade relativa é a quantidade de regiões que o estator teria no novo modelo, sendo essa quantidade igual à quantidade de elementos (triângulos) do arquivo de resposta da etapa anterior. Os arquivos de respostas contém cerca de vinte mil elementos, muitos deles são pequenos a ponto de estarem no limite do menor triângulo possível de ser gerado pelo gerador de malhas. 
Portanto, o uso desses elementos como novas regiões no novo arquivo de entrada torna inviável a geração de nova malha para a solução do problema. Outro problema que pode ocorrer é que mesmo sendo possível a geração de uma nova malha, essa extrapolaria os limites de memórias disponíveis, ou ainda, geraria uma malha com quantidade muito grande de elementos, requerendo grande esforço computacional e tempo para a resolução da mesma.

Considerando a justificativa anterior, utiliza-se de uma margem de tolerância "a" determinado pelo usuário para o agrupamento de elementos vizinhos e a geração das novas regiões. No entanto, deve-se observar que a escolha indevida do valor de tolerância acarreta em imprecisões nos resultados. Tomando-se por base que para um sistema linearizado os valores de densidade energia e densidade de coenergia de um elemento na malha de elementos finitos são iguais, a Equação (5.1) é válida.

$$
\frac{W}{m^{3}}=\frac{W_{c}}{m^{3}}=\frac{B H}{2}
$$

Na Equação (2.1), a densidade de fluxo magnético é descrita em função da intensidade magnética, enquanto no método dos elementos finitos obtém-se o valor da densidade de fluxo magnético primeiro (a partir da derivação do potencial magnético, A), para em seguida se determinar o valor da intensidade magnética. Sendo assim, escreve-se a intensidade magnética em função da densidade de fluxo magnético.

$$
H=\frac{B}{\mu_{R} \mu_{0}}
$$

Aplicando-se a margem de tolerância "a" à permeabilidade relativa e substituindo (5.2) em (5.1) é determinada a variação máxima e mínima de densidade energia, e consequentemente do erro de energia que a consideração acarreta.

$$
\frac{B^{2}}{2 \mu_{R} \mu_{0}(1+a)} \leq \frac{W}{m^{3}} \leq \frac{B^{2}}{2 \mu_{R} \mu_{0}(1-a)}
$$

Quanto maior o valor da margem de tolerância maior será a quantidade de elementos agrupados em uma mesma região e menor será o número de regiões. Para se manter a fidelidade ao comportamento da máquina, valores menores que $10 \%$ para a margem de tolerância 
devem ser adotados. Vale notar que a Equação (5.3) mostra os valores extremos para a variação da densidade de energia o que não quer dizer que todos os elementos estejam exatamente nos pontos extremos.

\subsubsection{Simulação Linear}

A simulação do modelo linear ocorre em duas etapas, em uma é simulado o arquivo de entrada "modelo_PM.fem", o qual se tem apenas os ímãs permanentes como fonte de fluxo magnético, e na outra é simulado o arquivo de entrada "modelo_CURRENT.fem", o qual se tem apenas as bobinas como fonte de fluxo magnético. As duas simulações são conduzidas por um script LUA no próprio FEMM que realiza a simulação de todos os noventa arquivos (noventa do tipo "modelo_PM.fem" e noventa do tipo "modelo_CURRENT.fem") de entrada, contemplando uma revolução elétrica da máquina.

Como resultado para os arquivos "modelo_PM.fem" têm-se a forma de onda do fluxo concatenado por cada fase, a forma de onda do torque de borda e os valores de coenergia para o entreferro, para as bobinas, para o rotor, para o estator e para a coenergia total. A partir da forma de onda do fluxo concatenado obtém-se a forma de onda da força contra eletromotriz. A partir dessa, juntamente com a forma de onda da corrente de acionamento, obtém-se a parcela mútua do torque total como apresentado na Equação (3.4).

Como resultado para os arquivos "modelo_CURRENT.fem" têm-se a forma de onda do fluxo concatenado por cada fase, o perfil da indutância de cada fase e, consequentemente de linha, e os valores de coenergia para o entreferro, para as bobinas, para o rotor, para o estator e para a coenergia total. A partir do perfil da indutância de linha, juntamente com a forma de onda da corrente de acionamento da máquina, obtém-se a parcela do torque total relativa à variação da indutância dos enrolamentos da máquina. 



\section{Capítulo 6}

\section{Resultados}

Neste capítulo é feita a análise de duas máquinas síncronas com ímã permanente no rotor. A primeira é uma máquina síncrona de ímãs permanentes semi-enterrados apresentado nos artigos (Chu; Zhu, 2013, 2013). A simulação dessa máquina possibilita a comparação dos resultados gerados pelo software desenvolvido no presente trabalho, a fim de se validar a implementação do método da permeabilidade fixa. Assim como apresentado nos artigos (Chu; Zhu, 2013, 2013), a máquina é alimentada por três correntes puramente senoidais defasadas $120^{\circ}$. Das dificuldades presentes na reprodução desses artigos relata-se a falta de informações sobre as características magnéticas do aço das lâminas do estator, espessura dos ímãs, largura dos dentes, abertura de ranhura. Mesmo assim, após inúmeras iterações de desenho e refinamento das dimensões da máquina foi possível chegar em um modelo cujos resultados são próximos aos presentes no artigo. A Figura 6.1 mostra o modelo utilizado nas simulações.

Dos resultados gerados para essa máquina, são apresentados apenas os resultados relevantes, i.e., os que possibilitam comparação com os resultados apresentados nos artigos (Chu; Zhu, 2013, 2013) e também, os resultados relacionados ao fluxo magnético e força contra eletromotriz.

A segunda máquina é uma máquina síncrona com ímãs permanentes na superfície do rotor, contendo 24 ranhuras no estator e 4 polos no rotor. A máquina é muito semelhante a uma máquina já existente no Laboratório de Controle e Eletrônica de Potência do Departamento de Engenharia Elétrica, a menos dos ímãs escolhidos. Enquanto a máquina real é constituída por ímãs de ferrite (Teixeira, 2006), a máquina analisada contém ímãs de Neodímio-Ferro-Boro (10MGOe, Bonded). A Figura 6.2 apresenta o modelo da máquina utilizado 
nas simulações.

A máquina foi avaliada sob três condições de corrente, 10, 20 e 30A, sendo $11 \mathrm{~A}$ a condição calculada para a operação da máquina à 4500rpm segundo (Teixeira, 2006). Por se tratar de uma simulação magnetostática, considerou-se a máquina sendo alimentada por três correntes quadradas defasadas de $120^{\circ}$ elétricos como mostra a Figura 6.3. Essa forma de onda de corrente de alimentação foi adotada por ser a forma ideal de corrente empregada em máquinas com forma de onda de força contra eletromotriz trapezoidal.

Figura 6.1 - Máquina síncrona com ímãs permanentes semi-enterrados.

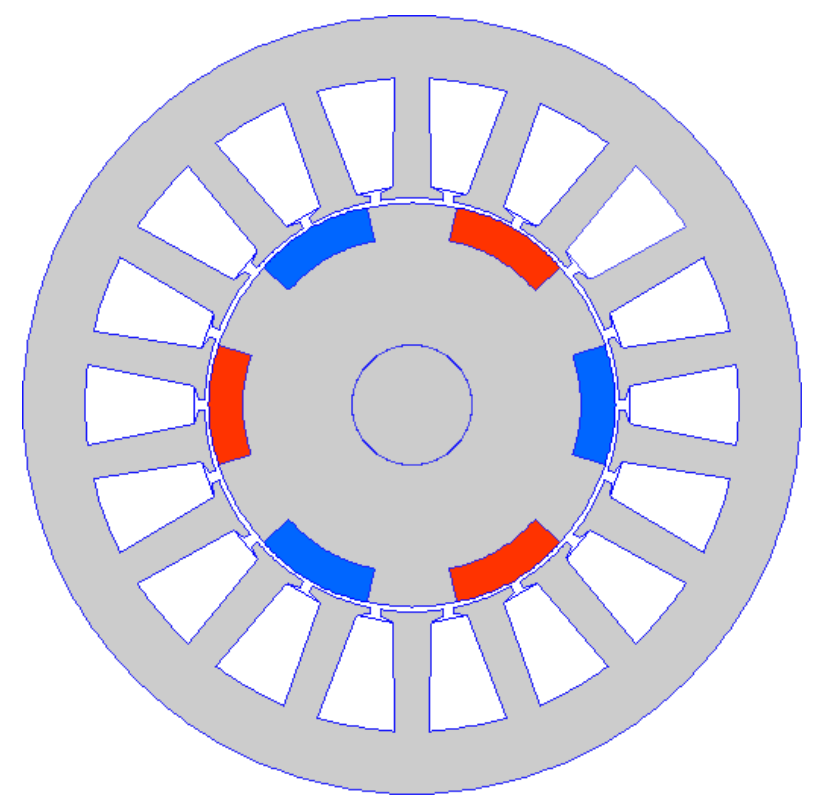

Figura 6.2 - Máquina síncrona com ímãs permanentes na superfície do rotor.




Figura 6.3 - Corrente de alimentação para a máquina trapezoidal

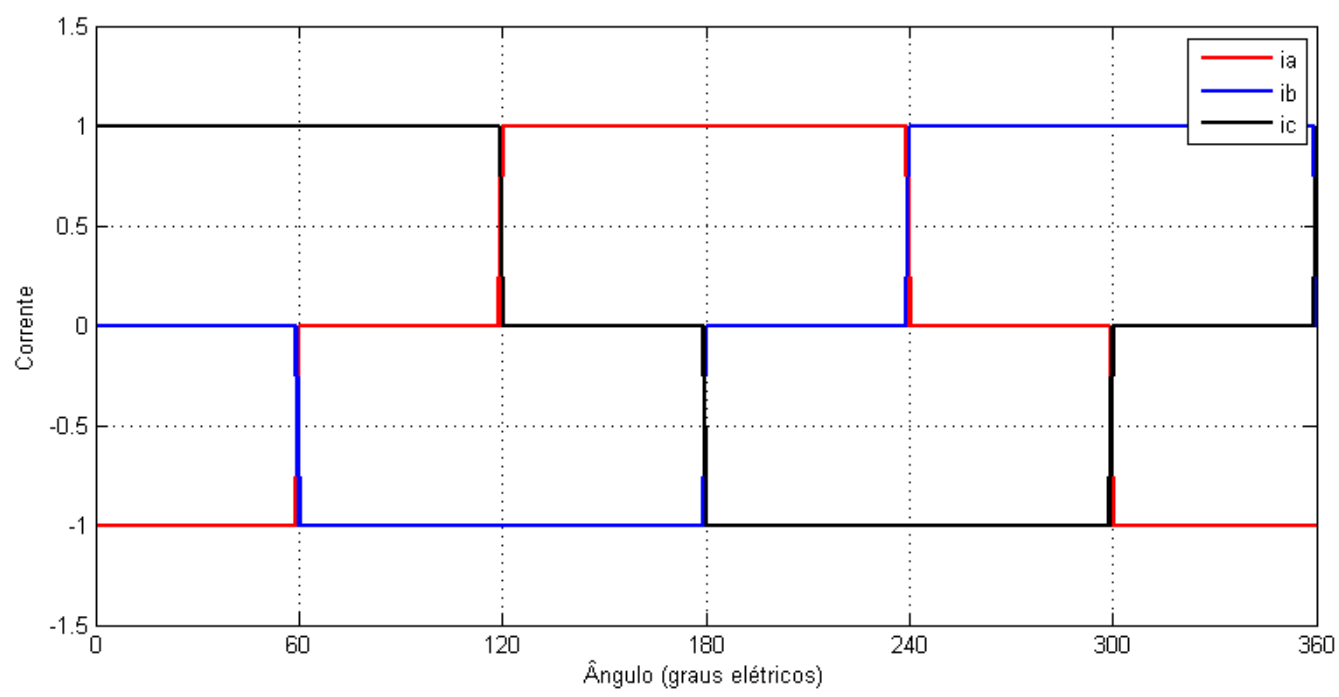

\subsection{Máquina Síncrona com Ímã Permanente Semi-Enterrado}

A simulação dessa máquina possibilita a comparação dos resultados gerados pelo software desenvolvido no presente trabalho, a fim de se validar a implementação do método da permeabilidade fixa. Da simulação realizada para a máquina síncrona com acionamento senoidal presente nos artigos (Chu; Zhu, 2013, 2013) obtêm-se as linhas de distribuição do fluxo eletromagnético. A Figura 6.4 reproduz a imagem presente no artigo (Chu; Zhu, 2013), ao passo que a Figura 6.5 mostra os resultados obtidos por meio de simulação e emprego do software desenvolvido.

A Figura 6.4a apresenta o gráfico de cores para a permeabilidade da máquina para a simulação com corrente, ao passo que a Figura 6.5a apresenta o gráfico de cores para a densidade de fluxo magnético da máquina para simulação com corrente. Tanto na Figura 6.4 quanto na Figura 6.5 têm-se ainda, b) linhas de fluxo para a simulação com corrente no modelo não linear; c) linhas de fluxo para a simulação com corrente, excitação feita apenas por ímãs, aplicado o método da permeabilidade fixa; d) linhas de fluxo para a simulação com corrente, excitação feita apenas pelas bobinas, aplicado o método da permeabilidade fixa.

Apesar das diferenças dimensionais que são devido à falta de informação sobre as dimensões da máquina, os resultados exibidos na Figura 6.5 quando comparados com os resultados obtidos pelos autores de (Chu; Zhu, 2013) (Figura 6.4) apresentam coerência, dando indicativos de que o software desenvolvido implementa o método da permeabilidade fixa corretamente. 
Figura 6.4 - Linhas de fluxo eletromagnético.

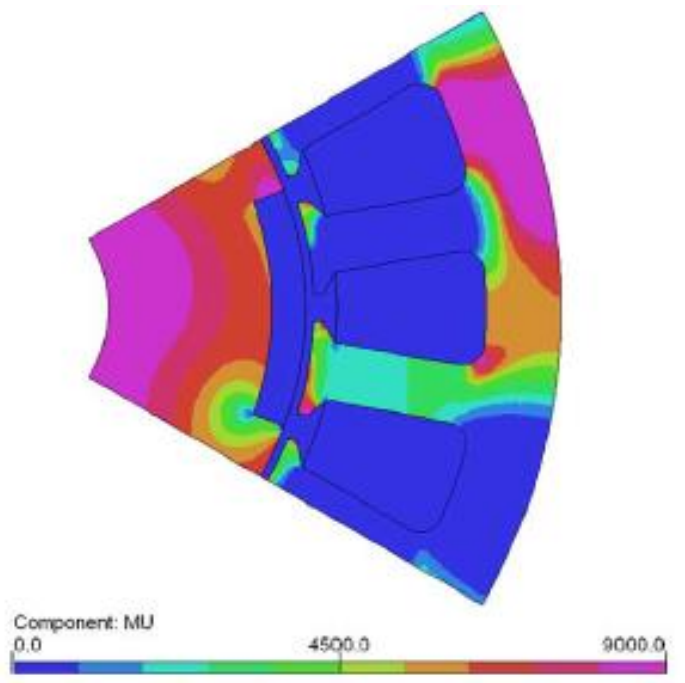

(a)

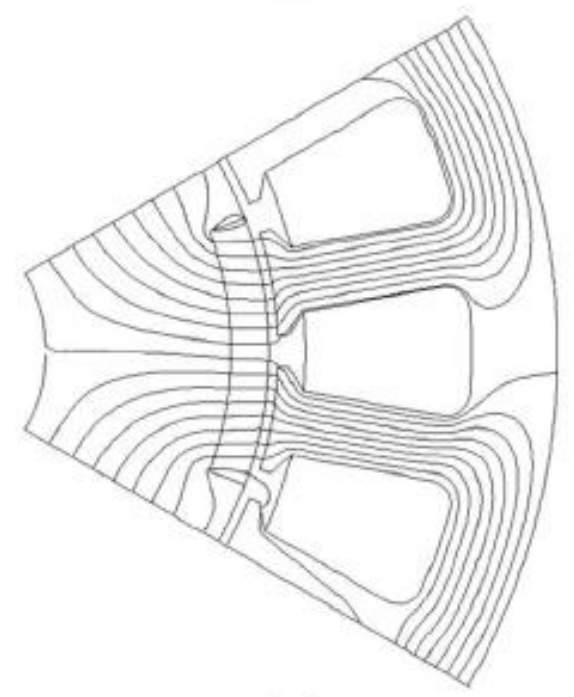

(c)

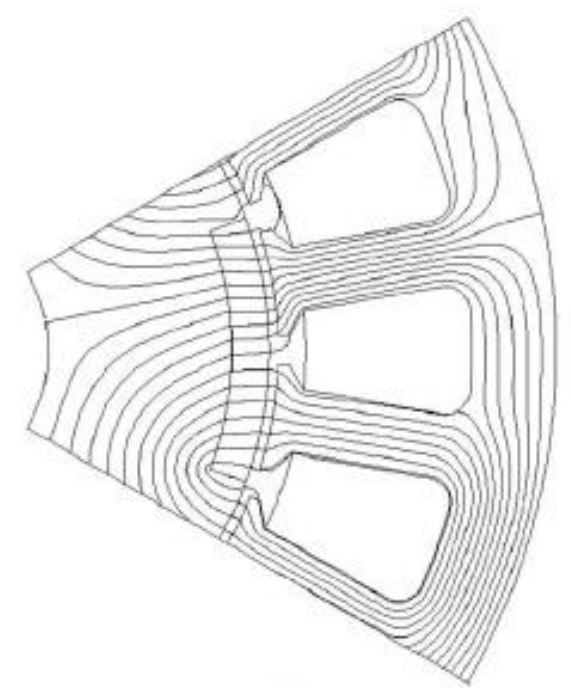

(b)

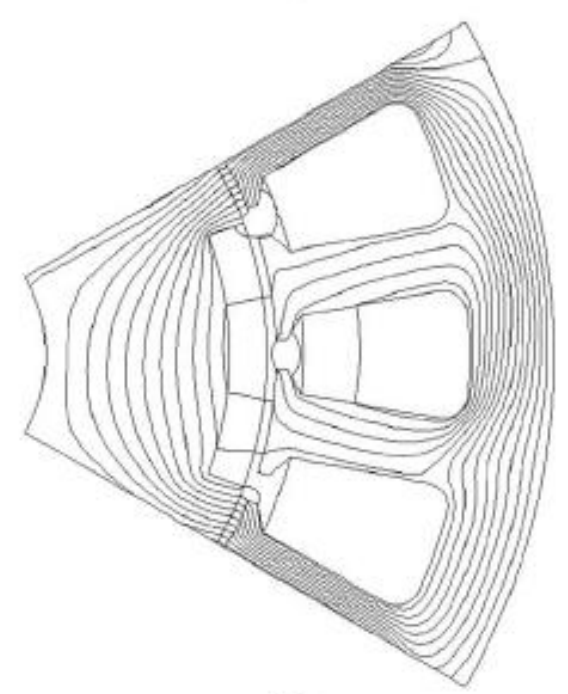

(d)

Fonte: Chu; Zhu (2013). a) gráfico de cores para a permeabilidade; b) linhas de fluxo para a simulação com corrente no modelo não linear; $c$ ) linhas de fluxo para a simulação com corrente, excitação feita apenas por ímãs, aplicado o método da permeabilidade fixa; d) linhas de fluxo para a simulação com corrente, excitação feita apenas pelas bobinas, aplicado o método da permeabilidade fixa.

Não obstante, busca-se outros indícios de que o método é implementado corretamente ao se observar a distribuição da densidade de fluxo radial ao longo do rotor. A Figura 6.6 reproduz a imagem presente no artigo (Chu; Zhu, 2013) com relação a distribuição da densidade de fluxo radial, ao passo que a Figura 6.7 mostra os resultados obtidos por meio de simulação através do emprego do software desenvolvido no presente trabalho.

Observa-se que os resultados obtidos são coerentes com os resultados de (Chu; Zhu, 2013) do ponto de vista qualitativo, i.e., o perfil da densidade de fluxo radial ao longo do rotor. No entanto, do ponto de vista quantitativo é possível notar uma diferença entre o perfil do 
modelo não linear (nomeado como Total (Não Linear) na Figura 6.7) e o perfil resultante da soma da simulação com ímãs e da simulação com corrente (nomeado como Total (Linear) na Figura 6.7). O erro é proveniente de duas fontes distintas. A primeira é relativa a margem de tolerância "a" empregada na composição das regiões de diferentes permeabilidades dentro da máquina, como explicado na Subseção 5.2.3. A segunda diz respeito, novamente, às diferenças dimensionais entre as máquinas.

Figura 6.5 - Linhas de fluxo eletromagnético obtidas pela utilização do software do presente trabalho.

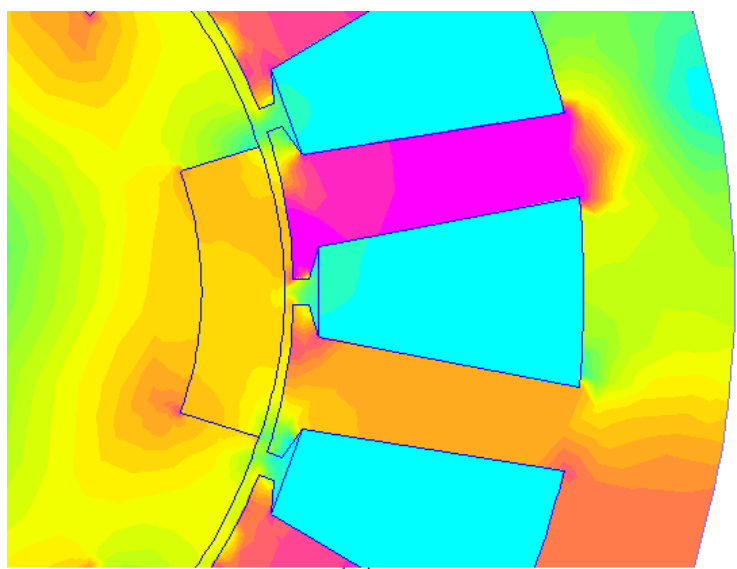

(a)

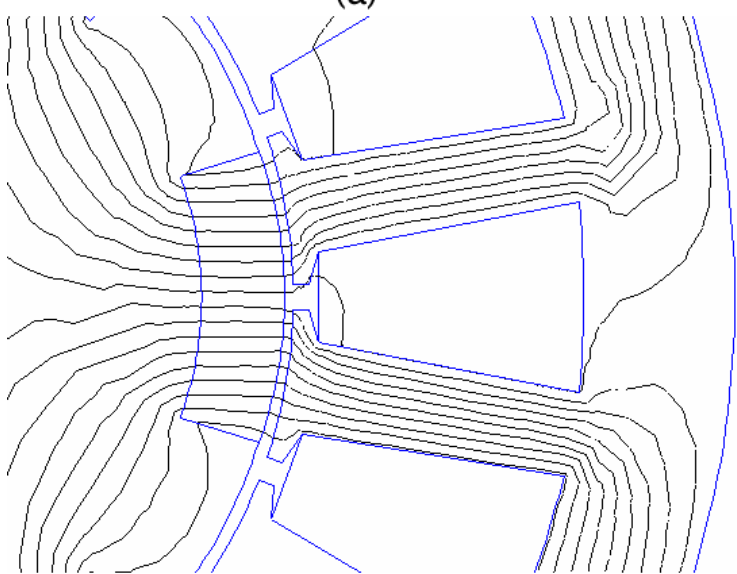

(c)

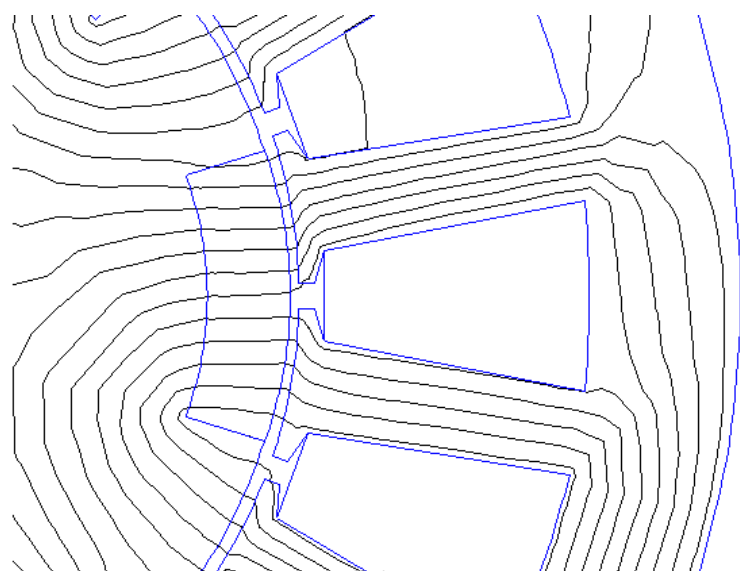

(b)

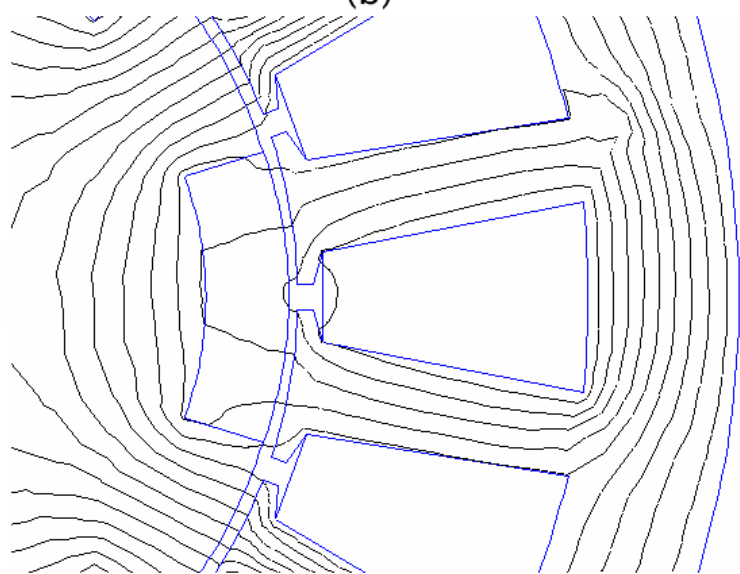

(d)

a) gráfico de cores para a permeabilidade; b) linhas de fluxo para a simulação com corrente no modelo não linear; c) linhas de fluxo para a simulação com corrente, excitação feita apenas por ímãs, aplicado o método da permeabilidade fixa; d) linhas de fluxo para a simulação com corrente, excitação feita apenas pelas bobinas, aplicado o método da permeabilidade fixa.

Da implementação do método da permeabilidade fixa melhorado apresentado nos dois artigos (Chu; Zhu, 2013, 2013) têm-se as Figura 6.8 e Figura 6.9, as quais mostram o resultado presente nos artigos e o resultado gerado pelo software desenvolvido, respectivamente.

Tanto na Figura 6.8 quanto na Figura 6.9, têm-se: a) gráfico de cores para a densidade de fluxo magnético para o método da permeabilidade fixa convencional; b) gráfico de cores para a densidade de fluxo magnético para o método da permeabilidade fixa melhorado. Tendo 
em vista que o método da permeabilidade fixa melhorado tem como proposta a correção da quantidade de energia armazenada no estator e não a alteração das linhas de fluxo magnético dentro da máquina, quando comparado com o método da permeabilidade fixa convencional, as Figuras 6.8 e 6.9 reforçam o indicativo de que o software desenvolvido implementa os dois métodos corretamente.

Figura 6.6 - Perfil da densidade de fluxo radial ao longo do rotor.

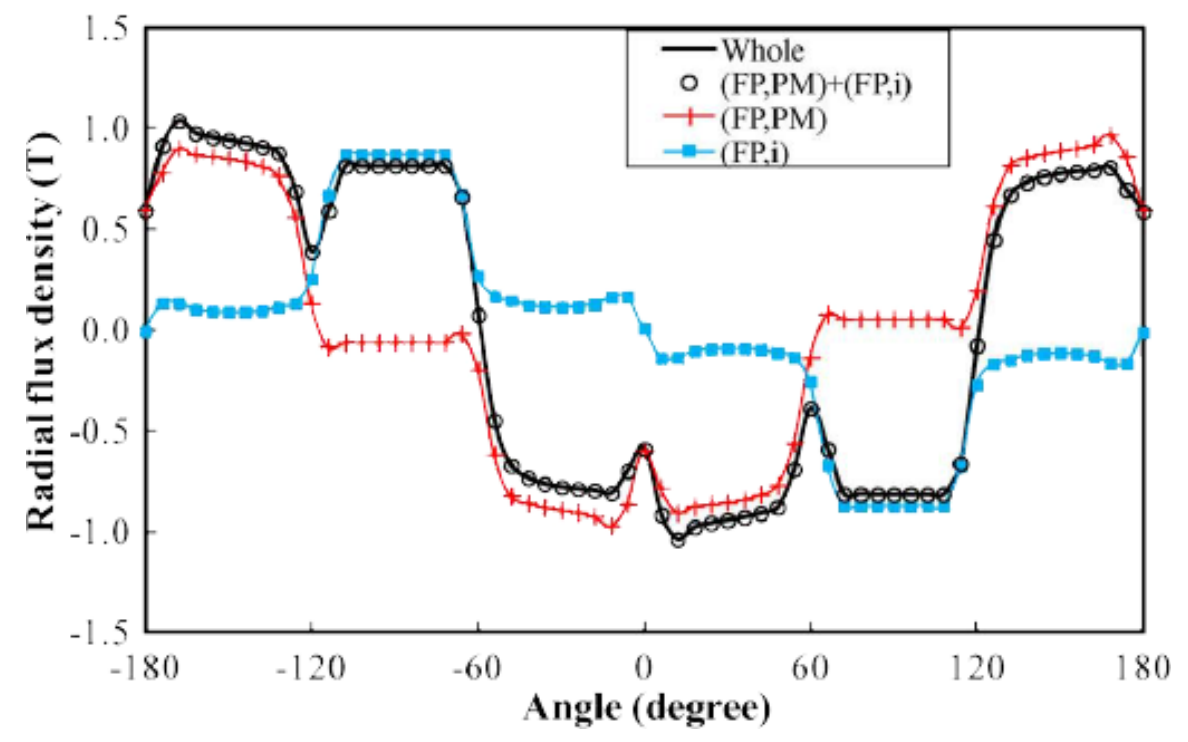

Fonte: Chu; Zhu (2013)

Figura 6.7 - Perfil da densidade de fluxo radial ao longo do rotor.

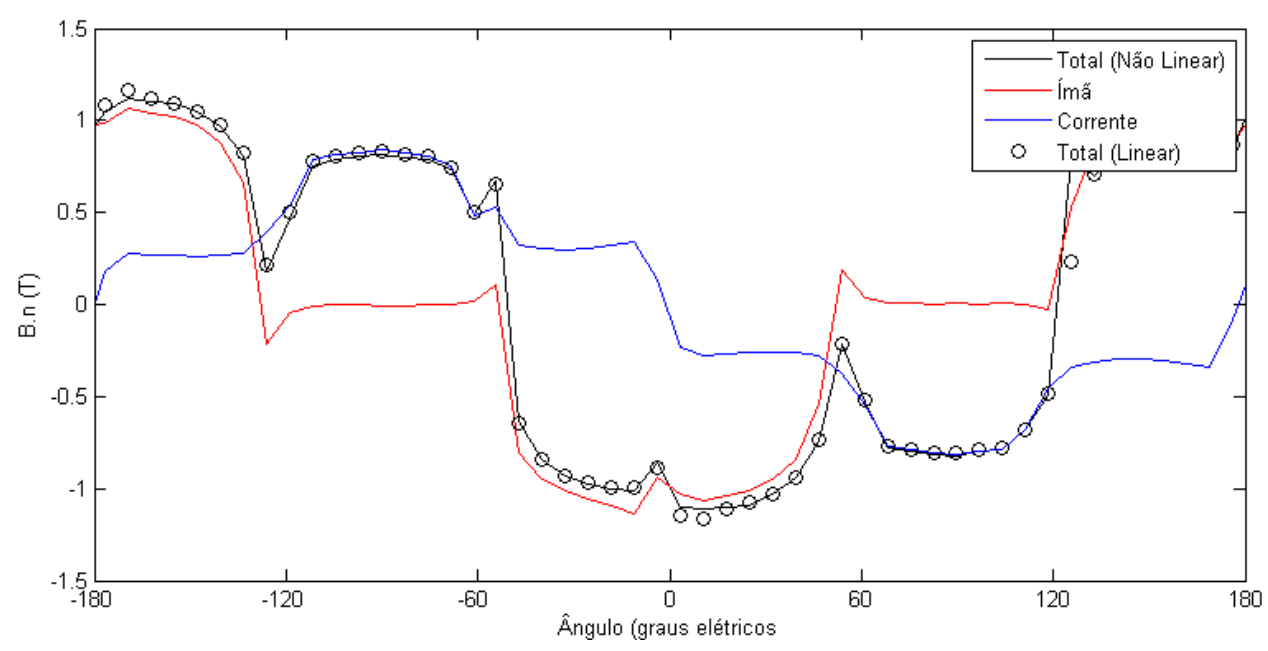

Segundo o que é apresentado na Seção 4.3 e em (Chu; Zhu, 2013), o método da permeabilidade fixa melhorado apresenta redução na quantidade de energia armazenada no estator quando da simulação linear com os ímãs permanentes como fonte de fluxo magnético, como expõe a Figura 6.10, extraída de (Chu; Zhu, 2013). No entanto, a quantidade de energia só será menor caso a posição $\theta$ do rotor, para o ponto de operação da máquina, apresente 
alinhamento entre o fluxo proveniente dos ímãs e o fluxo gerado pelas bobinas do estator, i.e., a intensidade magnética resultante seja a soma das intensidades magnéticas individuais no modelo linear. Caso contrário, quando a posição $\theta$ do rotor apresente oposição entre o fluxo proveniente dos ímãs e o fluxo gerado pelas bobinas do estator, i.e., a intensidade magnética resultante seja a diferença das intensidades magnéticas individuais no modelo linear, a quantidade de energia será maior. Dessa forma, a Figura 6.10 não representa um resultado que pode ser generalizado para o método melhorado já que representa o resultado para o acionamento com corrente com atraso de $30^{\circ}$ elétricos.

Figura 6.8 - Gráfico de cores.

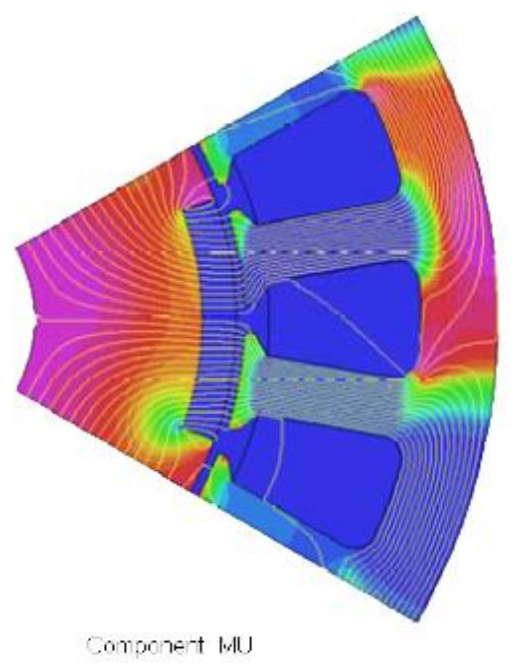

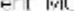

4500

(a)

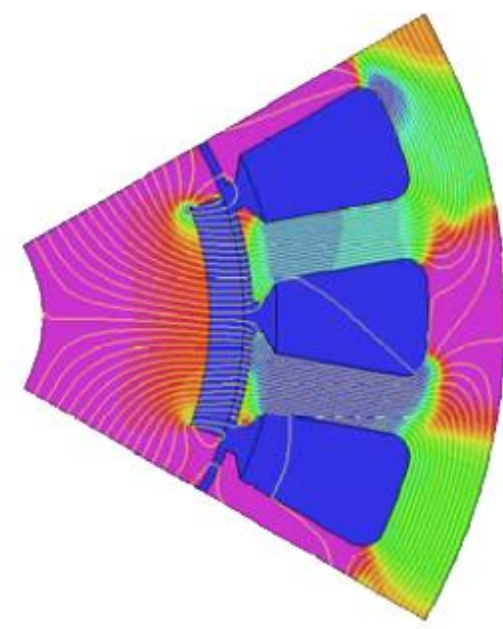

9000

(b)

Fonte: Chu; Zhu (2013). a) método convencional; b) método melhorado.

Figura 6.9 - Gráfico de cores.

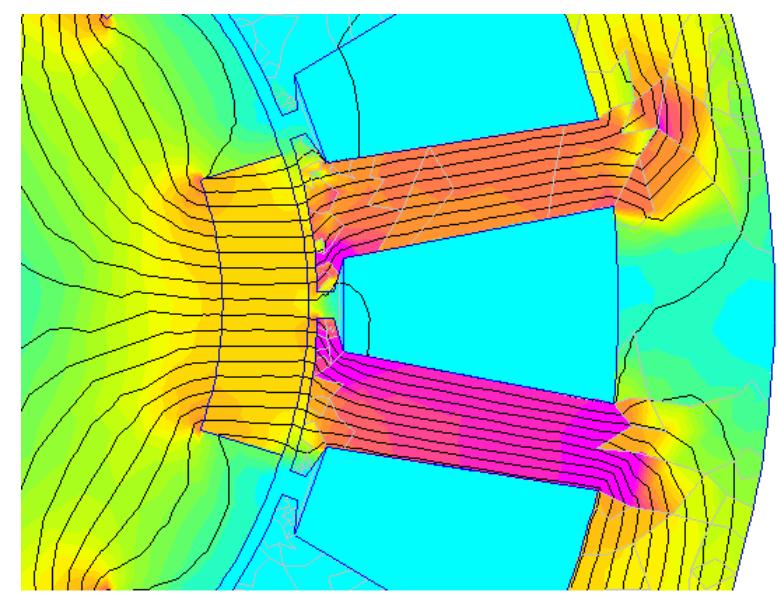

(a)

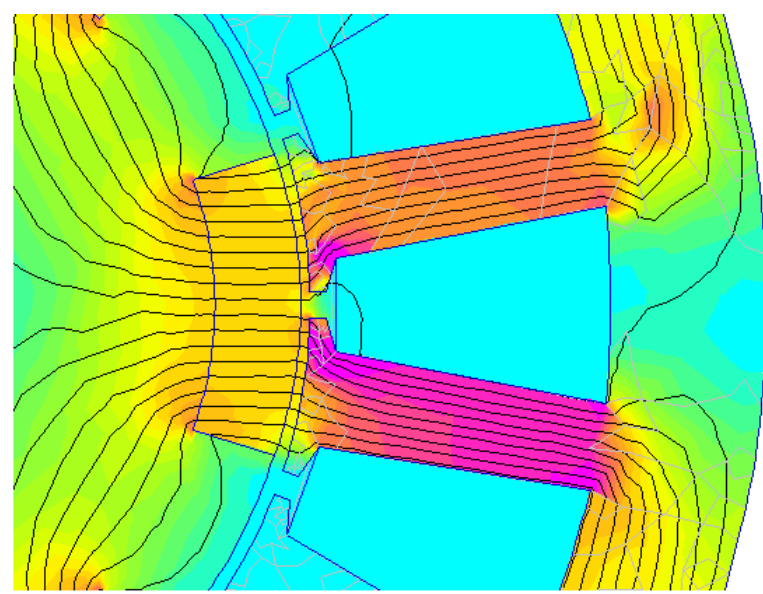

(b)

a) método convencional; b) método melhorado. 
Figura 6.10 - Energia no estator.

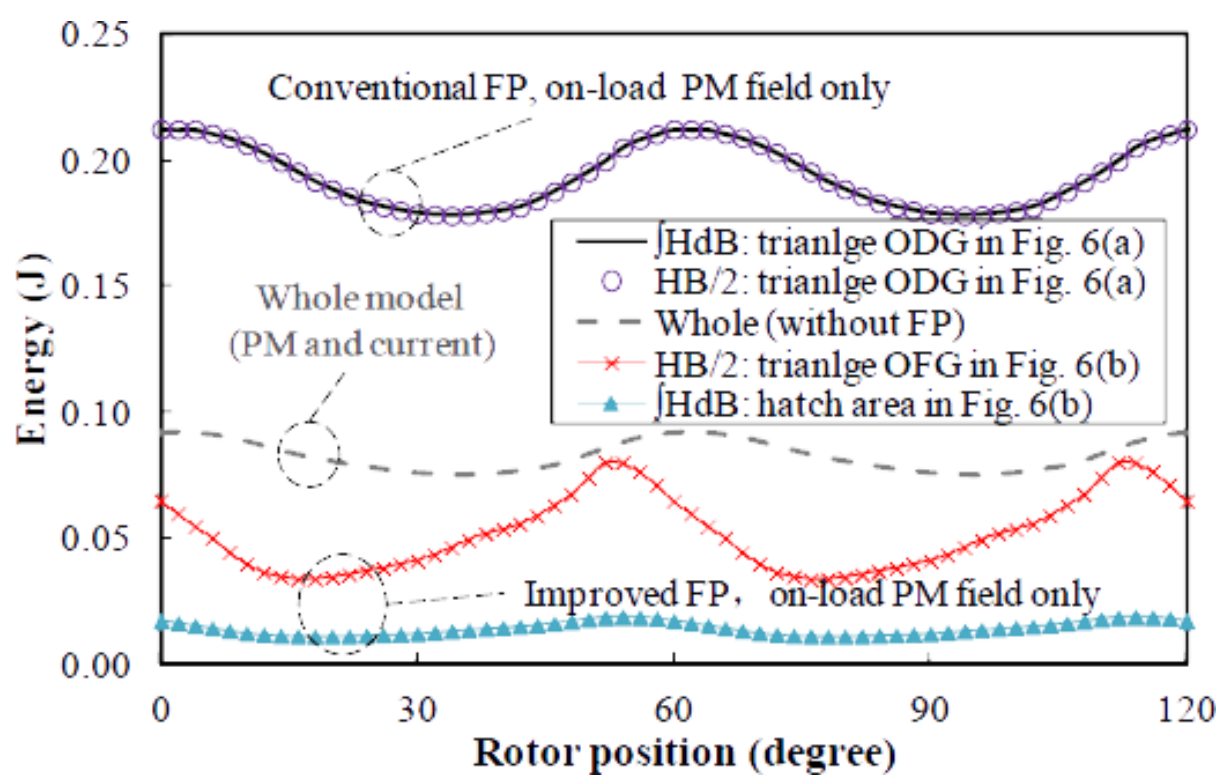

Fonte: Chu; Zhu (2013)

Das simulações realizadas com a máquina síncrona com ímãs permanentes semi-enterrados com corrente de acionamento puramente senoidal e com ângulo $0^{\circ}$ de atraso, obtémse o perfil de coenergia apresentado na Figura 6.11. Notavelmente os valores de energia são menores do que os valores de coenergia, no entanto, estes estariam dispostos no gráfico na mesma sequência.

Figura 6.11 - Coenergia no estator.

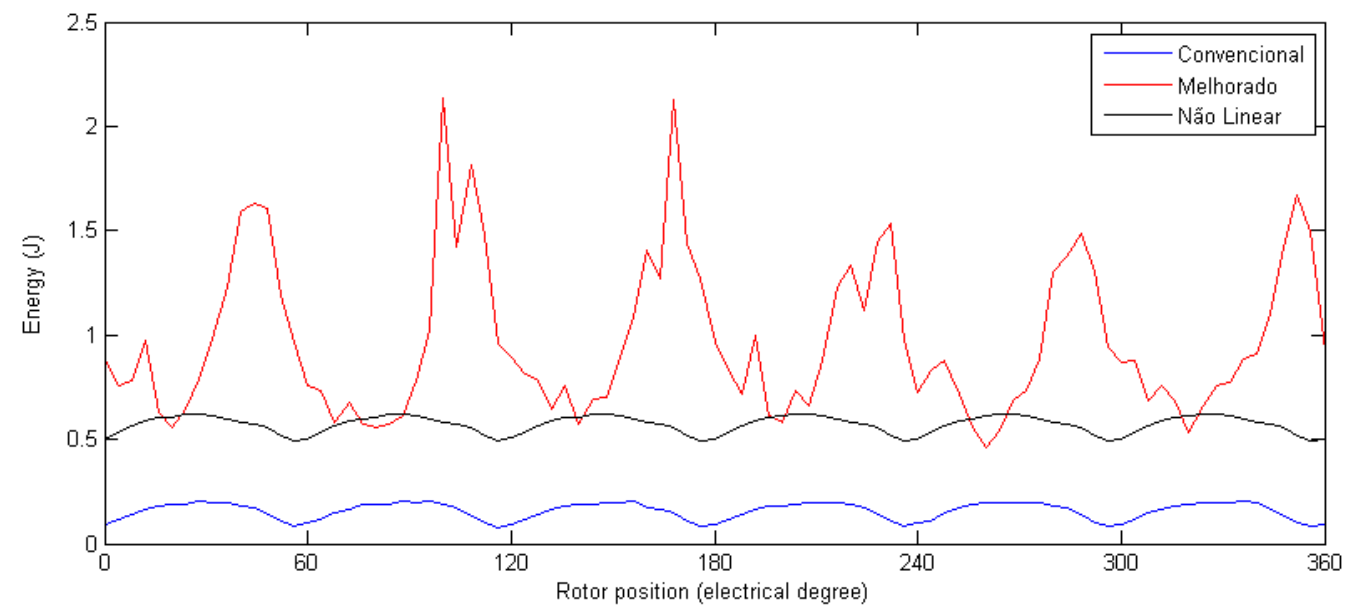

Como mencionado, os valores de coenergia e energia para a corrente com atraso de $30^{\circ}$ elétricos são menores que os valores para a corrente sem atraso.

Outros resultados relevantes, mas que não estão apresentados nos artigos (Chu; Zhu, 2013, 2013), dizem respeito ao fluxo concatenado e a força contra eletromotriz. A Figura 6.12 apresenta o fluxo concatenado para máquina sem corrente e com corrente de 4A. Já a Figura 
6.13 apresenta a força contra eletromotriz para a máquina sem corrente e com corrente de $4 \mathrm{~A}$.

Como a máquina é acionada com formas de onda puramente senoidais para as correntes, as três fases estão em operação ao mesmo tempo e não há variações bruscas no sentido do fluxo magnético quando do chaveamento das fases, i.e., as transições são suaves, o fluxo concatenado por fase não apresenta variações repentinas. Portanto, a força contra eletromotriz apresenta alterações suaves.

Figura 6.12 - Fluxo concatenado.

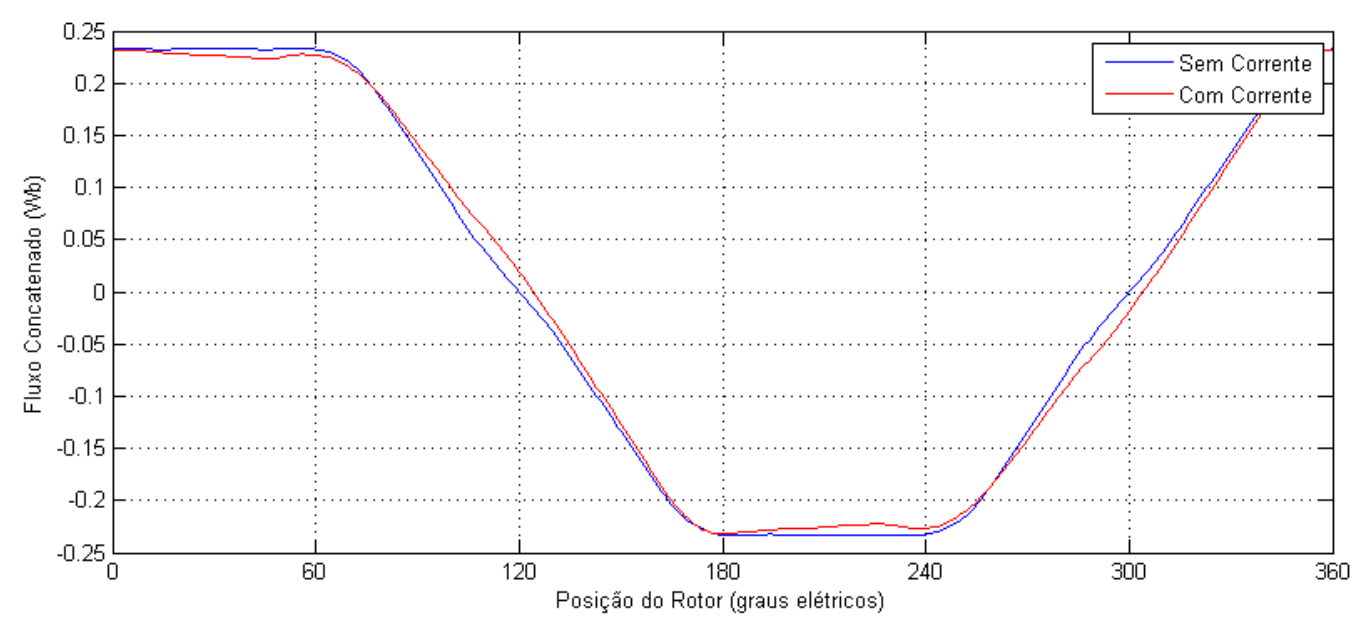

Figura 6.13 - Força contra eletromotriz.

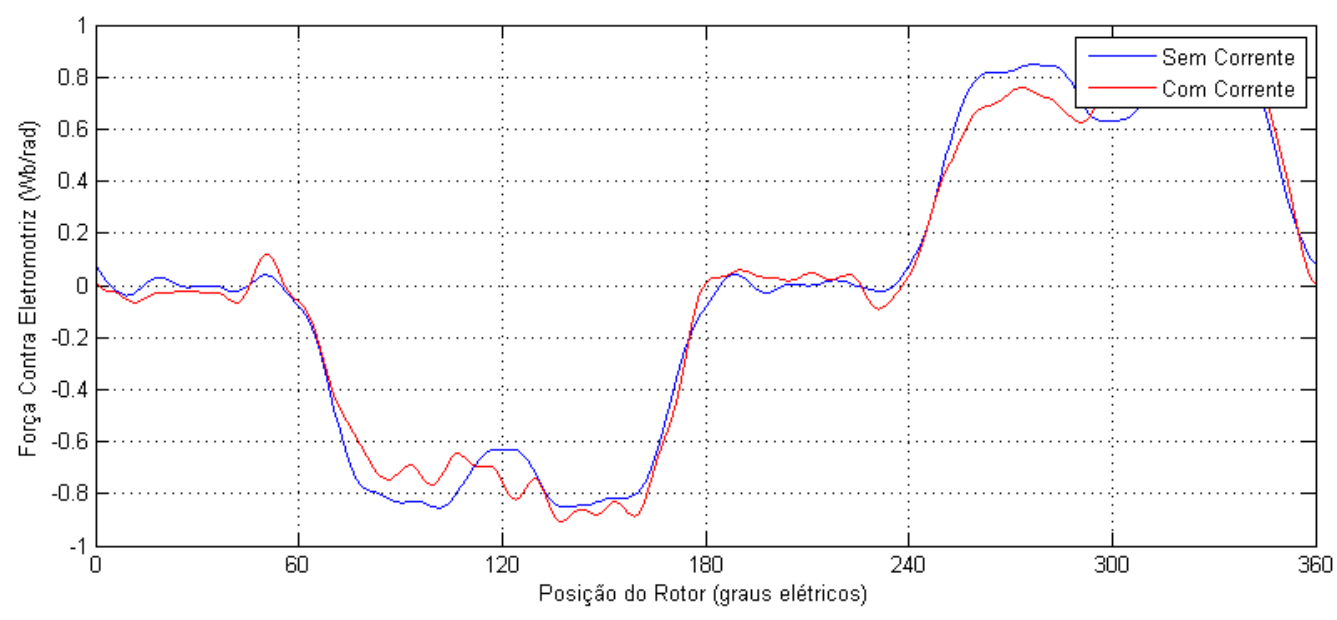




\subsection{Máquina Síncrona com Ímãs Permanentes na Superfície do Ro- tor}

As seções a seguir tratam dos seguintes resultados para a máquina síncrona de ímã permanente na superfície do rotor com forma de onda de força contra eletromotriz trapezoidal, de acionamento a seis pulsos:

- Fluxo concatenado por fase;

- Força Contra Eletromotriz;

- Indutância;

- Torque.

\subsubsection{Fluxo Concatenado por Fase}

Da simulação realizada na primeira etapa - simulação sem corrente - obteve-se a forma de onda do fluxo concatenado por fase da máquina conforme ilustra a Figura 6.14. A Figura 6.15 ilustra o conteúdo harmônico do fluxo concatenado para a fase $A$ (dada a simetria entre as fases os valores das outras fases serão omitidos).

Nota-se, portanto, que para a máquina sem corrente o fluxo concatenado se comporta de maneira suave, sem alterações notáveis nas regiões de crescimento de fluxo concatenado (entre $120^{\circ}$ e $240^{\circ}$ ) e de redução de fluxo concatenado (entre $0^{\circ}$ e $60^{\circ}$; e entre $300^{\circ}$ e $360^{\circ}$ ).

Figura 6.14 - Fluxo concatenado por fase (operação sem corrente).

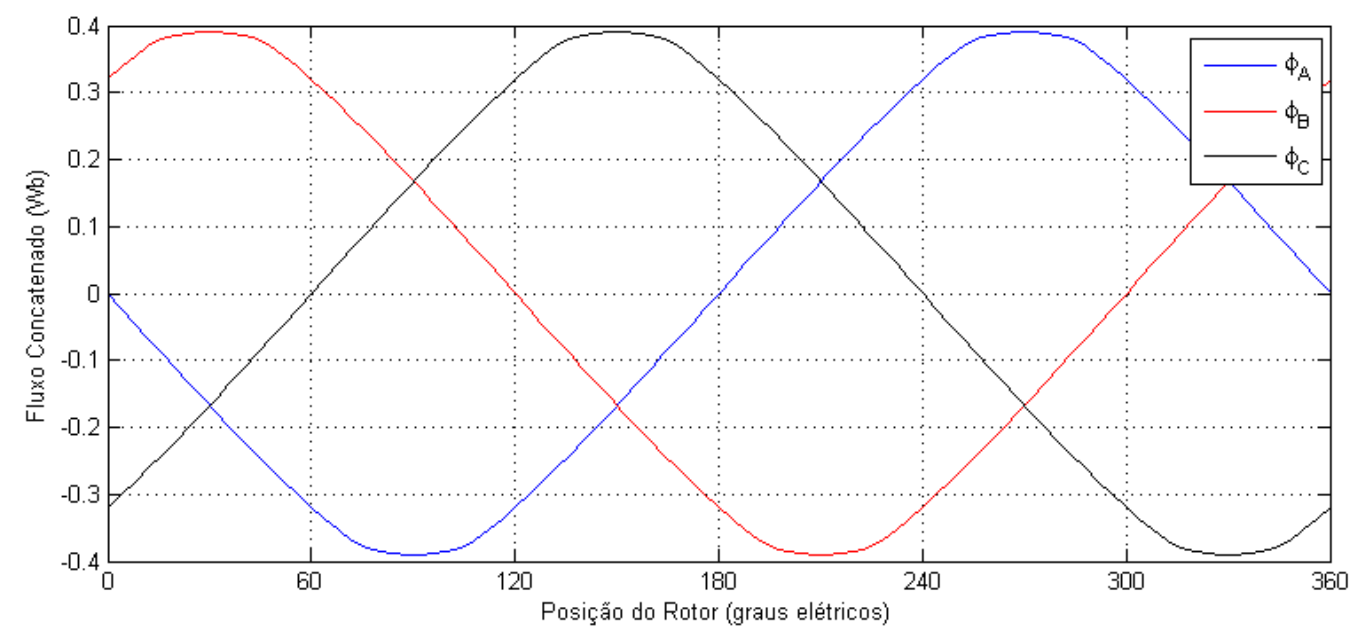


Figura 6.15 - Conteúdo harmônico do fluxo concatenado pela fase A (operação sem corrente).



Tomando-se os métodos da permeabilidade fixa (MPF) - convencional e melhorado -, aplicando-se as três condições de corrente na máquina e, realizadas as simulações da terceira etapa, obtêm-se a forma de onda do fluxo concatenado para a fase A em cada condição de corrente, conforme ilustra a Figura 6.16. A Figura 6.17 ilustra o conteúdo harmônico para o fluxo concatenado para a fase A em cada condição de corrente, sendo possível comparálos com o conteúdo harmônico do fluxo para a máquina sem corrente, Figura 6.15.

Lembrando que o método da permeabilidade fixa (MPF) melhorado proposto em (Chu; Zhu, 2013) não visa alterar as linhas de fluxo calculadas pelo método convencional, mas sim a quantidade de energia armazenada no estator, os resultados para o fluxo concatenado são os mesmos para os dois métodos.

Figura 6.16 - Fluxo concatenado da fase A (MPF).

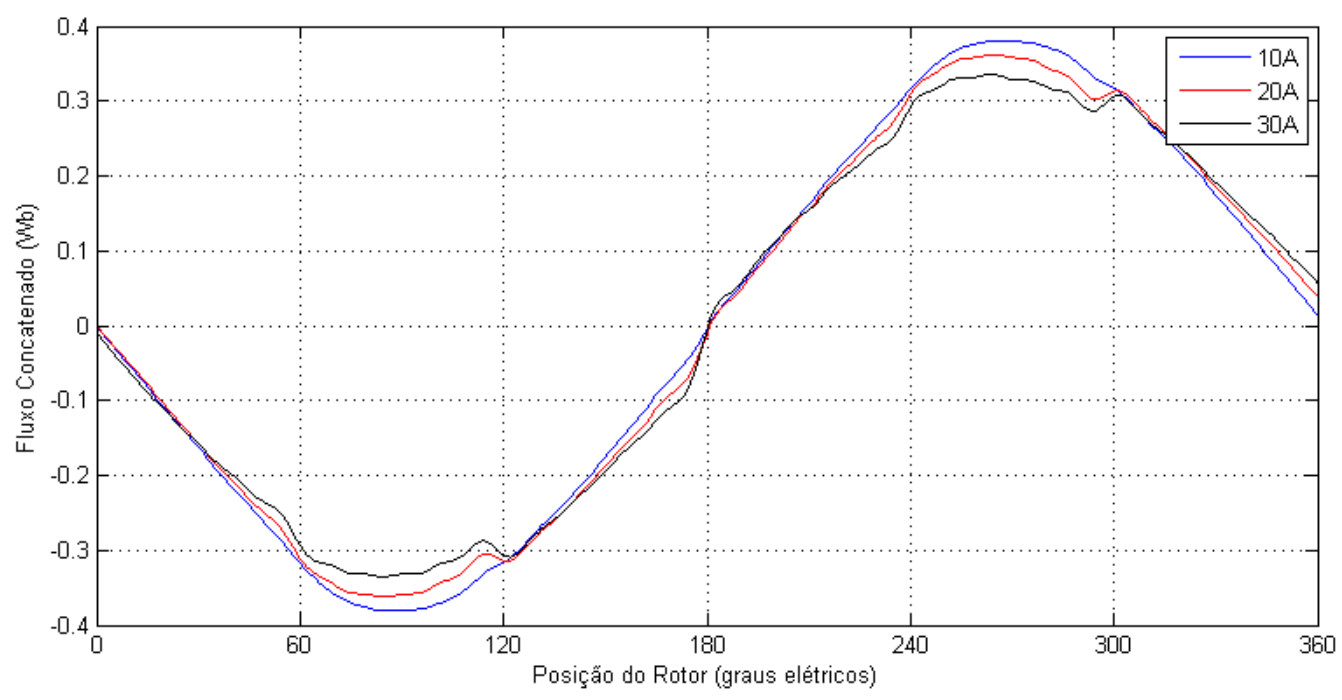


Figura 6.17 - Conteúdo harmônico do fluxo concatenado pela fase A (MPF).

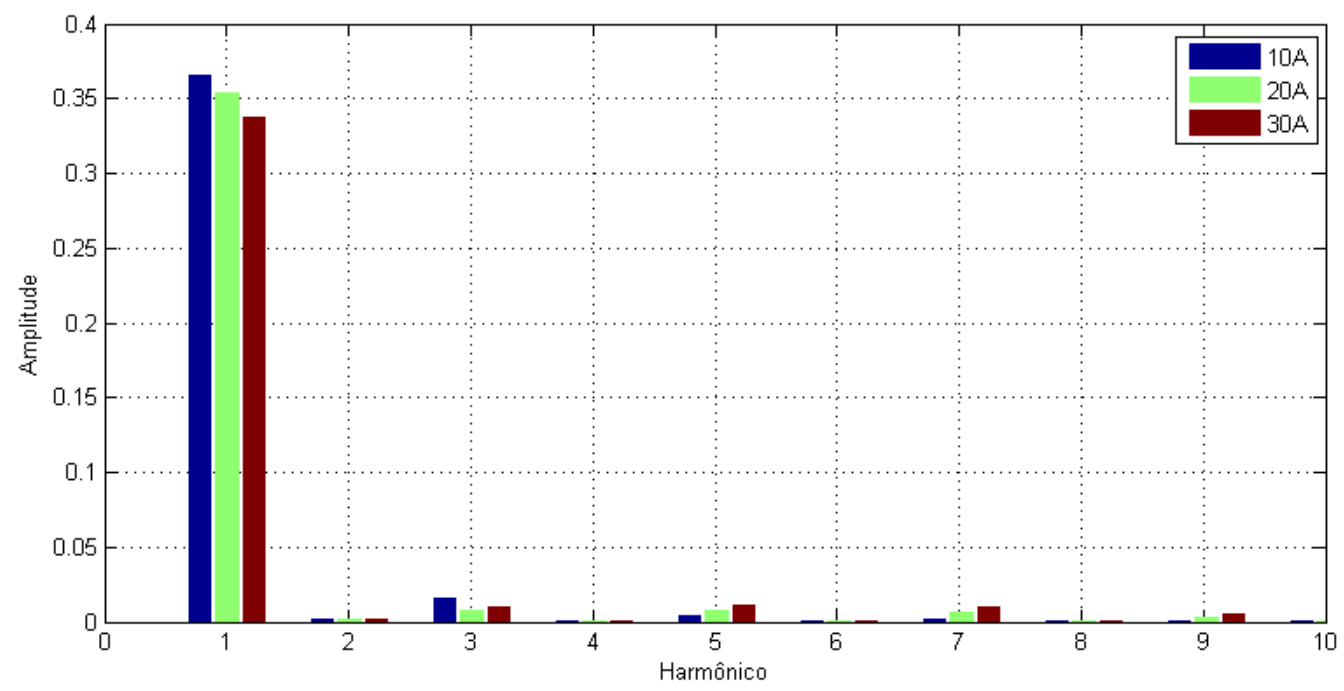

Para os dois métodos, convencional e melhorado, nota-se o acréscimo de alterações no fluxo concatenado à medida que a corrente aumenta. A Figura 6.17 comparada à Figura 6.15 demonstra a redução do harmônico de primeira ordem à medida que a corrente aumenta na máquina, assim como o crescimento dos valores nos harmônicos de ordem elevada. $O$ crescimento dos valores desses harmônicos afeta diretamente a forma de onda da força contra eletromotriz.

\subsubsection{Força Contra Eletromotriz por Fase}

Da simulação realizada na primeira etapa - simulação sem corrente - obteve-se a forma de onda do fluxo concatenado por fase e, por meio desta, obteve-se a forma de onda da força contra eletromotriz da máquina conforme ilustra a Figura 6.18. A Figura 6.19 ilustra o conteúdo harmônico da força contra eletromotriz da fase $A$.

Figura 6.18 - Força contra eletromotriz por fase (operação sem corrente).

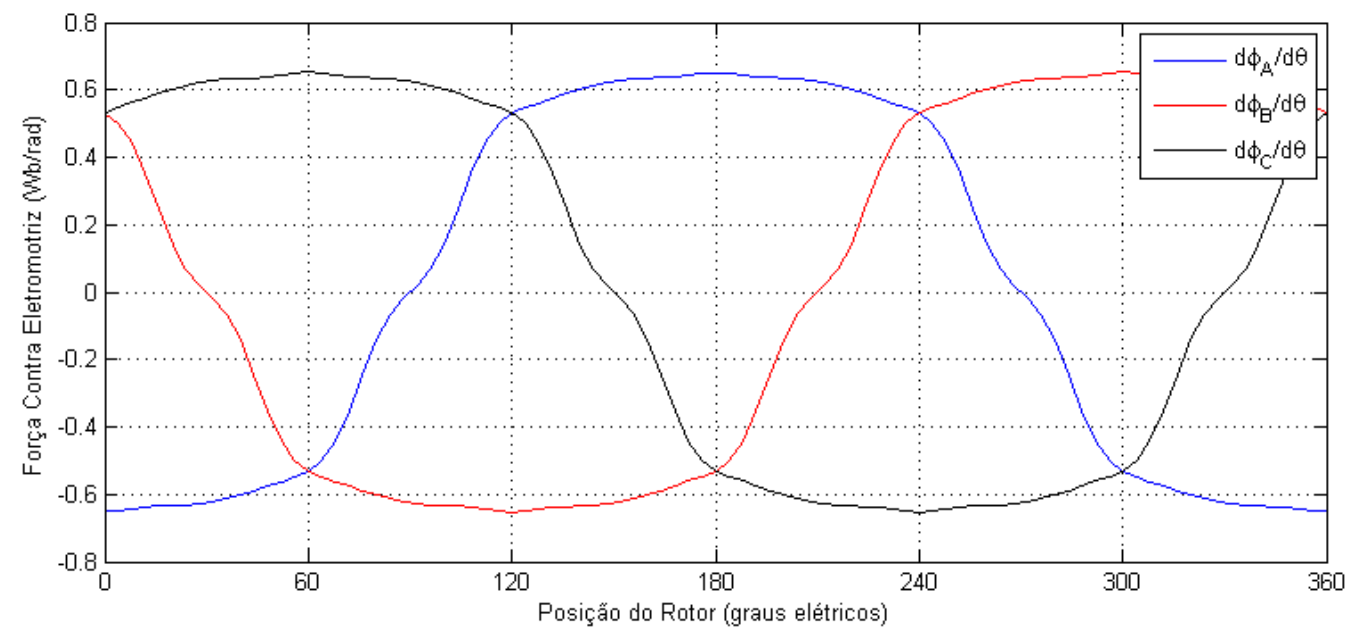


Figura 6.19 - Conteúdo harmônico da força contra eletromotriz da fase A (operação sem corrente).



Nota-se portanto, que para a máquina sem corrente, a força contra eletromotriz se comporta de maneira suave, sem alterações notáveis nas regiões de crescimento de fluxo concatenado (entre $120^{\circ}$ e $240^{\circ}$ ) e de redução de fluxo concatenado (entre $0^{\circ}$ e $60^{\circ}$; e entre $300^{\circ}$ e $\left.360^{\circ}\right)$.

Tomando-se os métodos da permeabilidade fixa (MPF) - convencional e melhorado -, aplicando-se as três condições de corrente na máquina e, realizadas as simulações da terceira etapa, obtêm-se a forma de onda do fluxo concatenado e, por meio desta, a forma de onda da força contra eletromotriz da fase A em cada condição de corrente, conforme ilustra a Figura 6.20. A Figura 6.21 ilustra o conteúdo harmônico da força contra eletromotriz da fase A em cada condição de corrente, sendo possível compará-los com o conteúdo harmônico da força contra eletromotriz para a máquina sem corrente.

Figura 6.20 - Força contra eletromotriz da fase A (MPF).

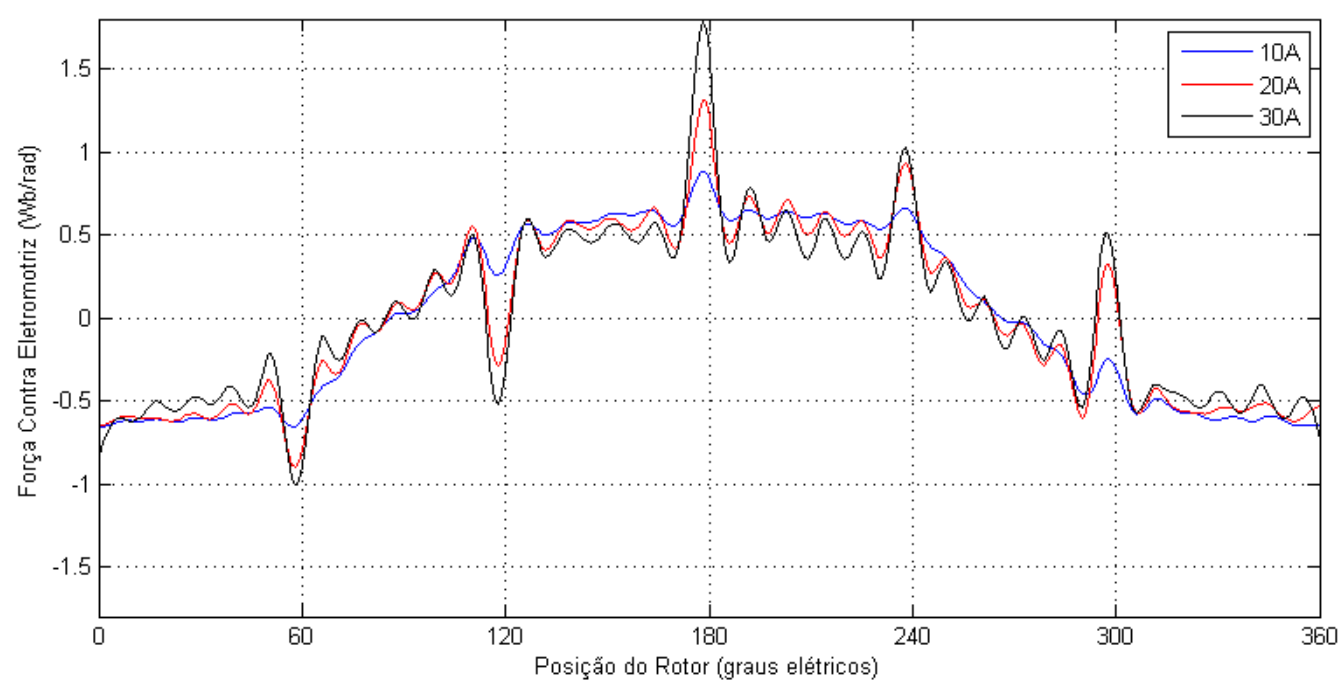


Figura 6.21 - Conteúdo harmônico da força contra eletromotriz da fase A (MPF).

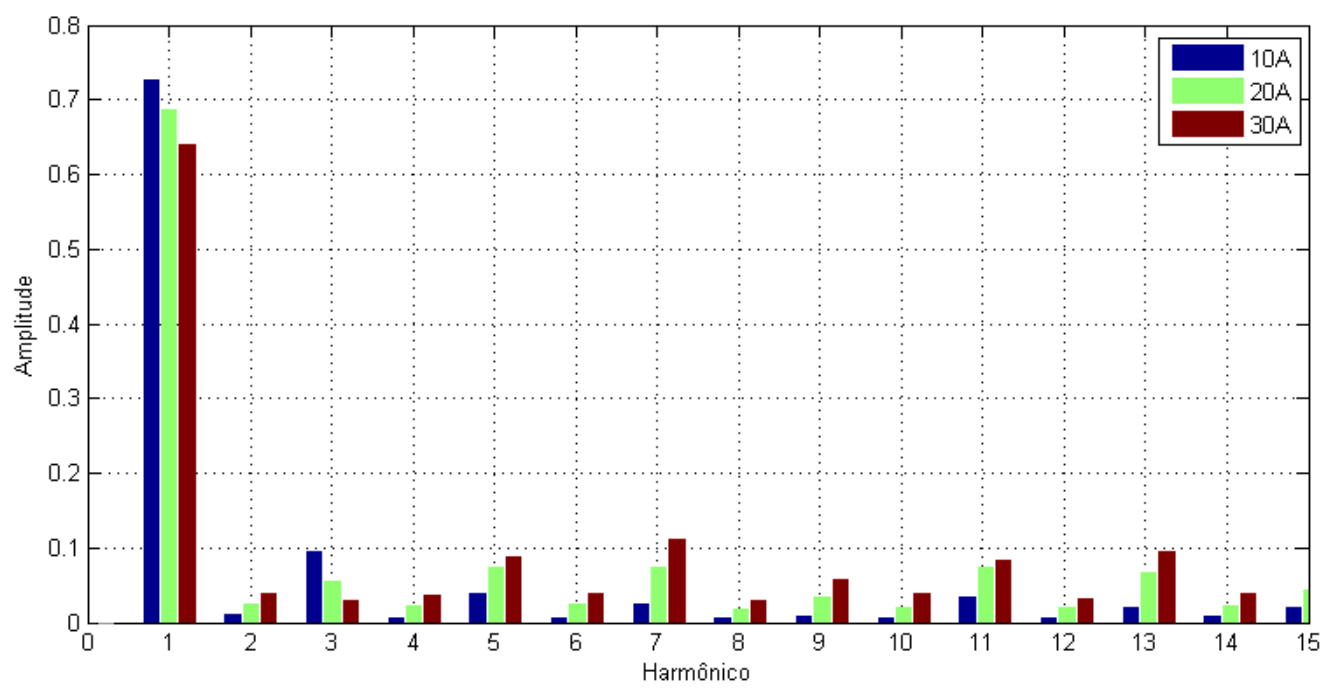

Para os dois métodos, convencional e melhorado, nota-se o acréscimo da intensidade das alterações na forma de onda da força contra eletromotriz a medida que a corrente aumenta. Três picos de alterações são bem notáveis, o primeiro está presente no início do patamar da força contra eletromotriz, reduzindo consideravelmente o valor da mesma, essa alteração coincide com o chaveamento desta fase; o segundo pico está no centro do patamar, elevando consideravelmente o valor da força contra eletromotriz, essa alteração coincide com o ponto de chaveamento das outras duas fases da máquina; o terceiro pico está no final do patamar, elevando de maneira considerável o valor da força contra eletromotriz, mas de maneira menos drástica que os outros picos. Todas essas alterações afetam diretamente o torque mútuo, como será visto na Seção 6.2.4.2 relacionada a essa parcela do torque.

\subsubsection{Indutância}

Da simulação realizada na quarta etapa - simulação linear com as bobinas (alimentadas) como única fonte de fluxo magnético - obteve-se o perfil da indutância de cada fase e, uma vez que as bobinas estão ligadas em $Y$ e seguindo-se o acionamento proposto na Figura 6.3, portanto, duas bobinas estão sempre energizadas, obteve-se o perfil da indutância de linha, sendo essa de maior importância para a análise do comportamento do torque. A Figura 6.22 ilustra o perfil da indutância de linha.

Observa-se que os valores médio, máximo e mínimo da indutância de linha diminuem com o acréscimo de corrente. Com relação à redução desses valores cabem algumas considerações, todas elas diretamente relacionadas à redução da permeabilidade magnética relativa. 
Figura 6.22 - Perfil da indutância de linha.

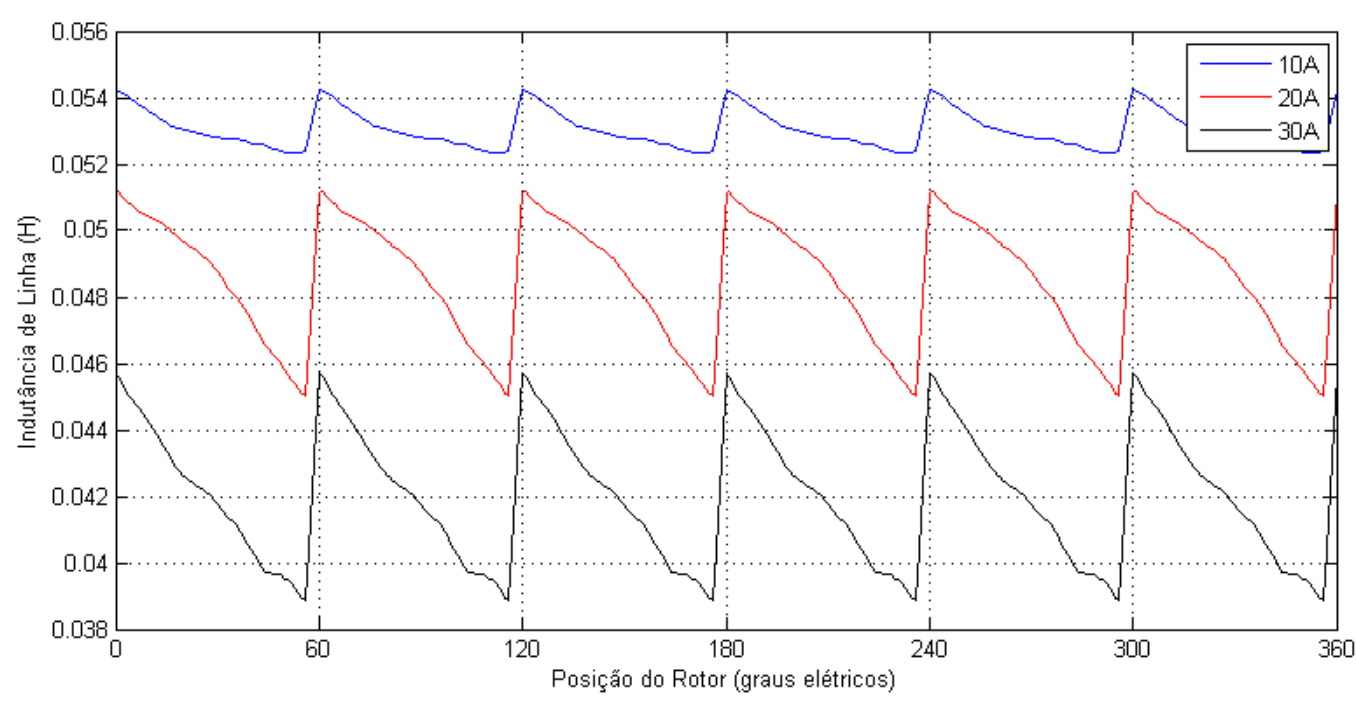

A primeira consideração justifica a redução desses valores de um modo geral. Essa redução ocorre uma vez que, há maior quantidade de fluxo magnético percorrendo o circuito magnético, portanto, ocorre a mudança do ponto de operação do material do estator para pontos mais elevados na curva de magnetização, em que a permeabilidade magnética relativa é menor. Retomando-se as Equações 2.12, 2.13 e 2.14, que descrevem cada parcela que constitui o valor da indutância de fase, apenas a Equação 2.14 é independente do ponto de operação da máquina. A priori, a Equação 2.12 é visivelmente mais dependente da permeabilidade magnética relativa, sendo a parcela mais afetada com a redução da permeabilidade relativa. No entanto, apesar da permeabilidade magnética relativa não estar presente diretamente na Equação 2.13, essa sofre influência da mesma já que, uma vez saturados alguns pontos da sapatas - notoriamente os pontos próximos às extremidades das sapatas e que são fronteiriços à abertura de ranhura -, ocorre, do ponto de vista do circuito magnético, o aumento do valor de $w_{s}$.

Já os pontos de máximo e mínimo coincidem com os instantes de chaveamento de duas fases, uma entrando em operação e a outra saindo de operação. Assim que uma fase entra em operação, o fluxo concatenado com a mesma e proveniente dos ímãs do rotor, se encontram próximos ao ponto de máximo ou de mínimo, conforme ilustra a Figura 6.14 (a justificativa da entrada de operação da fase é ilustrada pela Figura 6.18). Sendo assim, a corrente que alimenta essa fase produzirá um fluxo magnético contrário ao fluxo magnético concatenado, a fim de se produzir torque na máquina. Portanto, para o ponto de máximo fluxo concatenado, tem-se a maior permeabilidade magnética relativa já que ocorre a máxima oposição de fluxos. A medida que o rotor gira, devido ao torque produzido, a fase que já estava em operação passa a ter o fluxo magnético concatenado com mesma direção e sentido que 
o fluxo magnético produzido por suas bobinas, ocorrendo o máximo alinhamento dos fluxos (fluxos no mesmo sentido) e consequentemente, a menor permeabilidade magnética relativa. Deve-se lembrar que, as variações mencionadas também afetam a parcela mútua da indutância.

A modelagem vetorial, para a máquina síncrona de ímãs permanentes com forma de onda de força contra eletromotriz trapezoidal, apresentada em (Monteiro et al., 2012) e cuja alimentação da máquina é feita por três correntes quadradas, assim como as correntes empregadas no presente trabalho, demonstra valor constante para a componente de quadratura $\left(i_{q_{x}}\right)$ e valores variáveis para a componente direta $\left(i_{d_{x}}\right)$. Os valores da componente direta variam seguindo um perfil triangular, com média zero, e cujos picos coincidem com o chaveamento de cada fase. A componente direta da corrente indica o alinhamento entre os fluxos do ímã e da bobina. A Figura 6.23, reproduz o resultado presente em (Monteiro et al., 2012).

Comparando-se os resultados de (Monteiro et al., 2012) com os resultados presentes na Figura 6.22, nota-se que o perfil da componente direta da corrente de alimentação comporta-se de maneira inversa ao perfil da indutância, i.e., componente direta mínima para o valor máximo de indutância e componente direta máxima para o valor mínimo de indutância. Assim como o perfil de indutância ilustrado na Figura 6.22, a componente direta da Figura 6.23 apresenta periodicidade de $60^{\circ}$ elétricos.

Figura 6.23 - Perfil da corrente e suas componentes $i_{d_{x}}$ e $i_{q_{x}}$.

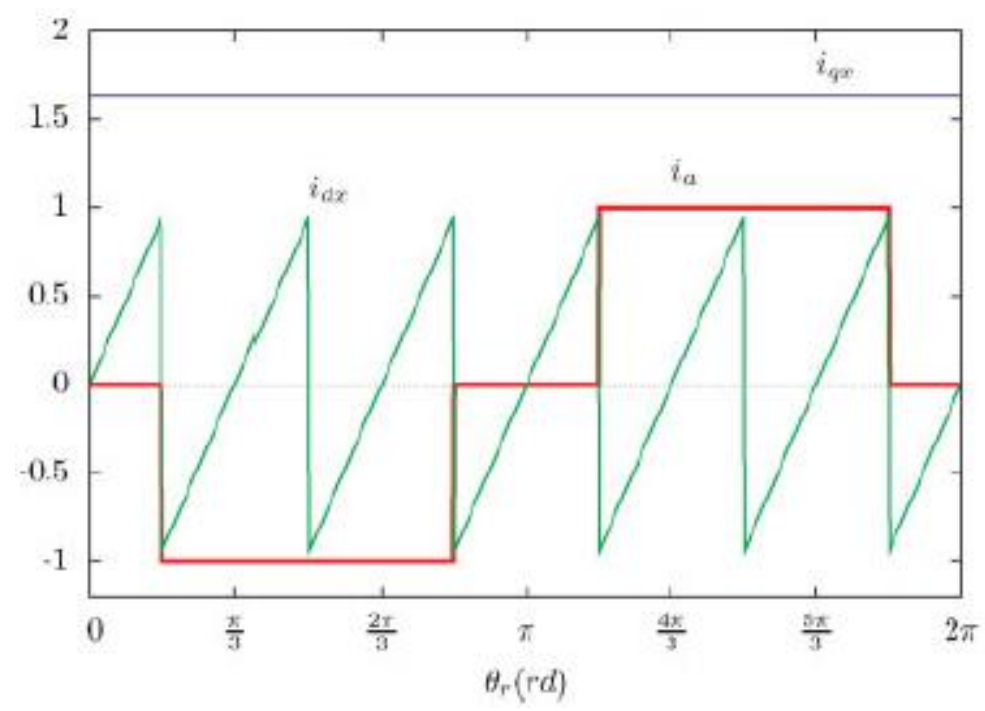

Fonte: Monteiro et al (2012)

\subsubsection{Torque Eletromagnético}

Mediante o que foi apresentado no Capítulo 3, o torque eletromagnético da máquina 
em estudo é composto por três parcelas distintas. Nessa seção são avaliadas cada uma dessas parcelas, o torque total da máquina e o quão acurado o método da permeabilidade fixa se mostra ao estimar cada uma das parcelas a fim de se compor o torque total da máquina.

A Equação 3.4 pode ser reescrita como:

$$
T_{\text {Total }}=T_{\text {Ind }}+T_{\mathrm{Re}}+T_{\text {Mútuo }}
$$

Onde:

- $T_{\text {Total }} \quad$ - Torque Total, $T$ na Equação 3.4;

- $\quad T_{\text {Ind }} \quad$ - Torque devido à variação da indutância, $\frac{1}{2} i^{2} \frac{d L}{d \theta}$ na Equação 3.4;

- $\quad T_{\mathrm{Re}} \quad$ - Torque de borda, $-\frac{1}{2} \phi_{M}^{2} \frac{d \Re}{d \theta}$ na Equação 3.4;

- $\quad T_{\text {Mútuo }} \quad$ - Torque mútuo, $N i \frac{d \phi_{M}}{d \theta}$ na Equação 3.4

\subsubsection{Torque Total}

A avaliação do torque eletromagnético total da máquina é feito por meio da simulação não linear (segunda etapa de simulação segundo a metodologia, Capítulo 4). A avaliação por meio da simulação não linear se dá pelo fato de que, essa simulação analisa a máquina levando-se em consideração todos os efeitos magnéticos, inclusive o de saturação, mostrando um resultado mais acurado.

$\mathrm{Da}$

Figura 6.24 à Figura 6.26 são mostrados o perfil do torque eletromagnético para as condições de corrente de 10, 20 e 30A, respectivamente. Os valores médio, máximo e mínimo do torque total para cada condição de corrente são apresentados na Tabela 6.1. A Figura 6.27 mostra como a razão torque/corrente varia com a corrente. Essa razão foi calculada com base no valor médio do torque apresentado na Tabela 6.1 para cada condição de corrente.

Tabela 6.1 - Torque Total.

\begin{tabular}{cccc}
\cline { 2 - 4 } & 10A & 20A & 30A \\
\hline \hline Máximo & 12,45 & 23,38 & 30,06 \\
\hline Mínimo & 11,78 & 19,90 & 25,71 \\
Médio & 12,05 & 21,80 & 28,31
\end{tabular}


Figura 6.24 - Perfil do torque total (10A).

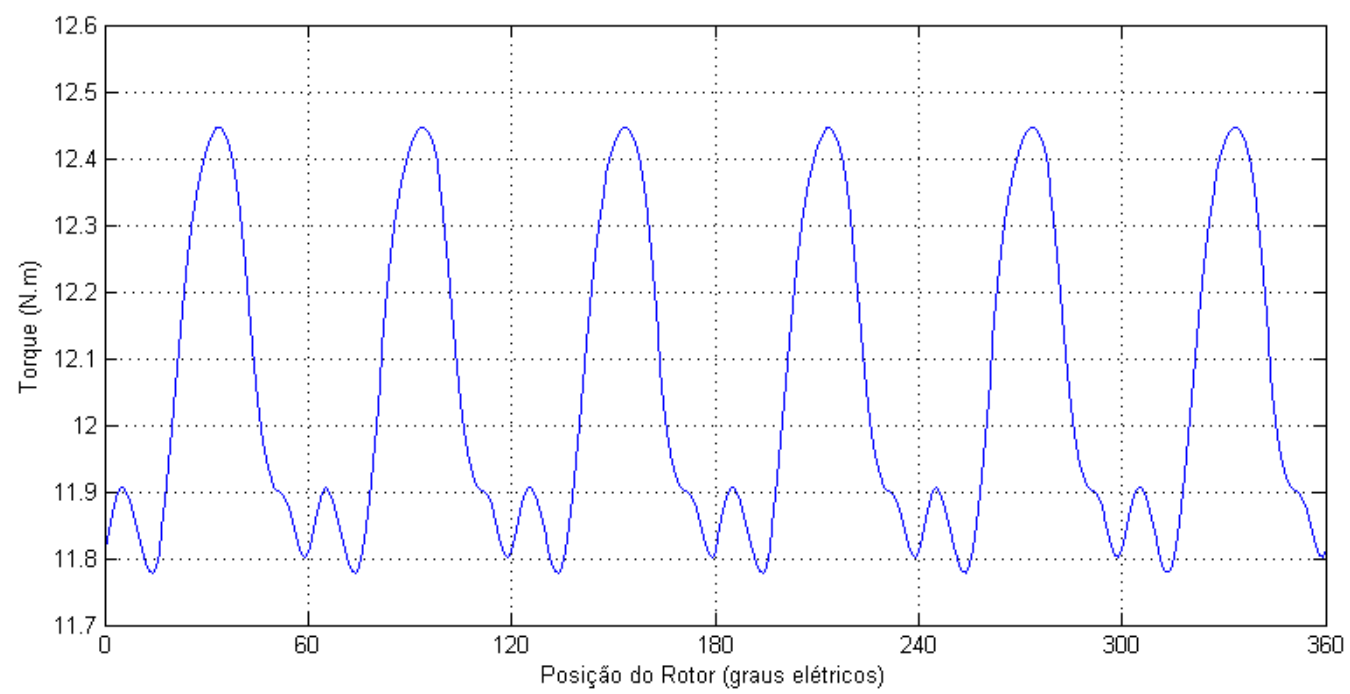

Figura 6.25 - Perfil do torque total (20A).

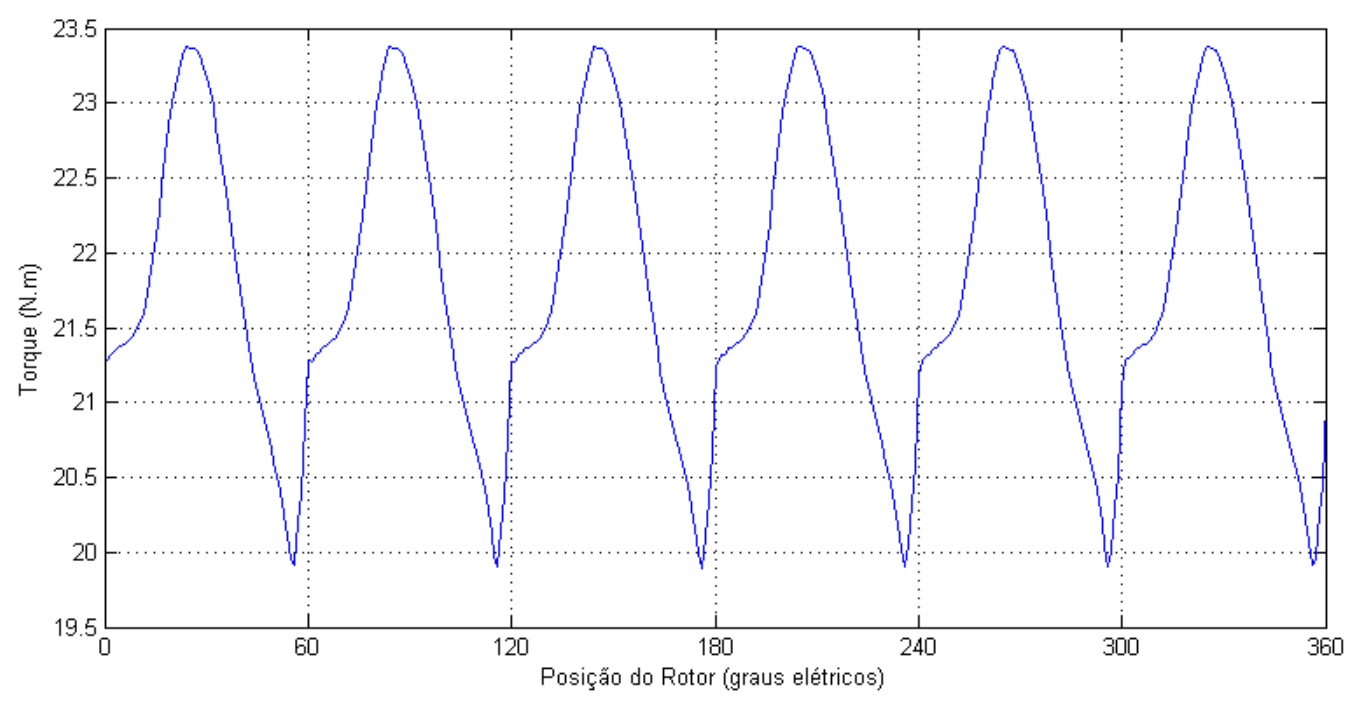

Figura 6.26 - Perfil do torque total (30A).

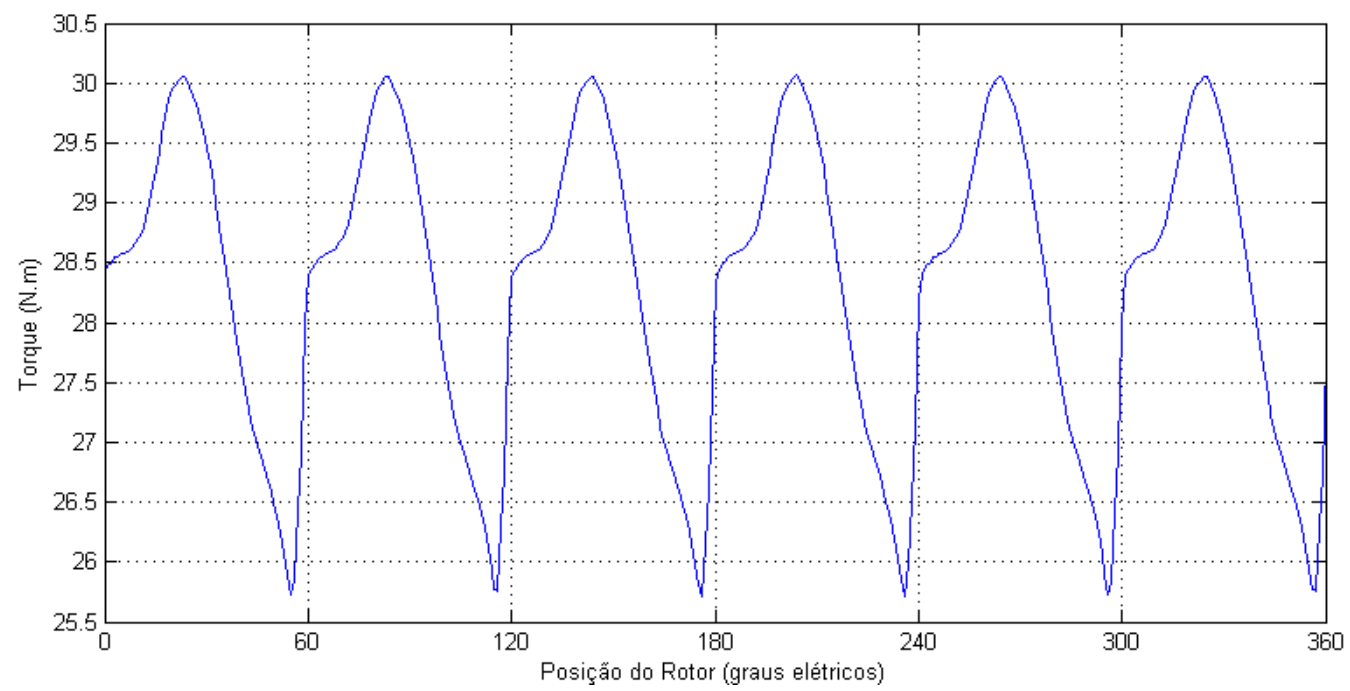


Figura 6.27 - Razão Torque/Corrente.

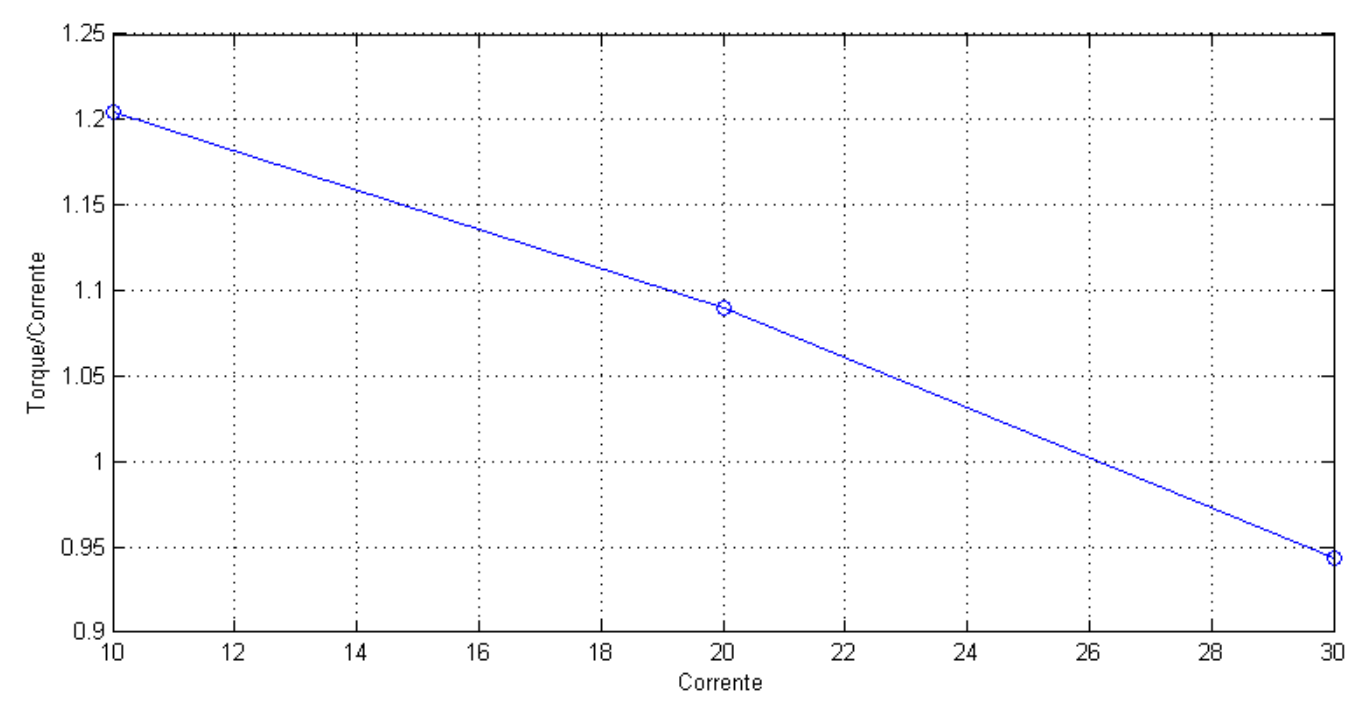

Nota-se que, à medida que a corrente aumenta, a saturação da máquina fica mais evidente e o torque produzido deixa de crescer na mesma proporção, i.e., a razão torque/corrente não tem o mesmo valor para todas as condições de corrente.

\subsubsection{Torque Mútuo}

O torque mútuo é formulado pela Equação 6.2. Com as forma de onda da força contra eletromotriz apresentadas na Seção 6.2.2 e considerando a mesma corrente utilizada no acionamento da máquina nas simulações, têm-se o perfil do torque mútuo para cada condição de corrente apresentado da Figura 6.28 à Figura 6.30 empregando-se os métodos convencional e melhorado. A razão torque/corrente para o torque mútuo é expressa na Figura 6.31.

$$
T_{\text {Mútuo }}=N i \frac{d \phi_{M}}{d \theta}
$$

Os valores médio, máximo e mínimo do torque mútuo para cada condição de corrente são apresentados na Tabela 6.2.

Tabela 6.2 - Torque Mútuo.

\begin{tabular}{cccc}
\cline { 2 - 4 } & 10A & 20A & 30A \\
\hline \hline Máximo & 15,65 & 46,42 & 85,84 \\
Mínimo & 10,72 & 8,24 & 14,79 \\
Médio & 12,05 & 23,30 & 33,26 \\
\hline \hline
\end{tabular}

Dado que a corrente de alimentação empregada nas simulações foram quadradas e sem oscilações, as alterações presentes nos perfis de torque mútuo são provenientes exclusivamente das alterações na forma de onda das forças contra eletromotriz. 
Os picos de alteração se encontram exatamente nos pontos de comutação de fase, que assim como explicado na Seção 6.2.3, em que a alteração na permeabilidade relativa provocava mudanças no valor da indutância, a mesma alteração na permeabilidade relativa provoca mudanças repentinas no valor do fluxo concatenado, consequentemente na força contra eletromotriz e por fim, no torque mútuo.

Vale notar que o valor médio do torque mútuo é próximo do valor médio do torque total para as condições de 10 e $20 \mathrm{~A}$ e, consequentemente, a razão torque/corrente são próximas. Para a condição de 30A, o valor médio do torque mútuo é maior do que o valor médio do torque total devido aos picos de torque. No entanto, de uma forma geral, excetuando-se tais picos, os valores para os dois torques são próximos.

Figura 6.28 - Perfil do torque mútuo (10A).

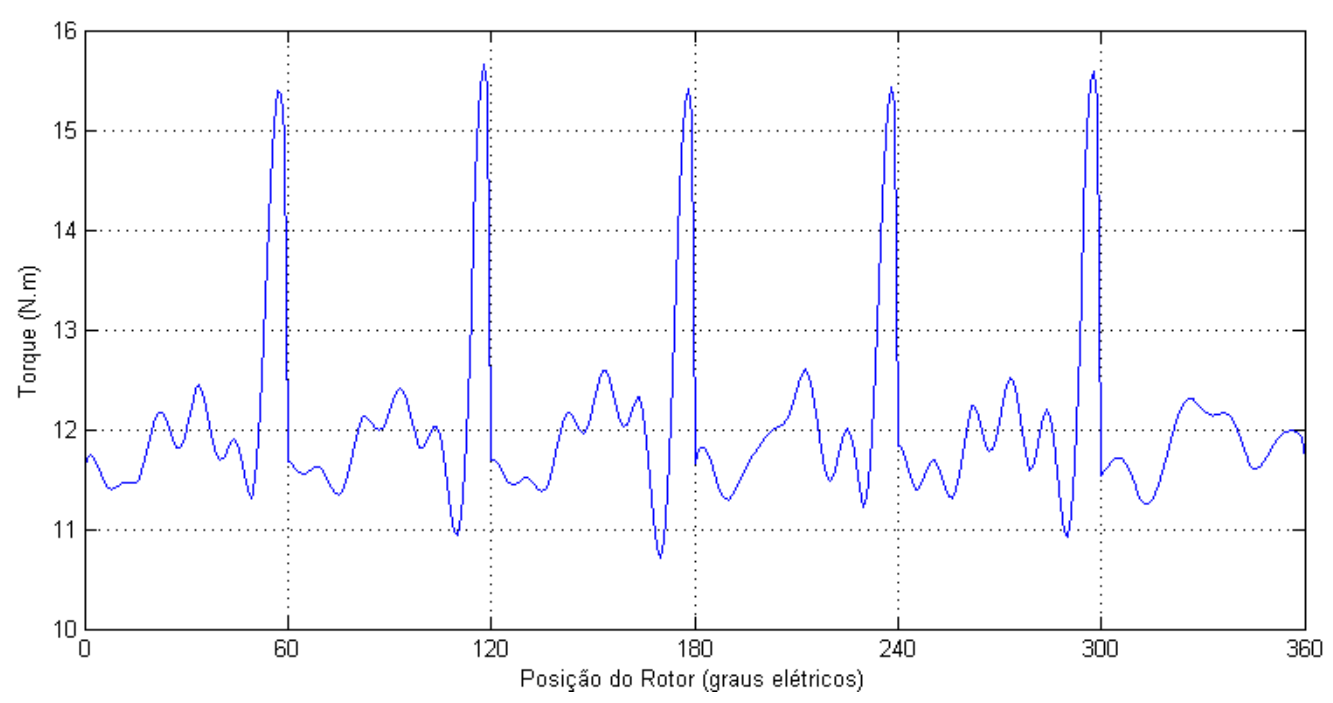

Figura 6.29 - Perfil do torque mútuo (20A).

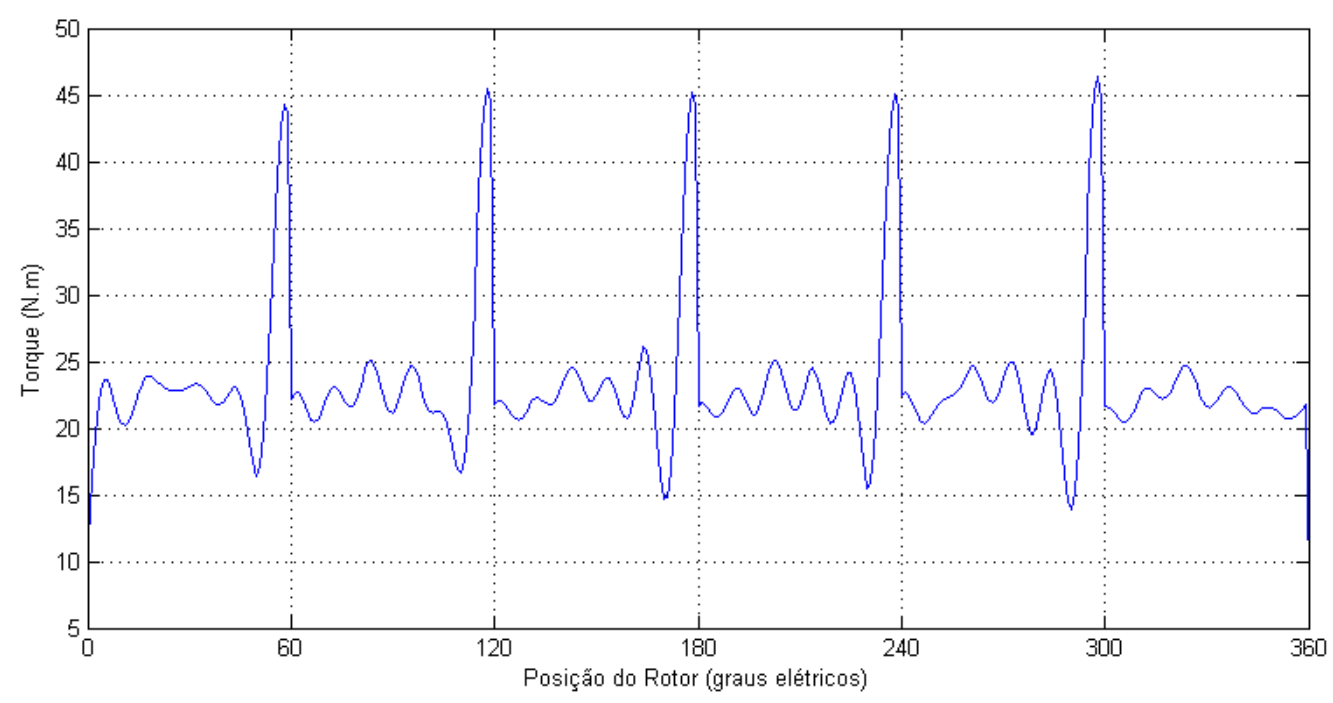


Figura 6.30 - Perfil do torque mútuo (30A).

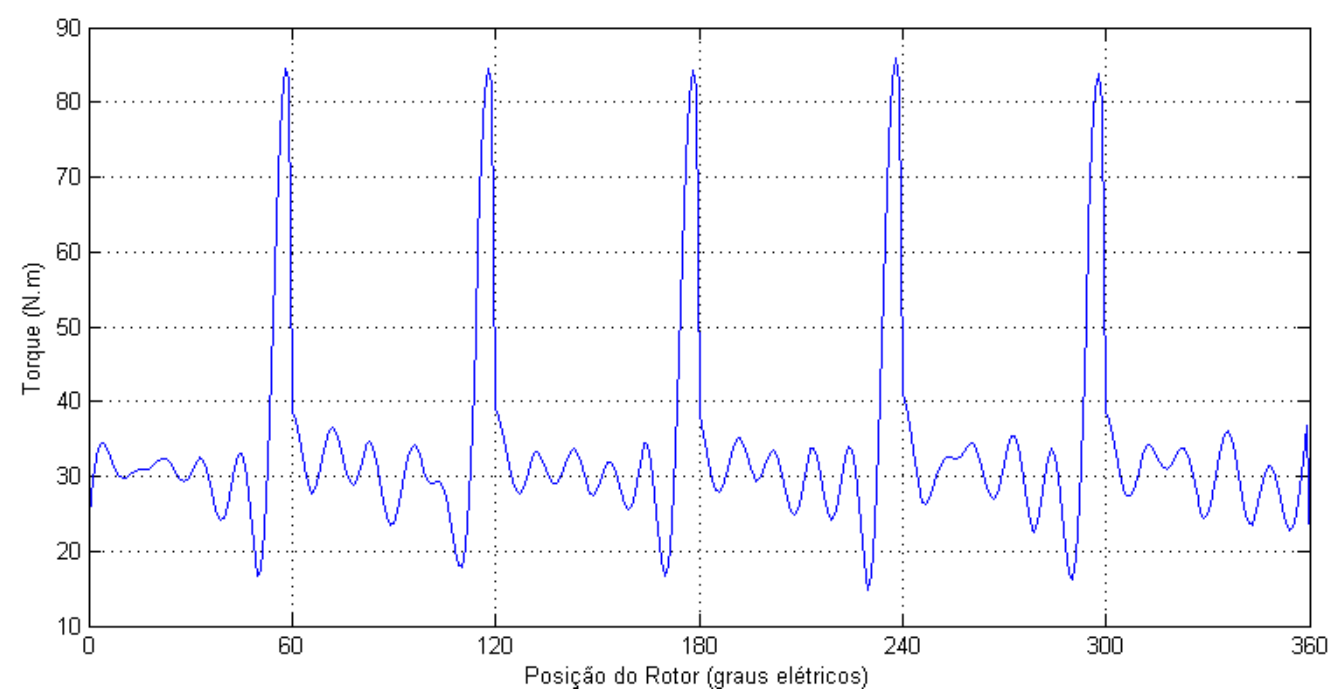

Figura 6.31 - Comparação Razão Torque/Corrente.

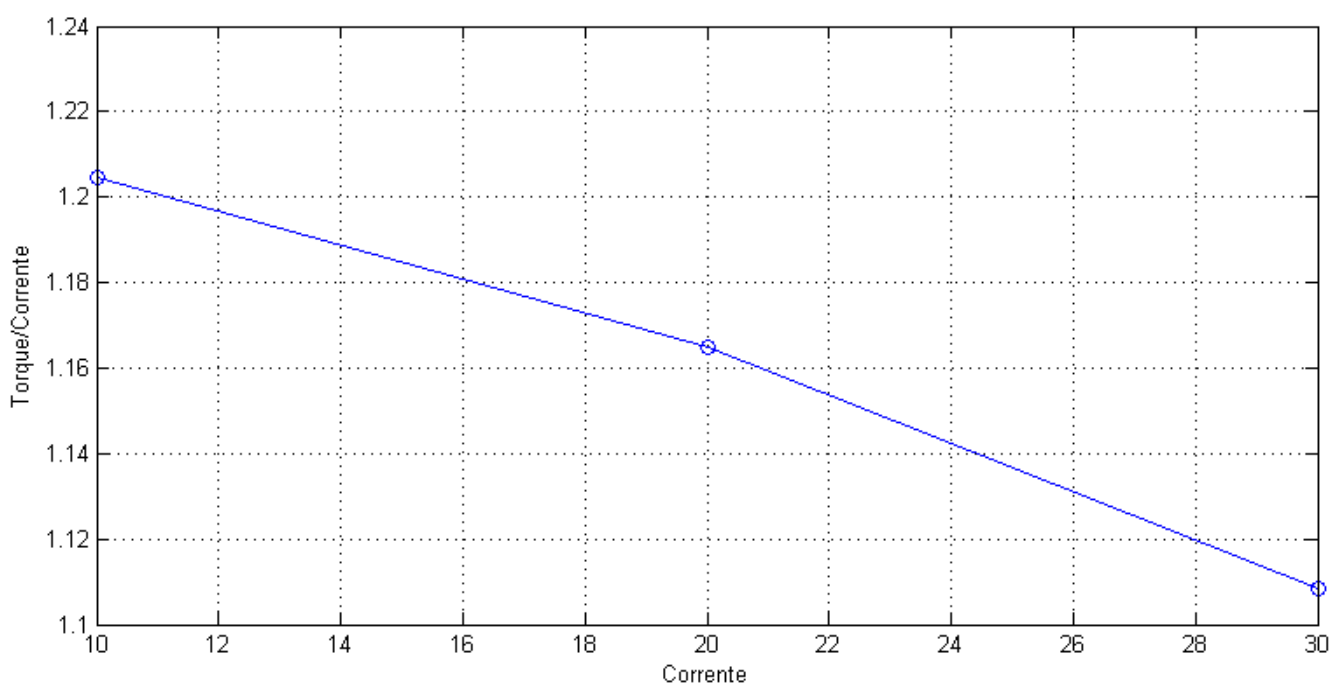

\subsubsection{Torque devido à Variação da Indutância}

O torque devido à variação da indutância é formulado pela Equação 6.3. Com os perfis de indutância apresentados na Seção 6.2.3, têm-se o perfil do torque devido à variação da indutância para cada condição de corrente apresentado da Figura 6.32 à Figura 6.34.

$$
T_{\text {Ind }}=\frac{1}{2} i^{2} \frac{d L}{d \theta}
$$


Figura 6.32 - Torque devido à variação da indutância (10A).

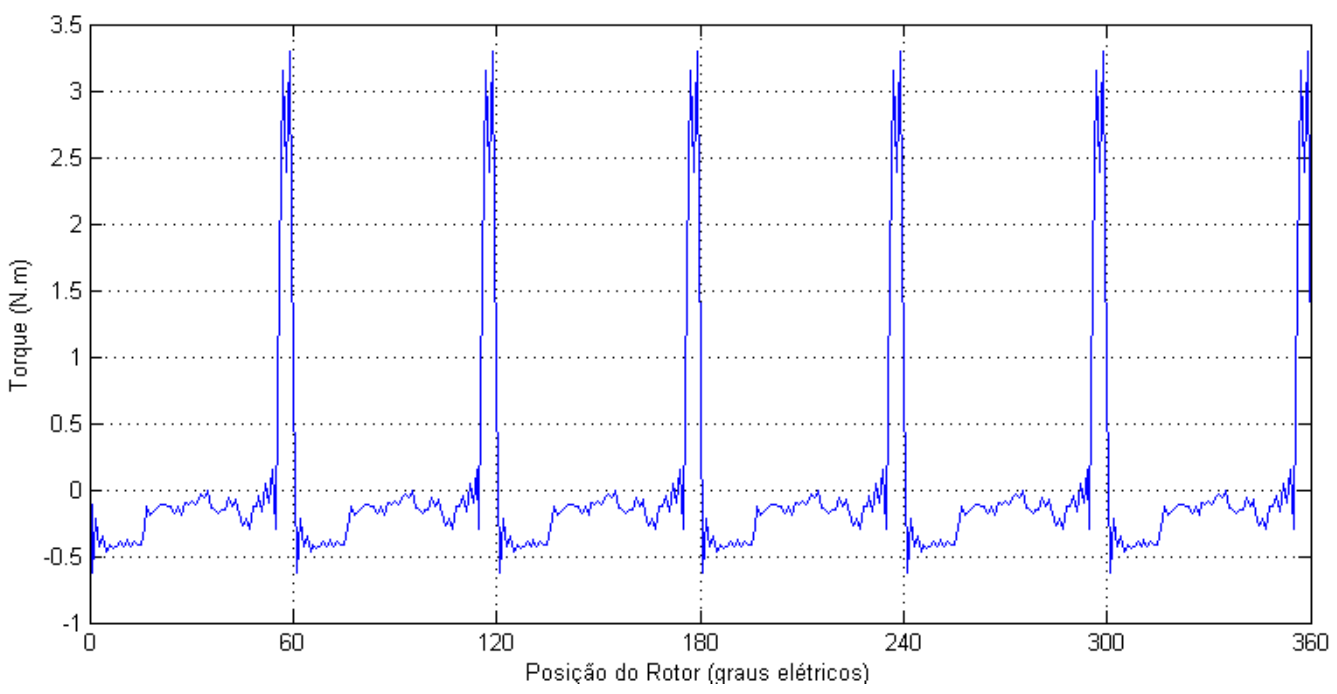

Figura 6.33 - Torque devido à variação da indutância (20A).

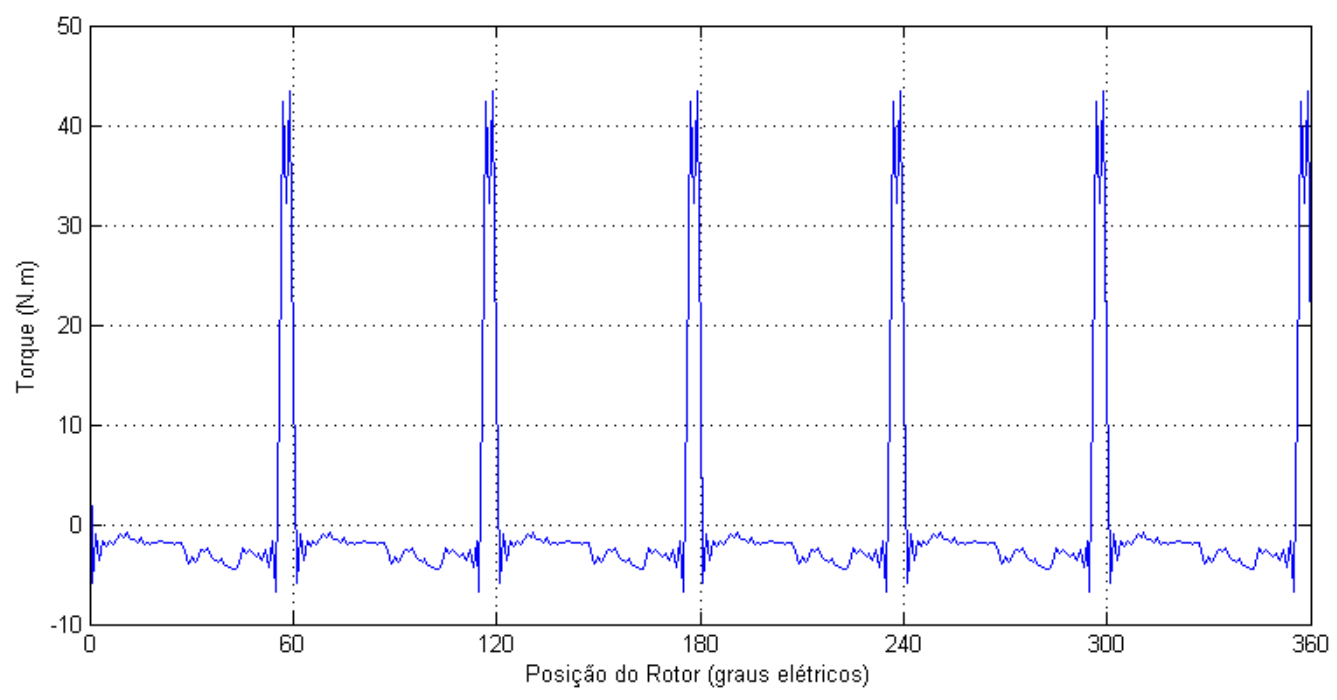

Figura 6.34 - Torque devido à variação da indutância (30A).

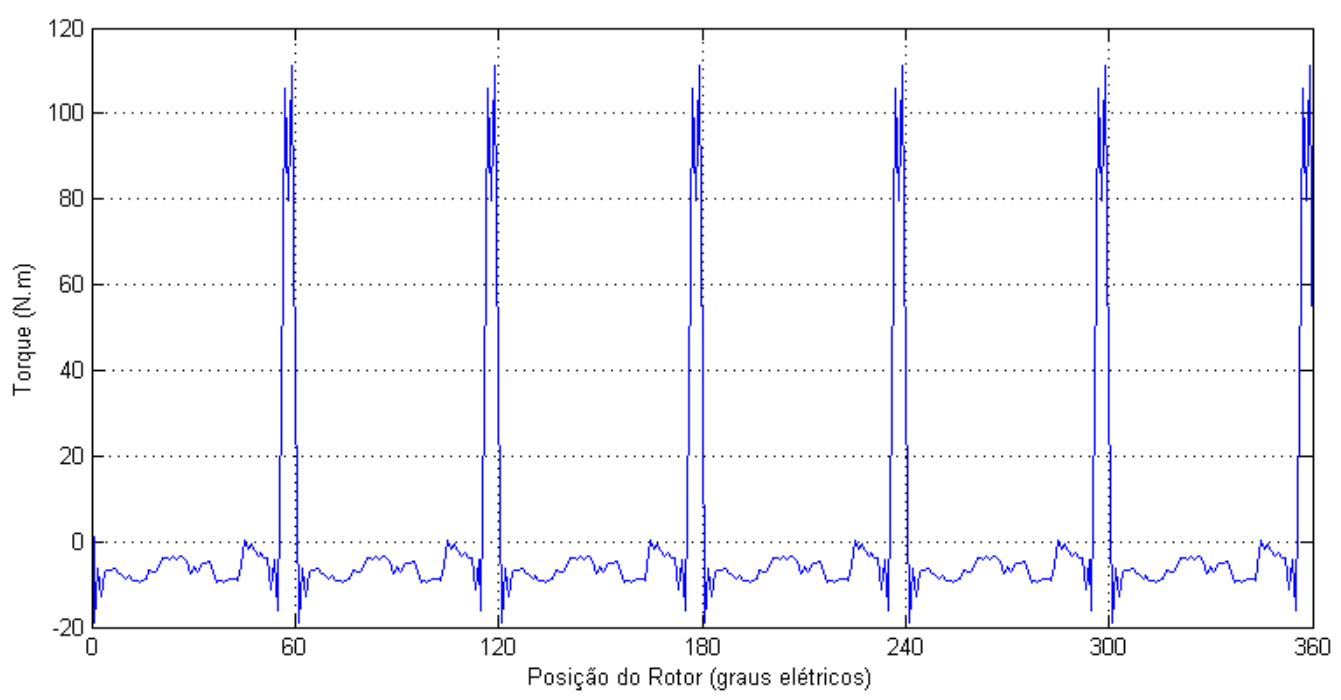


Os valores médio, máximo e mínimo do torque mútuo para cada condição de corrente são apresentados na Tabela 6.3.

Tabela 6.3 - Torque devido à variação da indutância.

\begin{tabular}{cccc}
\cline { 2 - 4 } & 10A & 20A & 30A \\
\hline \hline Máximo & 3,30 & 43,39 & 111,29 \\
Mínimo & $-0,62$ & $-6,72$ & $-18,80$ \\
Médio & 0,00 & 0,00 & 0,00
\end{tabular}

Notoriamente, os maiores picos do torque devido à variação da indutância ocorrem nos instantes de comutação de fase que, como explicado na Seção 6.2.3 ocorrem devido a variação repentina da permeabilidade e consequentemente da indutância.

A Figura 6.35 mostra como a razão torque/corrente varia com a corrente. Essa razão foi calculada com base na soma dos módulo dos valores do perfil de torque apresentado da Figura 6.32 à Figura 6.34 para cada condição de corrente.

Figura 6.35 - Comparação Razão Torque/Corrente.

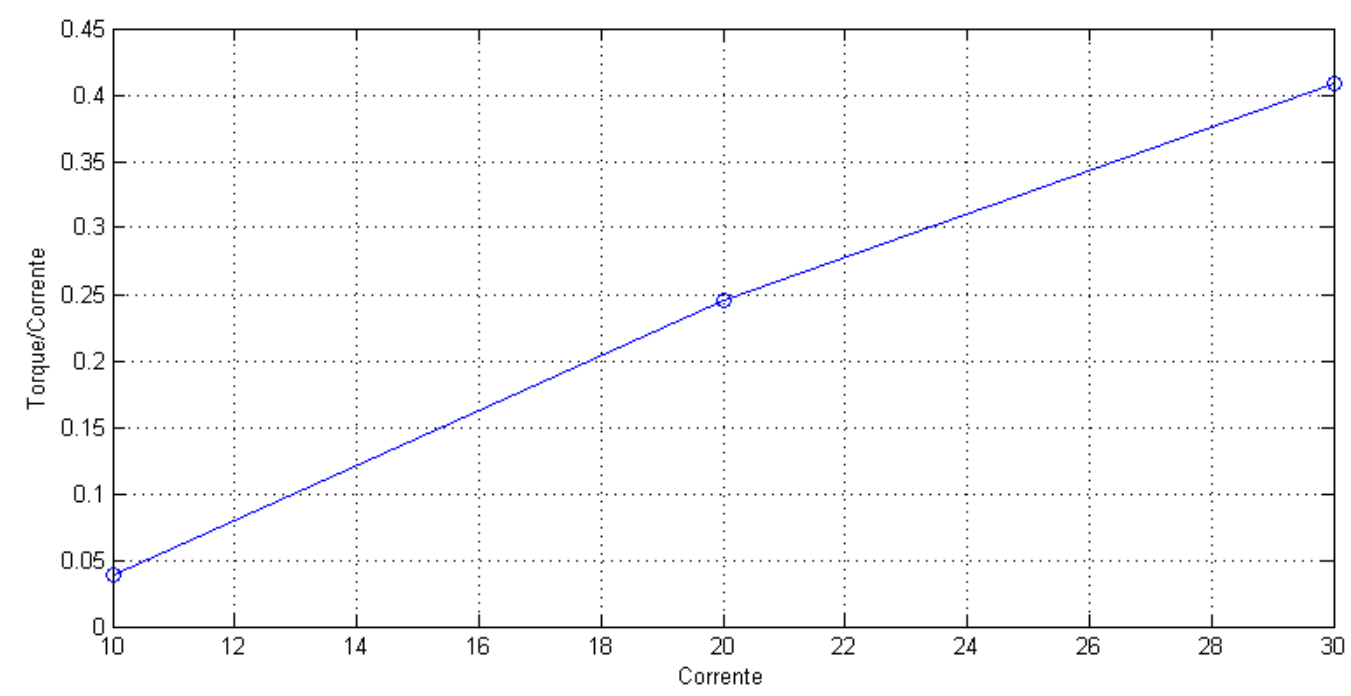

\subsubsection{Torque de borda}

Inicialmente, o torque de borda, cujas fontes de fluxo magnético são os ímãs permanentes do rotor, é avaliado para a máquina sem corrente. Como mencionado no Capítulo 3 o torque de borda nesse tipo de máquina tem comportamento oscilatório com frequência conhecida e para a máquina em estudo tem como frequência do primeiro harmônico o valor de 12 vezes a frequência do primeiro harmônico de um período elétrico. A Figura 6.36 apresenta o comportamento do torque de borda para a máquina sem corrente.

Existem três modos distintos para o cálculo dessa parcela do torque. O primeiro trata 
do emprego dos tensores de Maxwell para o cálculo do torque nas simulações dos modelos lineares com corrente em que apenas os ímãs são fonte de fluxo magnético - arquivos "modelo_PM.fem". No entanto, segundo os autores de (Chu; Zhu, 2013), o cálculo pelos tensores de Maxwell apresentam valores errôneos que não representam o comportamento do torque de borda uma vez que os valores de torque obtidos tem média diferente de zero. A justificativa para a média diferente de zero está relacionada ao acoplamento entre o campo dos ímãs permanentes e do campo das bobinas por meio da permeabilidade magnética, criando (virtualmente) uma saliência magnética que gira sincronamente com o rotor.

Figura 6.36 - Torque de borda (sem corrente).

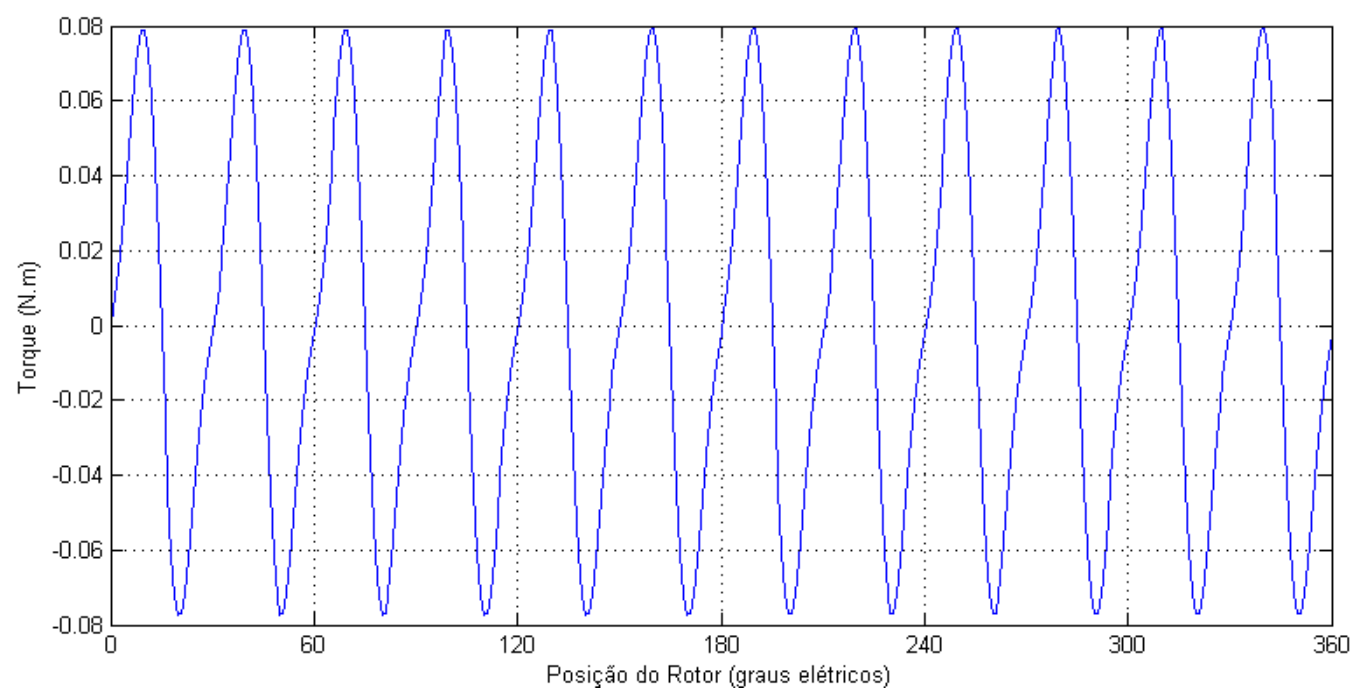

O segundo modo trata do emprego do método do trabalho virtual, onde o torque é calculado por meio da variação da coenergia do sistema. Os mesmos autores de (Chu; Zhu, 2013) afirmam ser esse o método mais confiável para o cálculo do torque de borda, contornando os problemas apresentados pelo métodos dos tensores de Maxwell.

O terceiro modo trata do cálculo do torque de borda por meio das Equações 3.4 e 6.1 uma vez que, obtidos os valores do torque total, torque mútuo e torque devido à variação da indutância, calcula-se o torque de borda isolando esse termo nas Equações 3.4 ou 6.1. No entanto, como o método da permeabilidade fixa é utilizado para se estimar o valor das componentes, pode ocorrer do cálculo acima resultar em um perfil de torque de borda com média diferente de zero, dependendo do refinamento da malha.

Nas subseções seguintes são apresentados os resultados para os três modos empregados para o cálculo do torque de borda. 


\subsection{Tensores de Maxwell}

O perfil do torque de borda obtido pelo método dos tensores de Maxwell para cada condição de corrente está apresentado na Figura 6.37, válidos para o método convencional e para o método melhorado. Como mencionado, o perfil de torque de borda obtido pelo método dos tensores de Maxwell apresentam média diferente de zero.

A Tabela 6.4 expõe os valores máximos, mínimos e médio do perfil de torque calculado para cada condição de corrente.

Tabela 6.4 - Torque de borda (Maxwell).

\begin{tabular}{cccc}
\cline { 2 - 4 } & 10A & 20A & 30A \\
\hline \hline Máximo & 0,019 & $-0,085$ & $-0,094$ \\
Mínimo & $-0,235$ & $-0,547$ & $-0,774$ \\
Médio & $-0,096$ & $-0,359$ & $-0,482$ \\
\hline \hline
\end{tabular}

Figura 6.37 - Torque de borda (Maxwell - MPF).

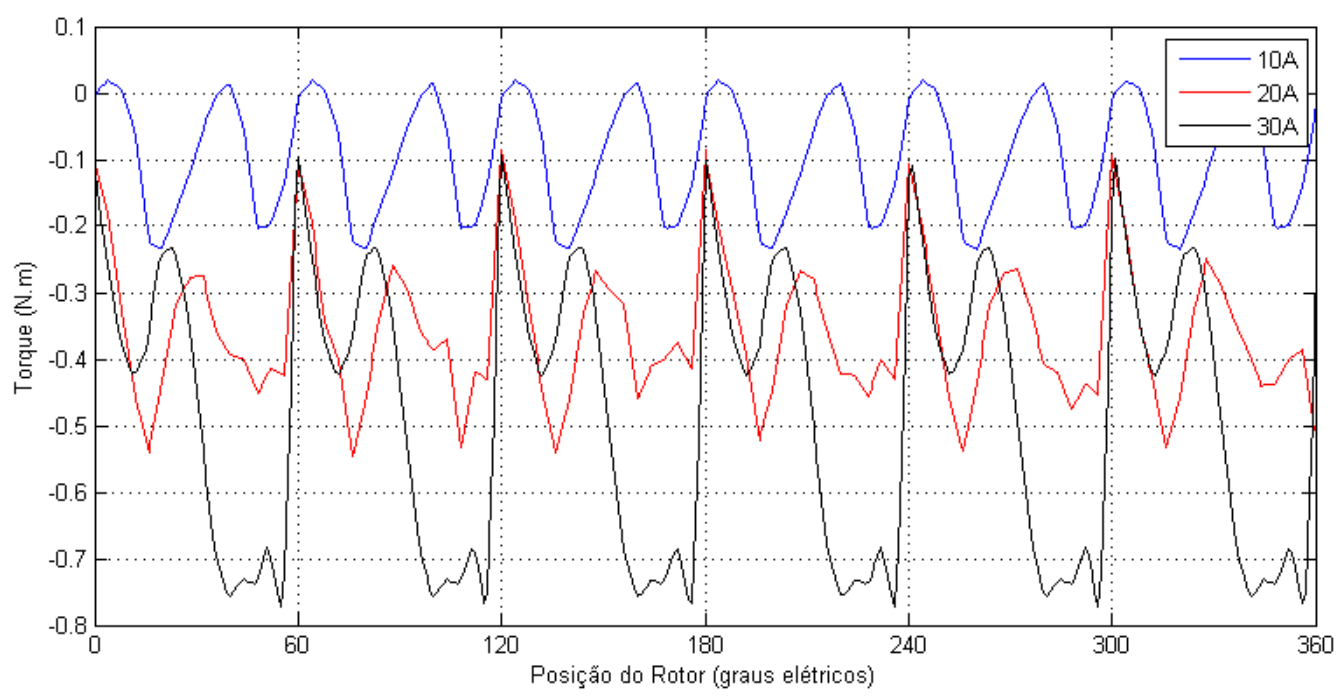

\subsection{Trabalho Virtual}

O perfil da coenergia total do sistema para cada uma das condições de corrente é apresentado na Figura 6.38 para o método convencional e, na Figura 6.39 para o método melhorado. Já o perfil do torque de borda obtido pelo método do trabalho virtual é apresentado na Figura 6.40 para o método convencional e, na Figura 6.41 para o método melhorado.

O fato mais curioso para essa máquina é a alteração da forma de onda do torque de borda com a máquina alimentada quando comparado com o torque de borda da máquina sem corrente. 
Figura 6.38 - Perfil da coenergia total do sistema (MPF Convencional).

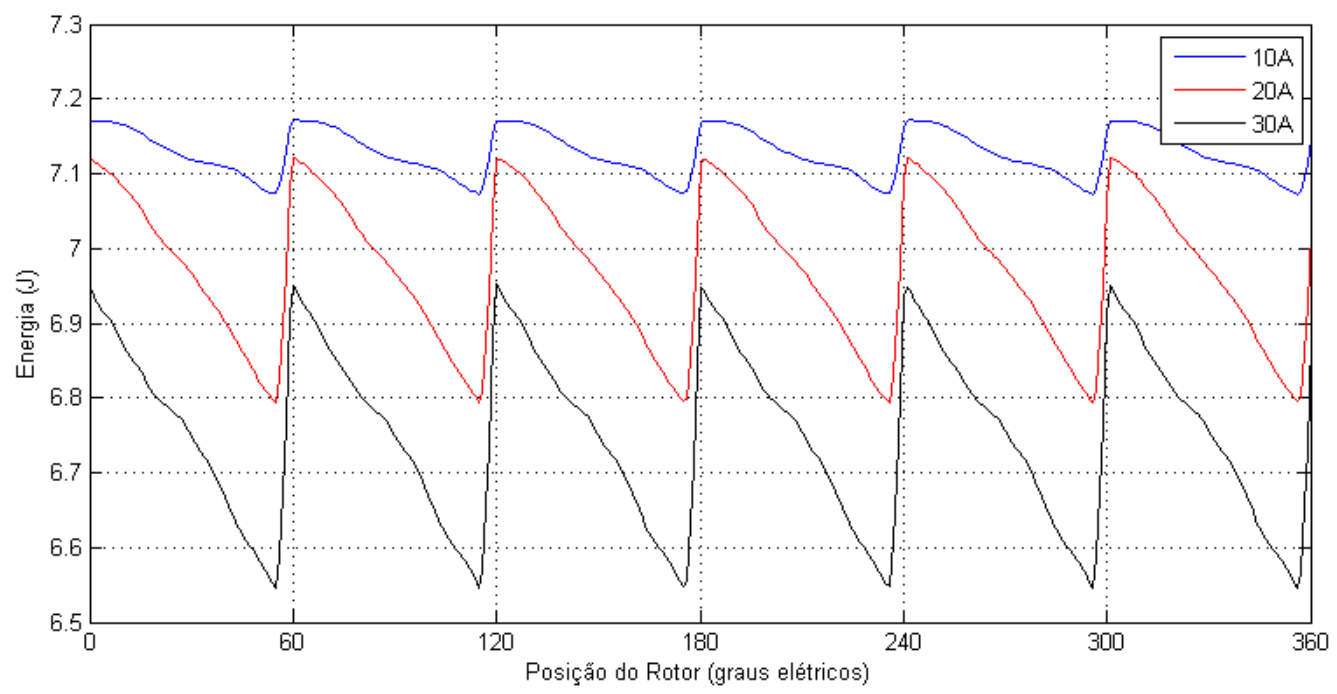

Figura 6.39 - Perfil da coenergia total do sistema (MPF Melhorado).

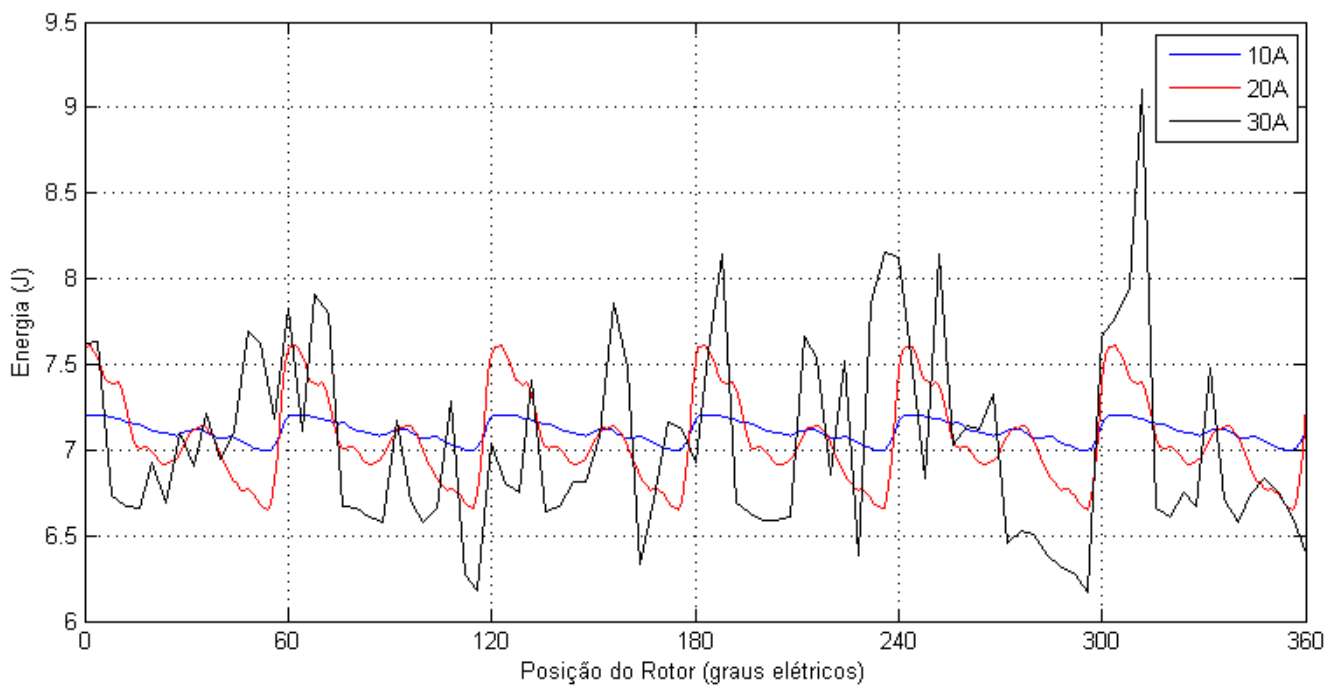

A Figura 6.42 mostra como a razão torque/corrente varia com a corrente. Essa razão foi calculada com base na soma dos módulo dos valores do perfil de torque apresentado da Figura 6.40 à Figura 6.41 para cada condição de corrente.

A Tabela 6.5 expõe os valores máximos, mínimos e médio do perfil de torque calculado para cada condição de corrente. Nota-se, que para todas as condições de corrente o valor médio é igual a zero. 
Figura 6.40 - Torque de borda (Trabalho Virtual - MPF Convencional).

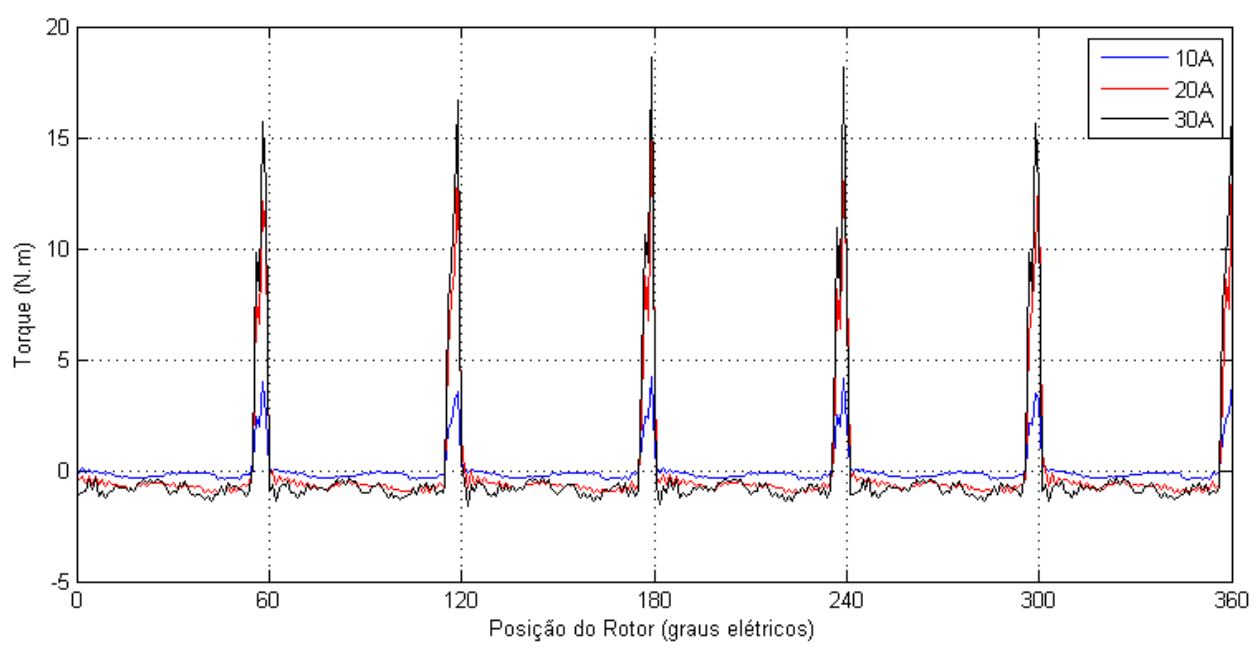

Figura 6.41 - Torque de borda (Trabalho Virtual - MPF Melhorado).

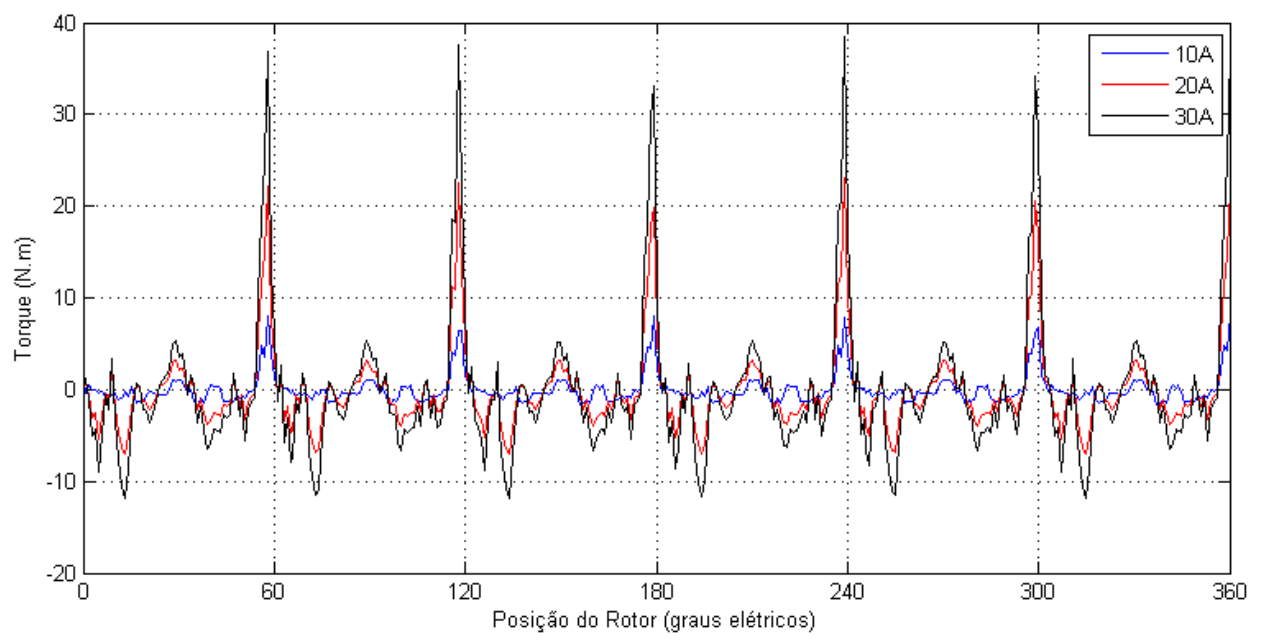

Figura 6.42 - Comparação Razão Torque/Corrente.

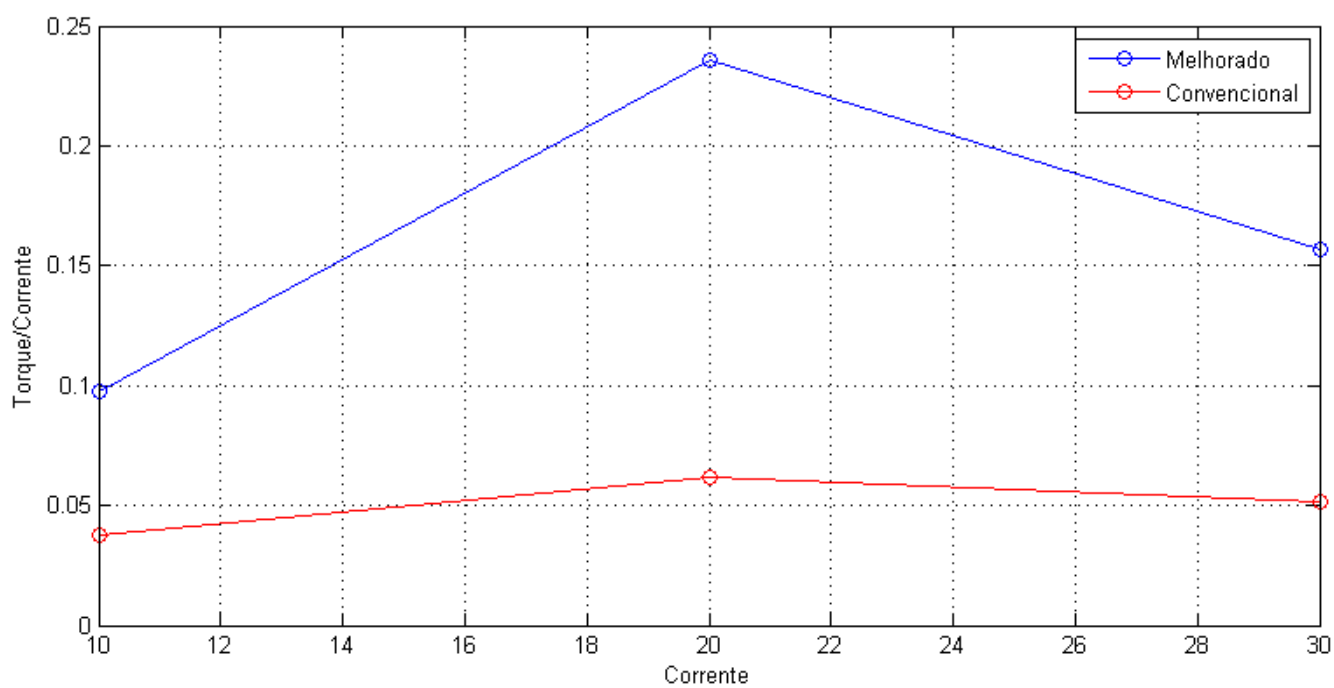


Tabela 6.5 - Torque de borda (Trab. Virtual).

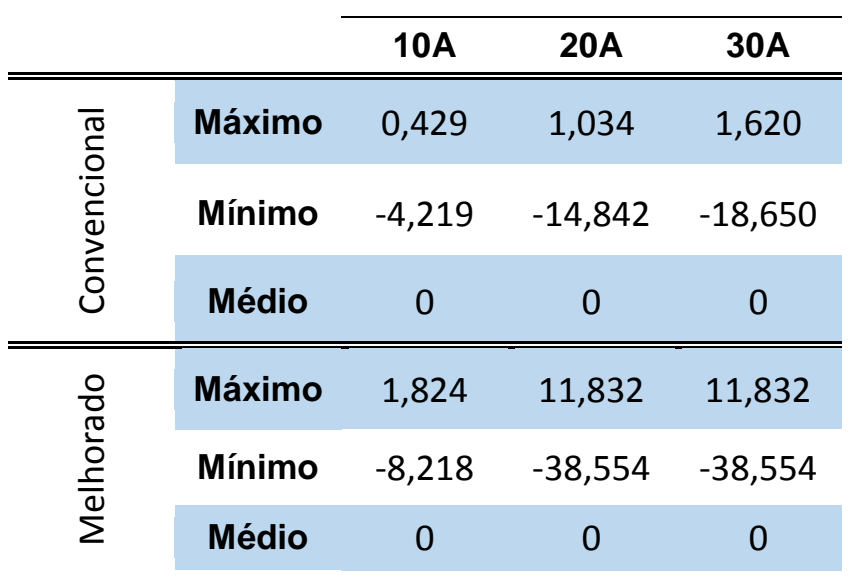

\subsection{Diferença}

Obtidos os valores do torque total, torque mútuo e torque devido à variação da indutância, calcula-se o torque de borda isolando esse termo nas Equações 3.4 ou 6.1. O perfil de torque de borda obtido, usando tanto o torque mútuo estimado pelo método da permeabilidade fixa convencional como o torque mútuo estimado pelo método melhorado é apresentado na Figura 6.43.

A Tabela 6.6 mostra os valores máximo, mínimo e médio do torque calculado para cada condição de corrente.

Figura 6.43 - Torque de borda pela diferença dos torques (MPF).

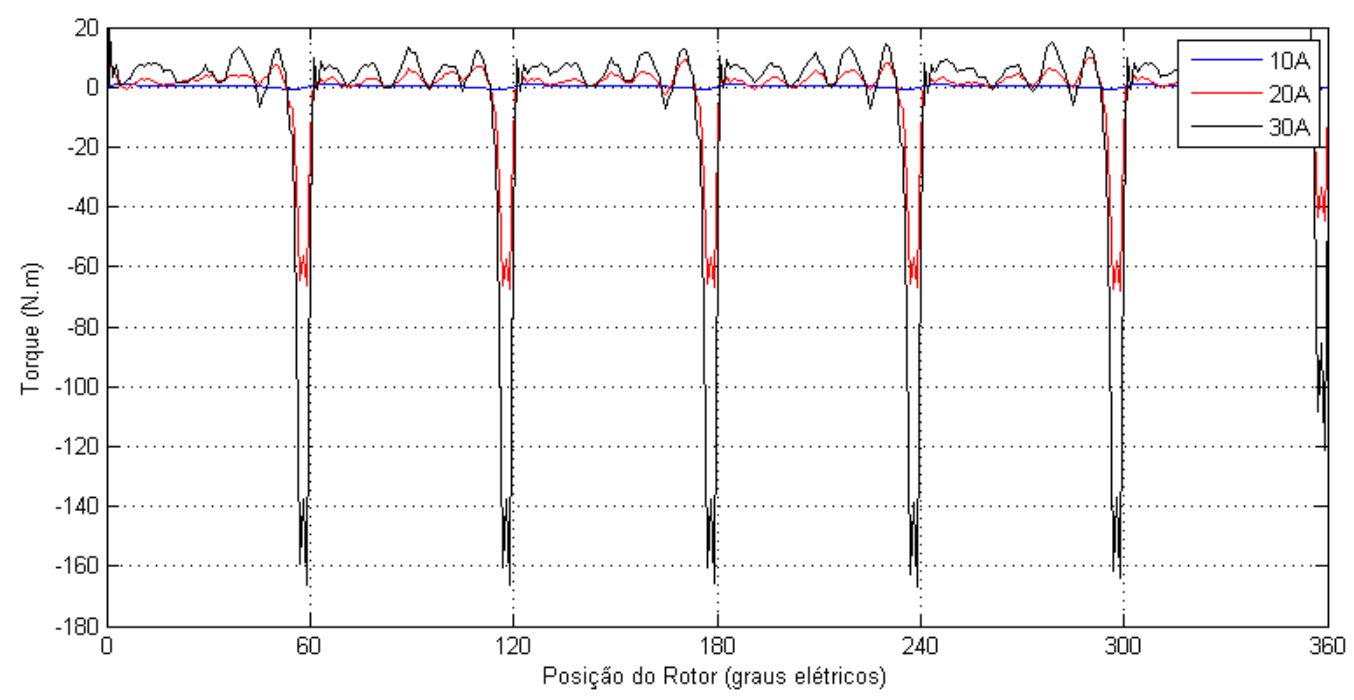


Tabela 6.6 - Torque de borda (Diferença).

\begin{tabular}{cccc}
\cline { 2 - 4 } & 10A & 20A & 30A \\
\hline \hline Máximo & 0,842 & 12,922 & 19,708 \\
Mínimo & $-0,770$ & $-67,741$ & $-166,705$ \\
Médio & 0,246 & $-1,542$ & $-5,047$ \\
\hline \hline
\end{tabular}

\subsubsection{Comparação: $T_{\text {Total }}$ vs $T_{\text {Ind }}+T_{\text {Rel }}+T_{\text {Mútuo }}$}

Um comparativo entre o torque calculado na simulação não linear $\left(T_{\text {Total }}\right)$ - Figura 6.24 à Figura 6.26 - e a soma das parcelas obtidas nas subseções anteriores são comparados da Figura 6.44 à Figura 6.46. A Tabela 6.7 mostra os valores máximo, mínimo e médio do torque total e do torque estimado.

Figura 6.44 - Comparação do perfil de torque (10A).

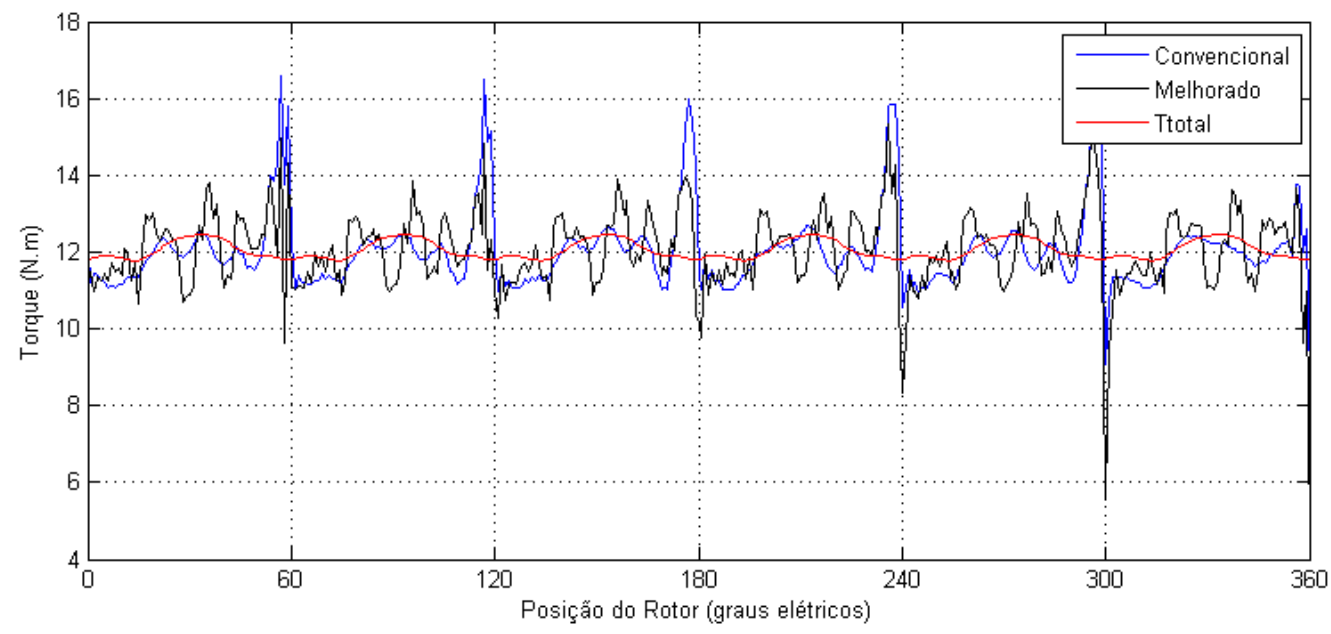

Figura 6.45 - Comparação do perfil de torque (20A).

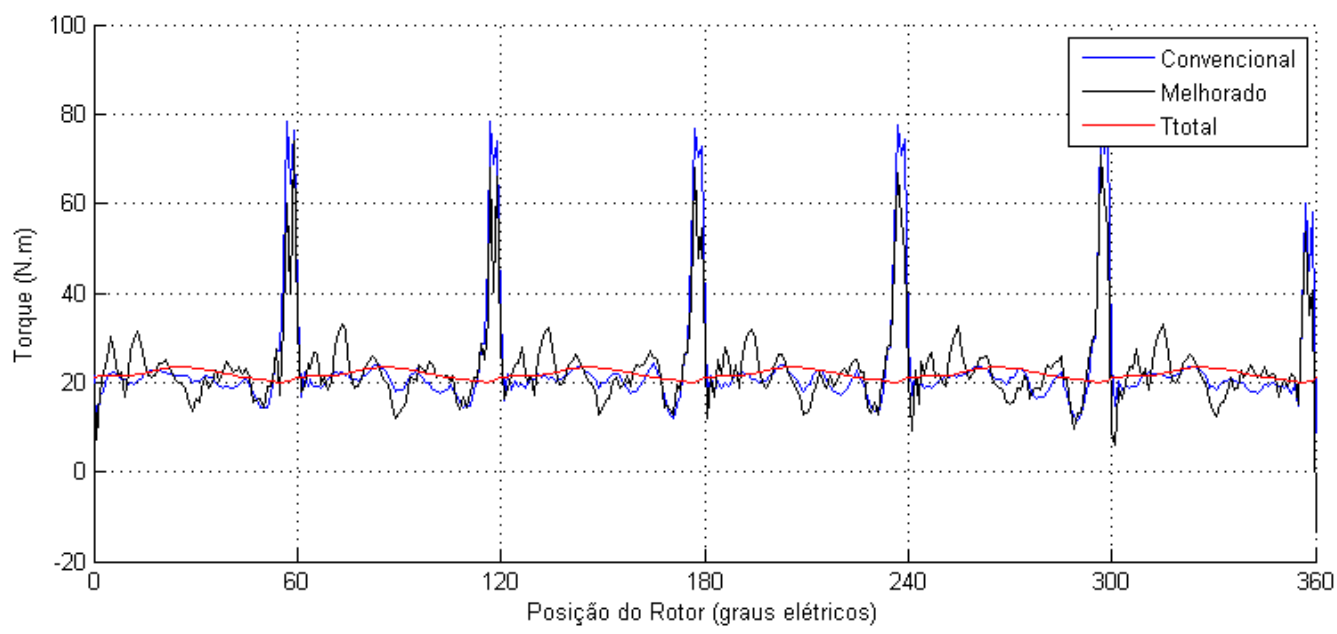


Figura 6.46 - Comparação do perfil de torque (30A).

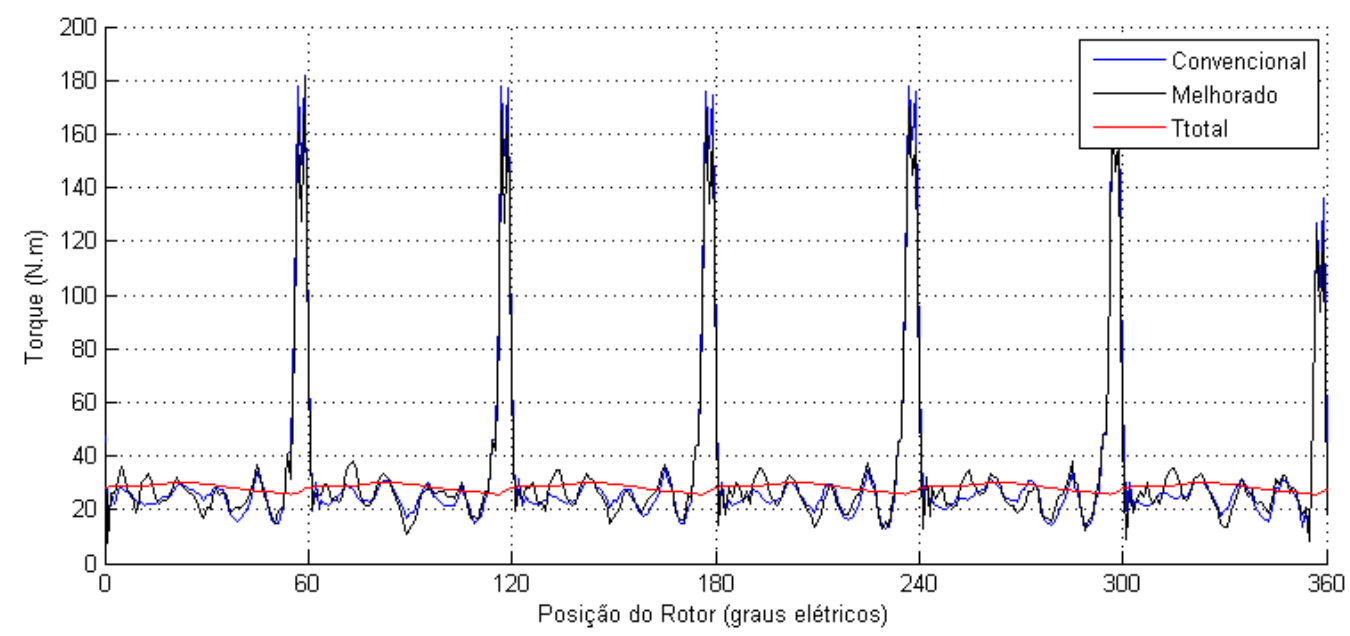

Assim como na Subseção 6.2.4.2, os valores médios de torque estimado foram sensivelmente afetados pelos picos presentes na força contra eletromotriz. De modo geral, o os valores de torque produzidos pelos métodos convencional e melhorado são muito próximos, não trazendo benefícios claros ao se optar por um deles.

Tabela 6.7 - Torque: Comparação.

\begin{tabular}{|c|c|c|c|c|}
\hline & \\
\hline & & $10 \mathrm{~A}$ & $20 A$ & $30 \mathrm{~A}$ \\
\hline \multirow{3}{*}{$\begin{array}{l}\bar{\pi} \\
\stackrel{0}{0} \\
\vdash\end{array}$} & Máximo & 12,45 & 23,38 & 30,06 \\
\hline & Mínimo & 11,78 & 19,90 & 25,71 \\
\hline & Médio & 12,05 & 21,80 & 28,31 \\
\hline \multirow{3}{*}{ 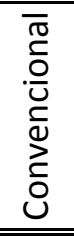 } & Máximo & 16,61 & 81,55 & 181,71 \\
\hline & Mínimo & 8,40 & 8,77 & 7,96 \\
\hline & Médio & 12,05 & 23,35 & 33,36 \\
\hline \multirow{3}{*}{$\begin{array}{l}\frac{0}{0} \\
\frac{\pi}{0} \\
\frac{0}{0} \\
\sum\end{array}$} & Máximo & 16,50 & 73,86 & 181,14 \\
\hline & Mínimo & 4,27 & $-13,41$ & 7,50 \\
\hline & Médio & 12,06 & 23,39 & 33,40 \\
\hline
\end{tabular}




\section{Capítulo 7}

\section{Conclusões}

Tendo em vista que nem todos os softwares de simulação em elementos finitos têm o Método da Permeabilidade Fixa implementado e, visando o emprego do método melhorado proposto por (Chu; Zhu, 2013), o uso do FEMM se destaca dentre inúmeros softwares por apresentar duas grandes vantagens que o tornam flexível e adaptável ao problema. Essas duas vantagens estão bem descritas na Seção 5.1. Além do FEMM, foi necessário desenvolver um algoritmo responsável pelo pós-processamento dos resultados obtidos com as simulações em elementos finitos e emprego dos métodos da permeabilidade fixa convencional e melhorado. Uma visão mais detalhada sobre o algoritmo desenvolvido e as considerações empregadas se encontra na Seção 5.2. A validação do mesmo é apresentada na Seção 6.1 ao se comparar os resultados obtidos em (Chu; Zhu, 2013, 2013) com os resultados para uma máquina semelhante - vide Figura 6.1. Dada a compatibilidade entre os resultados, o emprego do software é validado, cumprindo com as propostas dos métodos empregados.

No que diz respeito à forma de onda do fluxo concatenado, foi possível notar alterações consideráveis quando comparado com o fluxo concatenado para a máquina sem corrente tanto nos valores de pico, como no comportamento das regiões de transição (acréscimo ou decréscimo de fluxo concatenado). O fluxo, que para a máquina em vazio, apresenta comportamento suave passa a apresentar alterações de maneira a deformar a sua forma de onda. Portanto, essa degradação afeta diretamente a forma de onda da força contra eletromotriz. As principais oscilações, tanto do fluxo concatenado como da força contra eletromotriz, se encontram nos pontos de comutação de fase. Três pontos de oscilação são bem notáveis, 
sendo dois deles relacionados às entrada e saída de operação de uma fase; o outro é relacionado a comutação entre as outras duas fases.

As oscilações na componente mútua do torque eletromagnético, tomando por base a estratégia de acionamento empregada, são reflexo das oscilações presentes na forma de onda da força contra eletromotriz.

O perfil da indutância de linha apresentado na Seção 6.2.3 demonstra a variação nos valores da indutância a cada ciclo de $60^{\circ}$ elétricos, que coincide com a estratégia de alimentação das bobinas, onde a cada $60^{\circ}$ elétricos ocorre a comutação de duas das três fases da máquina. No início do intervalo é possível notar valores maiores de indutância, enquanto os menores valores se encontram no fim do intervalo de $60^{\circ}$ elétricos, demonstrando relação inversamente proporcional a componente direta da corrente apresentada em (Monteiro et al., 2012). Como explicado na Seção 6.2.3, a queda no valor da indutância de fase é justificada pelo alinhamento dos fluxos dos ímãs e bobinas à medida que o rotor gira. $\mathrm{O}$ alinhamento dos fluxos afeta diretamente a permeabilidade do meio, e consequentemente, as parcelas de indutância de entreferro e de indutância de dispersão de ranhura, de maneira a reduzir seus valores.

A variação no valor da indutância de fase provoca um torque indesejado na máquina, como avaliado na Subseção 6.2.4.3. Os picos no torque devido a variação da indutância ocorrem nos pontos de comutação entre fases, em que há a transição dos valores de indutância, do mínimo para o máximo.

A avaliação do torque de borda é feita na Subseção 6.2.4.4 por três métodos diferentes. A avaliação por meio dos tensores de Maxwell apresenta valores médios diferentes de zero, assim como enunciado em (Chu; Zhu, 2013, 2013), sendo considerado valores errôneos para essa parcela do torque. A segunda avaliação é feita por meio do trabalho virtual, que segundo (Chu; Zhu, 2013, 2013), é o método mais apropriado para descrever essa parcela do torque. O cálculo por meio do trabalho virtual foi empregado para o método convencional e para o melhorado. Tanto para o método convencional como para o método melhorado, resultou-se em um perfil de torque de borda diferente do conceitual e bem conhecido. Se comparados os perfis obtidos com os perfis apresentados nos artigos citados durante o trabalho, nota-se uma discrepância grande. Essa discrepância não invalida os resultados apresentados, mas levanta dúvidas sobre o emprego do método da permeabilidade fixa, convencional e melhorado, para a análise dessa máquina e a certeza sobre o emprego do trabalho virtual como método para o cálculo do torque de borda.

A soma das parcelas e a comparação dessa com o torque total da máquina é feita na 
Subseção 6.2.4.5. Em termos de valores médios é possível notar a proximidade entre os métodos e o torque total para as condições de 10, 20 e 30A. Como a principal parcela do torque é o torque mútuo, e esse apresenta picos exagerados nas regiões de comutação de fase, o valor médio da soma dos torques é influenciada por tais picos, tornando a comparação entre o torque total e o estimado discrepante. De modo geral, os valores de torque produzidos pelos métodos convencional e melhorado são muito próximos, não trazendo benefícios claros ao se optar por um deles.

Segundo o que é apresentado na Seção 4.3 e em (Chu; Zhu, 2013), o método da permeabilidade fixa melhorado apresenta redução na quantidade de energia armazenada no estator quando da simulação linear com os ímãs permanentes como fonte de fluxo magnético. No entanto, a quantidade de energia só será menor caso a posição $\theta$ do rotor, para o ponto de operação da máquina, apresente alinhamento entre o fluxo proveniente dos ímãs e o fluxo gerado pelas bobinas do estator, i.e., a intensidade magnética resultante seja a soma das intensidades magnéticas individuais no modelo linear. Caso contrário a posição $\theta$ do rotor apresente oposição entre o fluxo proveniente dos ímãs e o fluxo gerado pelas bobinas do estator, i.e., a intensidade magnética resultante seja a diferença das intensidades magnéticas individuais no modelo linear, a quantidade de energia será maior.

\section{Sugestões para Continuação do Trabalho}

Dado que na simulação magnetostática foram consideradas correntes ideais e quadradas no acionamento a seis pulso, portanto com forma descontínua e, levando-se em conta que a discretisação adotada é finita e de passo fixo, uma análise considerando uma discretisação de passo variável em torno dos pontos de comutação pode trazer resultados mais acurados para as variáveis.

Uma segunda perspectiva é a busca de meios para a aquisição de dados a fim de confrontá-los com os dados simulados, permitindo, dessa forma, uma melhor compreensão dos efeitos da saturação no pacote de lâminas do estator para a máquina em estudo e, consequentemente elucidar soluções para o aprimoramento do método da permeabilidade fixa.

Tendo em vista que o método da permeabilidade fixa - convencional e melhorado foi aplicado em máquinas com forma de onda da força contra eletromotriz senoidal, e a priori, aceito como bom estimador para as componentes do torque eletromagnético, o emprego do 
método tanto para uma máquina de acionamento senoidal como para uma máquina de acionamento a seis pulsos - por exemplo, uma máquina de 12 ranhuras e 10 polos - seria de grande valia uma vez que, abre-se a possibilidade de comparação entre o comportamento dos perfis de coenergia na máquina para diferentes acionamentos, a variação da indutância, a variação da forma de onda do fluxo concatenado, a variação da força contra eletromotriz e o perfil do torque de borda. 


\section{Referências Bibliográficas}

ARELLANO-PADILLA, J. et al. Inductance characteristics of PMSMs and their impact on saliency-based sensorless control. Proceedings of 14th International Power Electronics and Motion Control Conference EPE-PEMC 2010, p. 1-9, set. 2010.

AZAR, Z.; ZHU, Z.; OMBACH, G. Influence of Electric Loading and Magnetic Saturation on Cogging Torque, Back-EMF and Torque Ripple of PM Machines. Magnetics, IEEE Transactions on, v. 48, n. 10, p. 2650-2658, 2012.

AZAR, Z.; ZHU, Z. Q.; OMBACH, G. Torque-speed performance analysis of fractional slot PM machines having concentrated windings using alternate methods. 6th IET International Conference on Power Electronics, Machines and Drives (PEMD 2012), p. B73-B73, 2012.

BIANCHI, N.; BOLOGNANI, S. Magnetic models of saturated interior permanent magnet motors based on finite element analysis. Conference Record of 1998 IEEE Industry Applications Conference. Thirty-Third IAS Annual Meeting (Cat. No.98CH36242), v. 1, p. 27-34, 1998.

BIANCHI, N.; BOLOGNANI, S. Design techniques for reducing the cogging torque in surfacemounted PM motors. IEEE Transactions on Industry Applications, v. 38, n. 5, p. 1259-1265, set. 2002.

CHABCHOUB, M.; SALAH, I. BEN. PMSM cogging torque reduction: Comparison between different shapes of magnet. ... (REVET), 2012 First ..., p. 0-5, 2012.

CHAU, K. T.; CHAN, C. C. Overview of Permanent-Magnet Brushless Drives for Electric and Hybrid Electric Vehicles. IEEE Transactions on Industrial Electronics, v. 55, n. 6, p. 22462257, jun. 2008.

CHU, W. Q.; ZHU, Z. Q. Average Torque Separation in Permanent Magnet Synchronous Machines Using Frozen Permeability. IEEE Transactions on Magnetics, v. 49, n. 3, p. $1202-$ 1210, mar. 2013.

CHU, W. Q.; ZHU, Z. Q. On-Load Cogging Torque Calculation in Permanent Magnet Machines. IEEE Transactions on Magnetics, v. 49, n. 6, p. 2982-2989, jun. 2013. 
FUCHS, E. F.; ROESLER, D. J.; KOVACS, K. P. Aging of Electrical Appliances Due to Harnmonics of the Power System's Voltage. IEEE Transactions on Power Delivery, v. 1, n. 3, p. 301-307, 1986.

GIERAS, J. F.; WING, M. Permanent magnet motor technology: design and applications. [S.I.] CRC Press, 2002. v. 113p. 590

HANSELMAN, D. C. Brushless Permanent-Magnet Motor Design. [S.I.] Mcgraw-Hill, 1994. p. 191

IERUSALIMSCHY, R.; CELES, W.; FIGUEIREDO, L. H. LUA. Disponível em: $<$ http://www.lua.org/>. Acesso em: 26 jan. 2013.

ISLAM, M. S. et al. Design Considerations of Sinusoidally Excited Permanent-Magnet Machines for Low-Torque-Ripple Applications. IEEE Transactions on Industry Applications, v. 41, n. 4, p. 955-962, jul. 2005.

MEEKER, D. C. . Finite Element Method Magnetics, 2012. Disponível em: $<$ http://www.femm.info>

MILLER, T. J. E.; HENDERSOT JR, J. R. Design of brushless permanent-magnet motors. [S.I.] Oxford University Press, 1995. p. 584

MIYAMASU, M.; AKATSU, K. Efficiency comparison between Brushless dc motor and Brushless AC motor considering driving method and machine design. IECON 2011 - 37th Annual Conference of the IEEE Industrial Electronics Society, p. 1830-1835, nov. 2011.

MONTEIRO, J. R. B. A. Transformação DQ não senoidal para máquinas síncronas com ímã permanente no rotor. [S.I.] Escola de Engenharia de São Carlos - USP, 2002.

MONTEIRO, J. R. B. A. et al. Electromagnetic torque ripple and copper losses reduction in permanent magnet synchronous machines. European Transactions on Electrical Power, $\mathrm{v}$. 22, n. 5, p. 627-644, 10 jul. 2012.

MSDN. Introduction to ActiveX Controls. Disponível em: <http://msdn.microsoft.com/enus/library/aa751972(VS.85).aspx>. Acesso em: 26 jan. 2013.

SCHMIDT, E.; SUSIC, M. Parameter evaluation of permanent magnet synchronous machines with tooth coil windings using the frozen permeabilities method with the finite element analyses. 25th IEEE Canadian Conference on Electrical \& Computer Engineering (CCECE), 2012.

SUNG, S.; PARK, S.; JANG, G. Cogging torque of brushless DC motors due to the interaction between unevenly magnetized permanent magnet and teeth chamfering. APMRC, 2010 Digest, p. 1-2, 2010.

TANGUDU, J. K. et al. Lumped parameter magnetic circuit model for fractional-slot concentrated-winding interior permanent magnet machines. 2009 IEEE Energy Conversion Congress and Exposition, p. 2423-2430, set. 2009.

TANGUDU, J. K. et al. Segregation of torque components in fractional-slot concentratedwinding interior PM machines using frozen permeability. 2009 IEEE Energy Conversion Congress and Exposition, p. 3814-3821, set. 2009. 
TEIXEIRA, F. H. P. Metodologia para projeto, construção e ensaios em máquina síncrona de ímã permanente - MSIP. [S.I.] Universidade de São Paulo, 2006. 